NATIONAL LABORATORY

\title{
Low Enriched Uranium Fuel Design with Two-Dimensional Grading for the High Flux Isotope Reactor
}

\section{April 2011}

Prepared by

Germina Ilas

R. T. Primm III
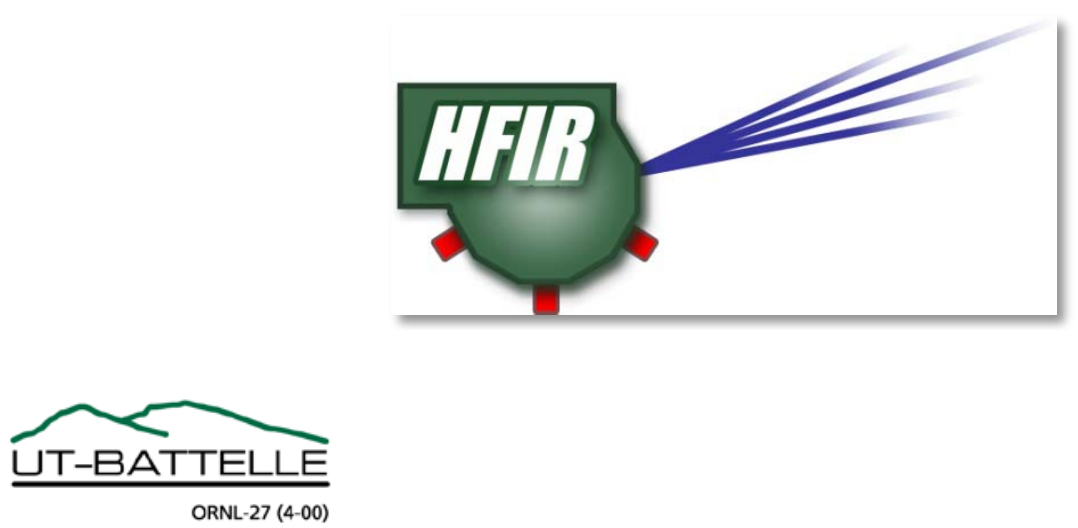


\title{
DOCUMENT AVAILABILITY
}

Reports produced after January 1, 1996, are generally available free via the U.S. Department of Energy (DOE) Information Bridge.

Web site http://www.osti.gov/bridge

Reports produced before January 1, 1996, may be purchased by members of the public from the following source.

\author{
National Technical Information Service \\ 5285 Port Royal Road \\ Springfield, VA 22161 \\ Telephone 703-605-6000 (1-800-553-6847) \\ TDD 703-487-4639 \\ Fax 703-605-6900 \\ E-mail info@ntis.gov \\ Web site http://www.ntis.gov/support/ordernowabout.htm
}

Reports are available to DOE employees, DOE contractors, Energy Technology Data Exchange (ETDE) representatives, and International Nuclear Information System (INIS) representatives from the following source.

Office of Scientific and Technical Information

P.O. Box 62

Oak Ridge, TN 37831

Telephone 865-576-8401

Fax 865-576-5728

E-mail reports@osti.gov

Web site http://www.osti.gov/contact.html

This report was prepared as an account of work sponsored by an agency of the United States Government. Neither the United States Government nor any agency thereof, nor any of their employees, makes any warranty, express or implied, or assumes any legal liability or responsibility for the accuracy, completeness, or usefulness of any information, apparatus, product, or process disclosed, or represents that its use would not infringe privately owned rights. Reference herein to any specific commercial product, process, or service by trade name, trademark, manufacturer, or otherwise, does not necessarily constitute or imply its endorsement, recommendation, or favoring by the United States Government or any agency thereof. The views and opinions of authors expressed herein do not necessarily state or reflect those of the United States Government or any agency thereof. 
Reactor and Nuclear Systems Division

\title{
LOW ENRICHED URANIUM FUEL DESIGN WITH TWO-DIMENSIONAL GRADING FOR THE HIGH FLUX ISOTOPE REACTOR
}

\author{
Germina Ilas
}

R. T. Primm III

Date Published: April 2011

\author{
Prepared by \\ OAK RIDGE NATIONAL LABORATORY \\ Oak Ridge, Tennessee 37831-6283 \\ managed by \\ UT-BATTELLE, LLC \\ for the \\ U.S. DEPARTMENT OF ENERGY \\ under contract DE-AC05-00OR22725
}





\section{CONTENTS}

Page

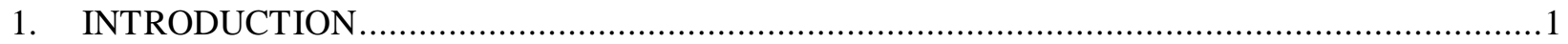

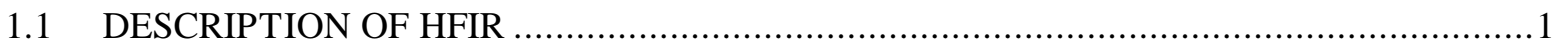

1.2 BACKGROUND ON THE HFIR CONVERSION STUDY .............................................2

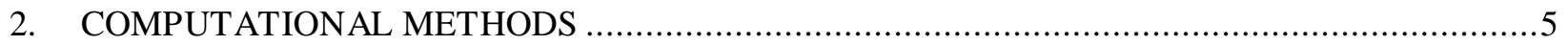

2.1 MCNP-MONTE CARLO TRANSPORT CODE ..............................................

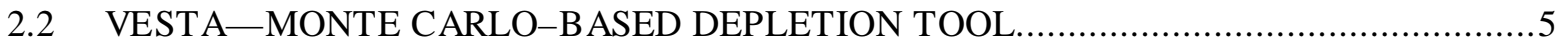

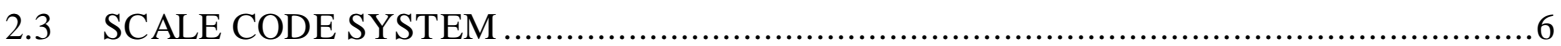

2.4 THERMAL HYDRAULIC ANALYSES-THE HFIR STEADY STATE HEAT

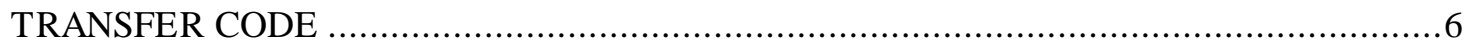

3. MONTE CARLO DEPLETION MODEL FOR HFIR LEU CONFIGURATIONS........................ 7

3.1 MCNP MODEL FOR HFIR LEU IN VESTA ................................................... 7

3.2 DEPLETION MODEL FOR HFIR LEU IN VEST A .............................................. 10

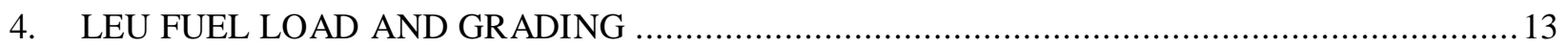

4.1 SEARCH FOR AN OPTIMAL LEU FUEL ........................................................... 13

4.2 OPTIMAL LEU FUEL LOAD AND GRADING ................................................. 14

5. PERFORMANCE AND SAFETY PARAMETERS FOR THE HFIR LEU CORE .......................17

5.1 PERFORMANCE PARAMETERS FOR THE HFIR LEU CORE.................................. 17

5.1.1 Cycle Length and Time-dependent Control Element Position ................................ 17

5.1.2 Core Power Distribution ....................................................................... 18

5.1.3 Peak Physics Parameters Relevant to Irradiation Tests..................................... 21

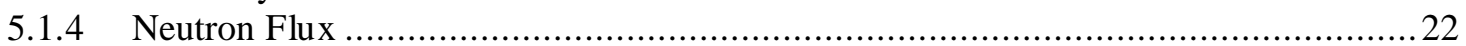

5.1.5 Differential Control Element Worth .............................................................2 24

5.2 THERMAL HYDRAULICS CHARACTERISTICS OF THE LEU CORE ........................ 25

5.2.1 Review of Input to Maximum Operating Power Calculation...................................25

5.3 SAFETY AND SAFEGUARDS PARAMETERS FOR THE HFIR LEU CORE ................ 34

5.3.1 Decay Heat in Used Fuel Elements............................................................. 34

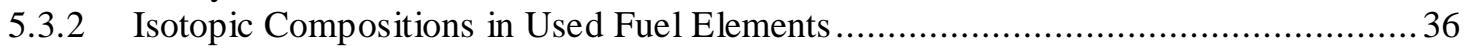

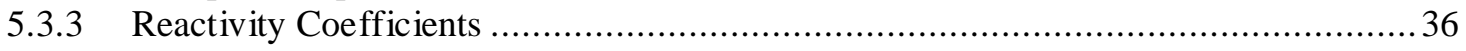

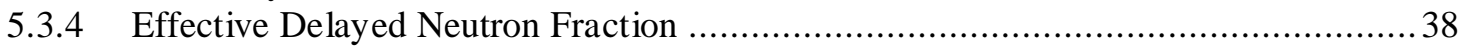

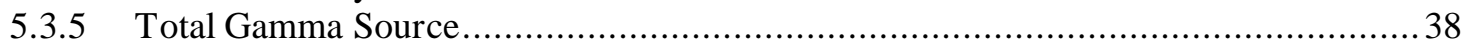

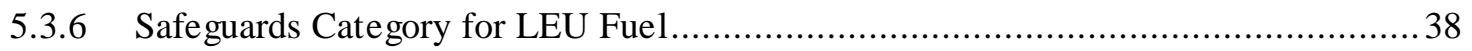

5.4 SUMMARY OF PERFORMANCE AND SAFETY PARAMETERS ............................ 40

6. SUPPLEMENTAL DOCUMENTATION AND RETENTION OF RECORDS ..........................47

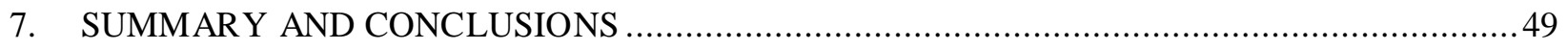

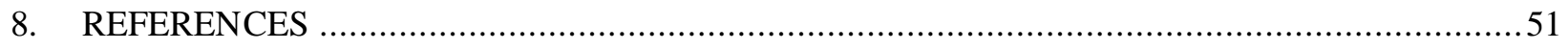

APPENDIX A. MATERIAL COMPOSITION FOR LEU CORE ..................................................A-1

APPENDIX B. METHODOLOGY FOR SIMULATING THE IRRADIATION OF THE CONTROL ELEMENTS IN HFIR. 
APPENDIX C. MODELING OF CONTROL ELEMENTS IN THE LEU CORE........................... C-1

APPENDIX D. IMPORTING VOLUME-CALCULATED POWER DENSITY DATA INTO

THE HSSHTC SPATIAL MESH ..................................................................

APPENDIX E. FISSION DENSITY DISTRIBUTIONS FOR LEU CORE .............................. E-1

APPENDIX F. CALCULATION OF THE EFFECTIVE DELAYED NEUTRON FRACTION ..........F-1

APPENDIX G. GAMMA SOURCE SPECTRA FROM DISCHARGED LEU FUEL ......................G-1 


\section{FIGURES}

Figure

Page

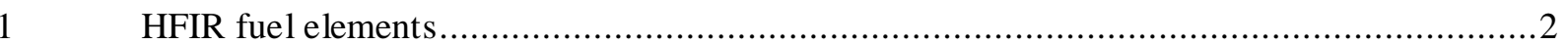

Cross section of the MCNP model for HFIR LEU at core axial midline ............................... 7

Axial cross section of the MCNP model for HFIR LEU ................................................. 8

Flux trap region in the LEU core model (radial view) ...............................................

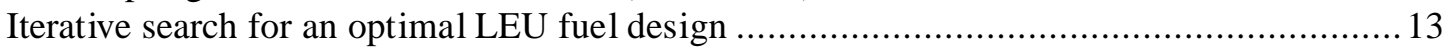

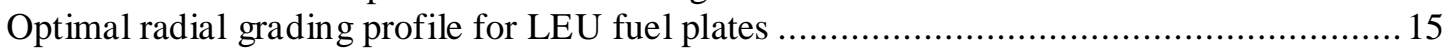

Axial grading profiles for LEU fuel (0-3 cm from bottom of fuel element) ......................... 16

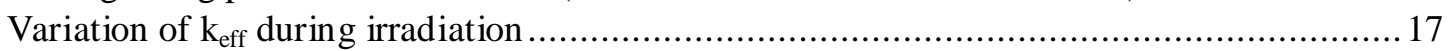

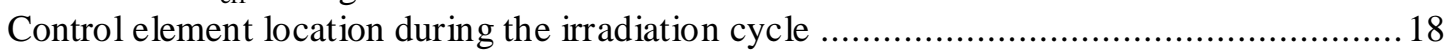

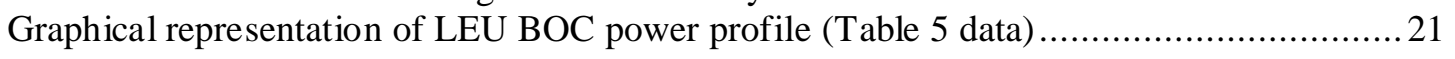

Graphical representation of LEU EOC power profile (Table 6 data) ................................ 21

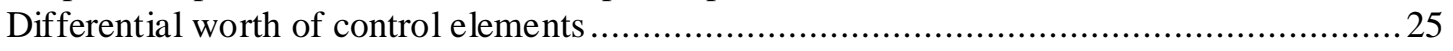

Incipient boiling temperature for LEU fuel, outer element plate (same data, two

views), after 1 day of irradiation at $100 \mathrm{MW}$.

Hot spot surface temperatures for LEU fuel, outer element fuel plate after 1 day of irradiation at $100 \mathrm{MW}$ (two views)

Surface-to-incipient boiling temperature ratio for LEU fuel, outer element (Fig.

15/Fig. 14)

Surface-to-incipient boiling temperature ratio for HEU fuel, outer element fuel plate,

SAR safety basis case

Surface-to-incipient boiling temperature ratio for HEU fuel, inner element (current,

MCNP-based methodology, cycle 400)

Decay heat for used fuel-comparison of HEU cycle 400 and LEU cores .........................35

Variation of $\mathrm{k}_{\text {eff }}$ in with reduction of water density in flux trap region ............................. 36

Burnup simulation methodology for control elements............................................... B-3

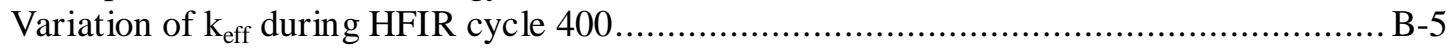

Axial dimensions of control elements in HFIR HEU core ............................................. C-1

Mapping MCNP zones to an HSSHTC mesh ........................................................... 



\section{TABLES}

Table

Page

1

2

3

4

5

6

7

8

9

10

11

12

13

14

15

16

17

18

19

20

21

22

23

24

25

26

A. 1

A. 2

A. 3

A. 4

B. 1

B. 2

C. 1

C. 2

C. 3

E.1

E. 2

E. 3

E. 4

E. 5

E. 6

G.1
Key parameters of HFIR HEU core

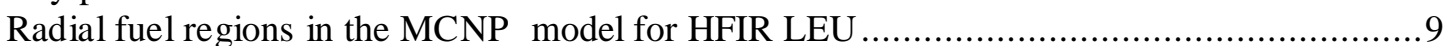

Axial fuel regions in the MCNP model for HFIR LEU .............................................9

Radial fuel regions in the MCNP model for HFIR LEU ........................................... 16

Relative fission density for HFIR LEU at BOC ................................................. 19

Relative fission density for HFIR LEU at EOC .................................................. 20

Peak performance parameters for LEU fuel in HFIR ............................................... 22

Neutron flux at BOC_comparison of HEU cycle 400 and LEU cores............................23

Neutron flux at EOC_-comparison of HEU cycle 400 and LEU cores ...........................23

Other neutron flux data_comparison of HEU cycle 400 and LEU cores .........................23

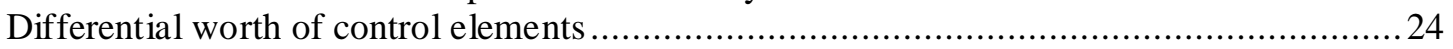

HSSHTC input parameters for LEU that differ from HEU .................................... 26

Current, HEU fuel, burnup-dependent heat transfer data-incipient boiling criteria

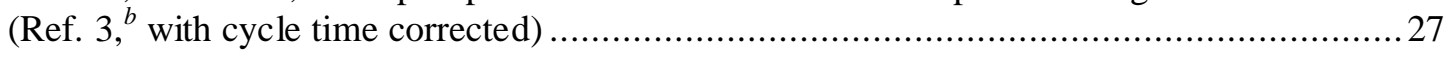

Current, HEU fuel, burnup-dependent heat transfer data based on power profile for

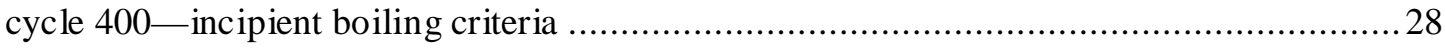

LEU fuel, burnup-dependent heat transfer data-incipient boiling criteria ......................28

Decay heat for used fuel_comparison of HEU cycle 400 and LEU cores.........................34

Major contributors to total decay heat at 1 day-comparison of HEU cycle 400 and

LEU cores ................................................................................. 35

Major actinides inventory (in grams) for HEU and LEU cores at EOC ..........................36

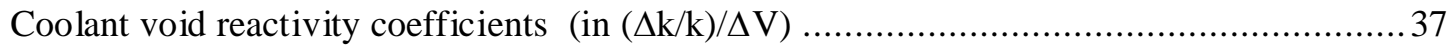

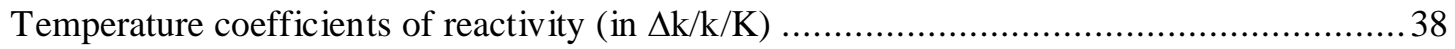

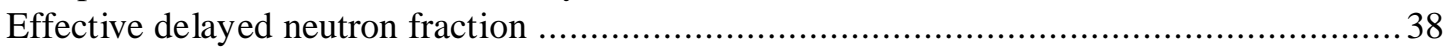

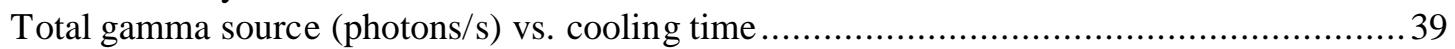

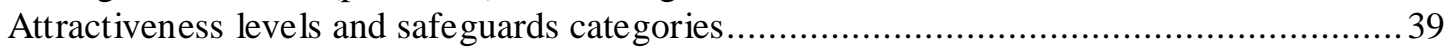

Strategic significance of special nuclear material [7, part 74.4] ................................ 40

U.S. version, strategic significance of special nuclear material [7, part 74.4] ..................40

Summary of performance and safety parameters ............................................. 41

Material composition for LEU fuel .............................................................

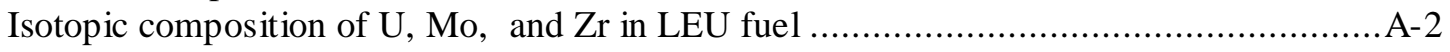

Composition of curium targets in the HFIR LEU core model................................A-2

Composition $^{a}$ of materials in control elements for the HFIR LEU core model...............A-3

Isotopies in CE gray and black regions at BOC-400 ........................................ B-4

Isotopes in $\mathrm{CE}$ gray and black regions at BOC-400 ............................................ B-6

Control element position in HEU cycle 400 model............................................

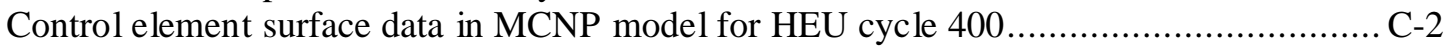

Control element position in LEU depletion model............................................

Relative fission density for HFIR LEU at 1 day irradiation ................................... E-2

Relative fission density for HFIR LEU at 5 days irradiation.................................. E-3

Relative fission density for HFIR LEU at 10 days irradiation .................................. E-4

Relative fission density for HFIR LEU at 15 days irradiation ................................... E-5

Relative fission density for HFIR LEU at 20 days irradiation ................................. E-6

Relative fission density for HFIR LEU at 23 days irradiation ................................... E-7

Decay gamma spectra for LEU, inner element for times up to 1 day (energy

boundaries in $\mathrm{MeV}$ ).... 
G.2 Decay gamma spectra for LEU, inner element for times up to 100 years (energy boundaries in $\mathrm{MeV}$ ).

G.3 Decay gamma spectra for LEU, outer element for times up to 1 day (energy

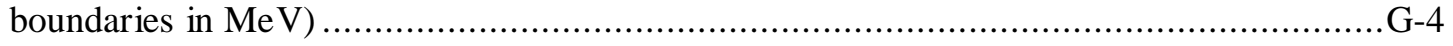

G.4 Decay gamma spectra for LEU, outer element for times up to 100 years (energy boundaries in $\mathrm{MeV}$ ). 


\section{ACKNOWLEDGMENTS}

The authors would like to acknowledge that the support for this project was provided by the Global Threat Reduction Initiative, Reduced Enrichment for Research and Test Reactors Program, a program of the Nuclear National Security Administration, U.S. Department of Energy. Review of the manuscript by S. M. Bowman, Reactor and Nuclear Systems Division (RNSD), and D. G. Renfro and K. A. Smith, Research Reactors Division, Oak Ridge National Laboratory, and formatting of the document by A. C. Alford, RNSD, are very much appreciated. 



\section{ACRONYMS AND ABBREVIATIONS}

$\begin{array}{ll}\text { 2-D } & \text { two dimensional } \\ \text { 3-D } & \text { three dimensional } \\ \text { BOC } & \text { beginning of cycle } \\ \text { C/E } & \text { calculated to experimental } \\ \text { CR } & \text { control element region } \\ \text { DOE } & \text { U.S. Department of Energy } \\ \text { EOC } & \text { end of cycle } \\ \text { FIFA } & \text { fissions per initial fissile atom } \\ \text { FTT } & \text { flux trap target region } \\ \text { FY } & \text { fiscal year } \\ \text { HEU } & \text { high-enriched uranium } \\ \text { HFIR } & \text { High Flux Isotope Reactor } \\ \text { IFE } & \text { inner fuel element } \\ \text { ICE } & \text { inner control element } \\ \text { IRSN } & \text { Institut de Radioprotection et de Sûreté Nucléaire (Institute for Radiological Protection } \\ & \text { and Nuclear Safety) } \\ \text { k } \text { eff } & \text { effective multiplication constant } \\ \text { LCS } & \text { limiting condition for safety } \\ \text { LEU } & \text { low-enriched uranium } \\ \text { LANL } & \text { Los Alamos Nuclear Laboratory } \\ \text { MIT } & \text { Massachusetts Institute of Technology } \\ \text { OCE } & \text { outer control element } \\ \text { OFE } & \text { outer fuel element } \\ \text { ORNL } & \text { Oak Ridge National Laboratory } \\ \text { PB } & \text { permanent beryllium reflector region } \\ \text { RB } & \text { removable beryllium reflector region } \\ \text { SAR } & \text { safety analysis report } \\ \text { RERTR } & \text { Reduced Enrichment for Research and Test Reactors Program } \\ \text { RRD } & \text { Research Reactor Division } \\ \text { RSND } & \text { Reactor and Nuclear Systems Division } \\ \text { SCALE } & \text { Standardized Computer Analyses for Licensing Evaluations } \\ \text { SCK-CEN } & \text { Studiecentrum voor Kernenergie-Centre d'Étude de l'Energie Nucléaire } \\ & \end{array}$





\begin{abstract}
An engineering design study of the conversion of the High Flux Isotope Reactor (HFIR) from highenriched uranium (HEU) to low-enriched uranium (LEU) fuel is ongoing at Oak Ridge National Laboratory. The computational models developed during fiscal year 2010 to search for an LEU fuel design that would meet the requirements for the conversion and the results obtained with these models are documented and discussed in this report. Estimates of relevant reactor performance parameters for the LEU fuel core are presented and compared with the corresponding data for the currently operating HEU fuel core. The results obtained indicate that the LEU fuel design would maintain the current performance of the HFIR with respect to the neutron flux to the central target region, reflector, and beam tube locations under the assumption that the operating power for the reactor fueled with LEU can be increased from the current value of $85 \mathrm{MW}$ to $100 \mathrm{MW}$.
\end{abstract}





\section{INTRODUCTION}

An engineering design study for a fuel that would enable the conversion of the High Flux Isotope Reactor (HFIR) from high-enriched uranium (HEU) to low-enriched uranium (LEU) is ongoing as part of an effort sponsored by the U.S. Department of Energy's (DOE's) National Nuclear Security Administration through the Global Threat Reduction Initiative/Reduced Enrichment for Research and Test Reactors (RERTR) Program. Given the unique fuel, particular core design, and high power density of HFIR, and the requirement that the impact of the fuel change on the core performance and operation be minimal, this conversion study represents a complex and challenging task. Such a task requires improvements in and extensions of the computational methodologies and tools that are currently used to support the operation of the reactor.

\subsection{DESCRIPTION OF HFIR}

The HFIR is an 85 MW, very high flux, pressurized light-water-cooled and moderated, flux-trap type reactor, which is operated at the Oak Ridge National Laboratory (ORNL). The missions of HFIR are currently to support neutron scattering experiments, isotope production, and materials irradiation research. The reactor core consists of a series of concentric annular regions: a central flux trap containing vertical experimental targets surrounded by two fuel elements separated by a thin water region, a region containing two control plates, a beryllium reflector, and a water region to the edge of the pressure vessel, which is located in a pool of water. Details of the reactor configuration and operation can be found elsewhere. ${ }^{1,2}$ For convenience, the core data most relevant to the study discussed in this report are presented in Table 1.

Table 1. Key parameters of HFIR HEU core

\begin{tabular}{|c|c|c|}
\hline \multicolumn{3}{|l|}{ Reactor data } \\
\hline Operating power (MW) & \multicolumn{2}{|c|}{85} \\
\hline Cycle length (days) & \multicolumn{2}{|c|}{$\sim 24$} \\
\hline Number of fuel elements & \multicolumn{2}{|c|}{2} \\
\hline \multicolumn{3}{|l|}{ Fuel data } \\
\hline Tyре & \multicolumn{2}{|c|}{$\mathrm{U}_{3} \mathrm{O}_{8}-\mathrm{Al}$} \\
\hline Enrichment (wt \% ${ }^{235} U$ ) & \multicolumn{2}{|c|}{93.1} \\
\hline Total load ${ }^{235} \mathrm{U}(\mathrm{kg})$ & \multicolumn{2}{|c|}{9.4} \\
\hline Total load uranium (kg) & \multicolumn{2}{|c|}{10.1} \\
\hline Fuel elements data & Inner fuel element & Outer fuel element \\
\hline Load of ${ }^{235} \mathrm{U}(\mathrm{kg})$ & 2.6 & 6.8 \\
\hline Number of fuel plates & 171 & 369 \\
\hline Fuel plate width $(\mathrm{cm})$ & 8.1 & 7.3 \\
\hline Fuel plate thickness (cm) & 0.127 & 0.127 \\
\hline Coolant channel between plates (cm) & 0.127 & 0.127 \\
\hline Fuel plate clad thickness $(\mathrm{cm})$ & 0.0254 & 0.0254 \\
\hline
\end{tabular}

The two fuel elements in HFIR are identified as inner fuel element (IFE) and outer fuel element (OFE). They are composed of numerous, involute-shaped fuel plates $1.27 \mathrm{~mm}$ thick, as illustrated in Fig. 1(a). The plates are separated by a water-filled cooling channel $1.27 \mathrm{~mm}$ thick, and are held together by two cylindrical aluminum side walls. The fuel plates have a sandwich-type design with a fuel region enclosed in an aluminium-based clad, as illustrated in Fig. 1(b). The fuel meat inside the fuel region contains a mixture of aluminium powder and uranium oxide $\left(\mathrm{U}_{3} \mathrm{O}_{8}\right)$ with $93.1 \mathrm{wt} \%{ }^{235} \mathrm{U}$ enrichment and is characterized by variable thickness along the width of the fuel plate (radial grading) and a uniform thickness along the length of the fuel plate for a given radius (no axial grading). 


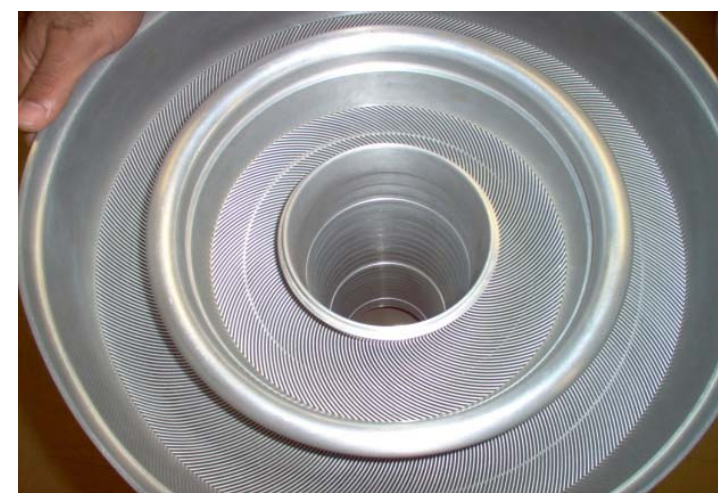

(a) inner and outer fuel elements

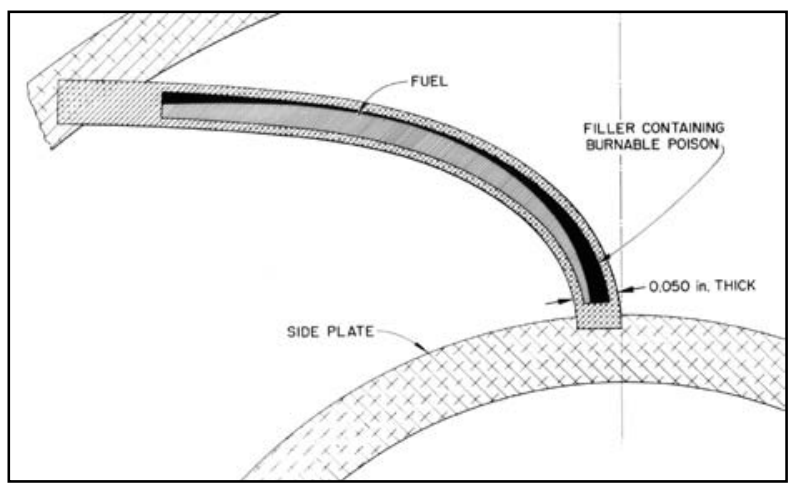

(b) fuel plate profile

Fig. 1. HFIR fuel elements.

\subsection{BACKGROUND ON THE HFIR CONVERSION STUDY}

In accordance with the U.S. nonproliferation policy to minimize and possibly eliminate the use of HEU fuel in civilian nuclear programs, the DOE RERTR Program has initiated and supported fuel development and engineering studies that would facilitate the conversion of high-performance U.S. research reactors from HEU fuel to LEU fuel. A study to assess the feasibility of converting HFIR to an LEU fuel and determine the performance goals for the candidate LEU fuel forms considered was initiated in 2006. Two types of high-density LEU fuels were initially under consideration and were studied: a fuel consisting of uranium-molybdenum (U-Mo) dispersion in aluminum and a monolithic U-Mo alloy fuel. The LEU fuel currently under consideration is a high-density monolithic alloy, U-10Mo, which contains $90 \mathrm{wt} \%$ uranium and $10 \mathrm{wt} \%$ natural molybdenum. It has a density of $17.02 \mathrm{~g} / \mathrm{cm}^{3}$ and an enrichment of 19.75 wt $\%{ }^{235} \mathrm{U}$.

As included in the key top-level assumptions established to guide the HFIR conversion study, ${ }^{3}$ there shall be no change in the physical dimensions of the core or fuel geometry, no reduction in the core power or core lifetime, no major changes to the current control and protection systems, and the margins of safety in the bases of the currently approved Technical Safety Requirements ${ }^{4}$ shall be maintained.

The fuel meat is the region that will need to be changed when the current HEU fuel is replaced with LEU fuel, with no changes to the basic geometry of the fuel plate. In the current HEU fuel plate, in order to minimize the peak power density the thickness of the fuel meat region varies smoothly along the width of the fuel plate; the corresponding flat plate (i.e., plate prior to forming into an involute shape) profiles of the fuel regions are illustrated in Fig. 2 for the IFE and OFE, respectively. 

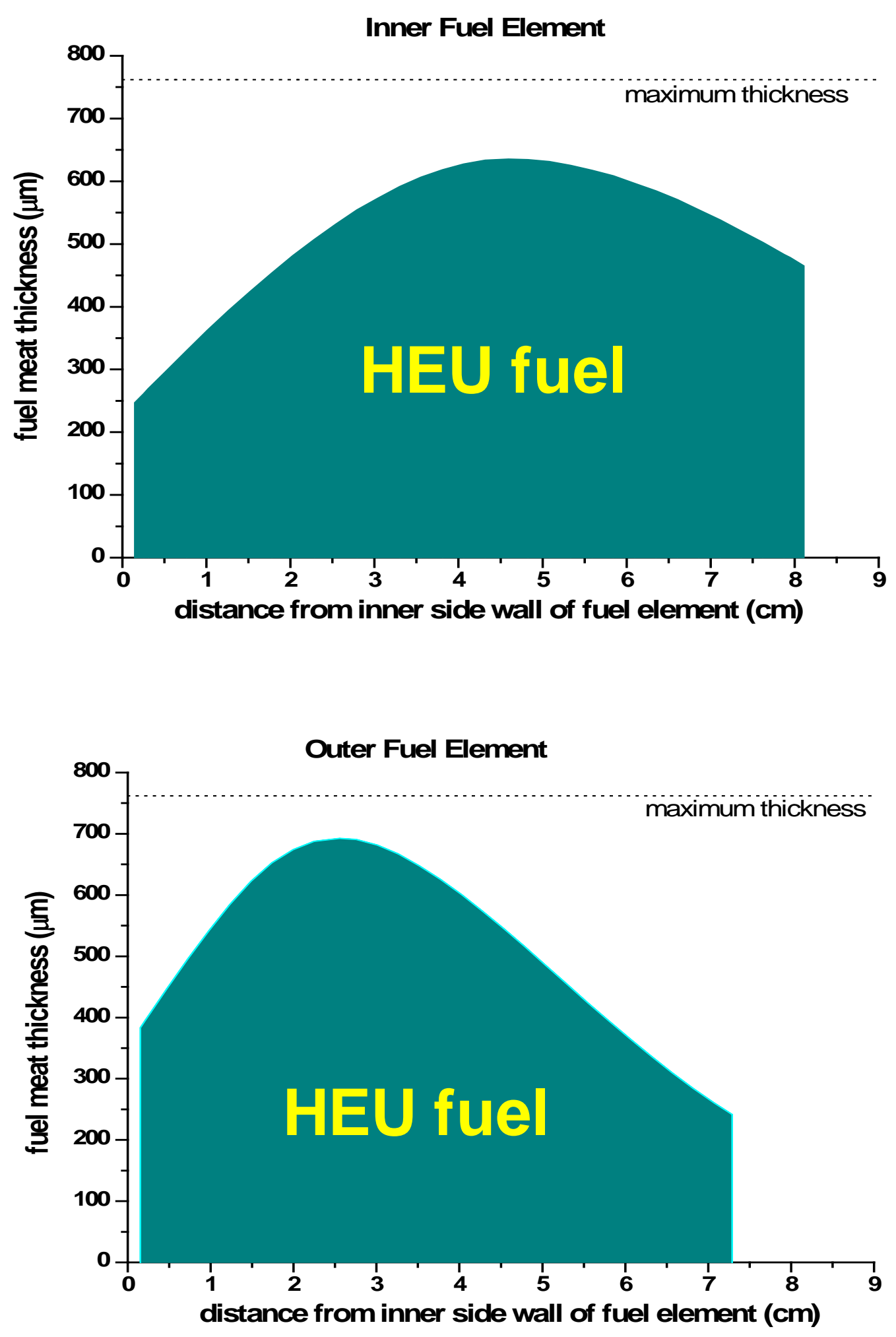

Fig. 2. "Flat plate" profiles of fuel meat regions for HEU fuel. 



\section{COMPUTATIONAL METHODS}

The HFIR core analysis for an LEU fuel initially used as a basis for neutronics studies the standard set of computational methods and tools that are currently employed or have been employed until recently to support the operation of the HFIR HEU core. This set of tools include the Monte Carlo neutron transport code MCNP, ${ }^{5}$ the diffusion theory-based code system with depletion capabilities BOLDVENTURE, ${ }^{6}$ and the nuclear analysis code system SCALE. ${ }^{7}$ Taking advantage of the recent developments in computational methodologies and codes, the neutronics analyses for an LEU fuel have evolved from diffusion-based depletion to Monte Carlo-based depletion methodologies. A Monte Carlobased depletion model for HFIR with LEU fuel, using the ALEPH ${ }^{8}$ computational tool, has been established and validated ${ }^{9}$ based on the core configuration and cycle length for a recent HFIR HEU fuel cycle. ${ }^{10}$ More recently, to enable the use of nuclear cross-section data based on the most recent data evaluations, the Monte Carlo-based depletion tool VESTA ${ }^{11}$ has been used for the LEU fuel study, as described in detail in the current report. A brief description of the codes used for this study is provided in this section.

\subsection{MCNP-MONTE C ARLO TR ANSPORT CODE}

MCNP is a general-purpose Monte Carlo code developed at Los Alamos Nuclear Laboratory (LANL) that can be used to simulate the neutron, photon, electron, or coupled neutron/photon/electron transport, including the capability to calculate eigenvalues for critical systems, in three-dimensional (3-D) arbitrary geometry configurations. Its capabilities to model complex geometries and to use pointwise cross-section data for the neutron transport treatment make the code a desirable tool for analysis of highly heterogeneous systems such as HFIR. An MCNP model of the HFIR HEU reactor, which includes a detailed representation of the reactor components, was previously developed ${ }^{10}$ and has served as a reference model to perform analyses in support of HFIR operation. Based on the existing model for the HEU core, an MCNP model for the LEU fuel core has been developed and used in the design of a new LEU fuel for HFIR.

\subsection{VESTA-MONTE CARLO-BASED DEPLETION TOOL}

VESTA is a Monte Carlo-based depletion tool developed at Institut de Radioprotection et de Sûreté Nucléaire (IRSN) - Institute for Radiological Protection and Nuclear Safety — in France. The current version of VESTA couples a Monte Carlo transport code from the MCNP family of LANL codes (e.g., MCNP) and the point depletion and decay code ORIGEN 2.2. ${ }^{12}$ Though other Monte Carlo codes can be used within VEST A, MCNP is the basis for LEU design calculations due to the ability to model control element movement over time and because extensive resources have been devoted to benchmarking MCNP models of HFIR.

VESTA is a relatively user-friendly code; if an appropriate MCNP model of the configuration to be analyzed is available, the changes and/or additions to this model are minimal. At each depletion step, the transport flux solution from MCNP is used to generate the cross-section data for the ORIGEN 2.2 depletion calculation; the isotopic composition data resulting from ORIGEN 2.2 are used in the subsequent MCNP transport calculation to obtain cross sections for the next depletion step, and so forth in an iterative manner.

Compared with other Monte Carlo depletion tools, VEST A has a particular approach in determining from MCNP the data needed for the ORIGEN 2.2 depletion calculation. Whereas other tools obtain the cross sections for depletion based on reaction rate tallies in the Monte Carlo transport calculation, VEST A requires only flux tallies in a fine-group structure. The one-group cross sections for ORIGEN 2.2 are obtained by weighting pre-generated pointwise cross-section data with the MCNP-calculated fine-group flux. These pointwise cross-section data are consistent with the cross-section data used in the MCNP 
transport calculation, as both sets are pre-computed based on the same ENDF/B data files. By calculating only the flux with MCNP, compared with calculating reaction rates, execution times for VEST A are considerably less than for other Monte Carlo depletion tools.

VESTA has capabilities and features not found in other Monte Carlo/depletion systems. One of these capabilities refers to the depletion of nonfissile materials, which in the case of HFIR makes possible accounting for the irradiation of control elements, beryllium reflector, or nonfissile targets during the reactor cycle. In addition, VESTA can be used with an extended set of nuclear cross sections, including those that are based on the most recent nuclear data evaluations, such as ENDF/B-VII.

As for any other Monte Carlo-based tool, the drawback of using VESTA is the computational efficiency, especially when depletion calculations are involved. However, the capability of modeling the geometry in detail, including the explicit simulation of the control element movement during the cycle, and of using continuous energy cross-section data for the neutron transport, make this tool an excellent choice for HFIR LEU reference depletion studies. In addition, improvement in computational efficiency can be achieved through the use of the software on a multiprocessor platform (computer cluster).

\subsection{SCALE CODE SYSTEM}

SCALE (Standardized Computer Analyses for Licensing Evaluation) is a modular nuclear analysis code system that has been developed and maintained by ORNL under support from the U.S. Nuclear Regulatory Commission and DOE. This code system uses automated sequences to provide cross-section processing, reactor lattice physics, criticality safety, radiation shielding, and spent fuel characterization analysis capabilities. SCALE has been used in HFIR analyses for this report to perform source term calculations, and thereby to derive the security classification level for spent HFIR fuel elements.

\subsection{THERMAL HYDRAULIC ANAL YSES-THE HFIR STEADY STATE HEAT TRANSFER CODE}

The margin to incipient boiling, and therefore the determination of the maximum allowable operating power for the HFIR, is determined from custom-designed software described in Ref. 3. The program requires, as input, reactor geometry, a two-dimensional (2-D), radial and axial, power profile as a function of irradiation time, and manufacturing uncertainty factors. Geometry and power profiles are known or calculated, but manufacturing uncertainty factors have not yet been defined for U-10Mo fuel. Since almost no data are available, the uncertainty values associated with the current HEU fuel and documented in Ref. 3 were used in the analyses reported here. Details about the input data used and the calculation of the maximum operating power are provided in Section 5.2 of the current report. 


\section{MONTE CARLO DEPLETION MODEL FOR HFIR LEU CONFIGURATIONS}

\subsection{MCNP MODEL FOR HFIR LEU IN VESTA}

The MCNP model used for the HFIR LEU configuration is based on the 3-D MCNP revised model for HFIR HEU cycle $400 .{ }^{9}$ The model is illustrated in Figs. 3 and 4, which show a radial cross section at the core midline and an axial cross section through the center of the core, respectively; various regions and materials are shown in different colors. The model, which explicitly represents the experiment locations in the central target region and beryllium reflector, includes six regions:

1. Flux trap target region (FTT)

2. Inner fuel element region (IFE)

3. Outer fuel element region (OFE)

4. Control element region (CR)

5. Removable beryllium reflector region (RB)

6. Permanent beryllium reflector region (PB)

Compared with the FTT model for the revised cycle 400 model $^{9}$-in which 31 of the 37 experimental locations in FTT included 28 dummy aluminum targets, one hydraulic tube, and two stainless steel targets-the LEU model contains one hydraulic tube and 30 curium targets in the interior basket, as illustrated in Fig. 5. The composition of the curium targets is listed in Appendix A.

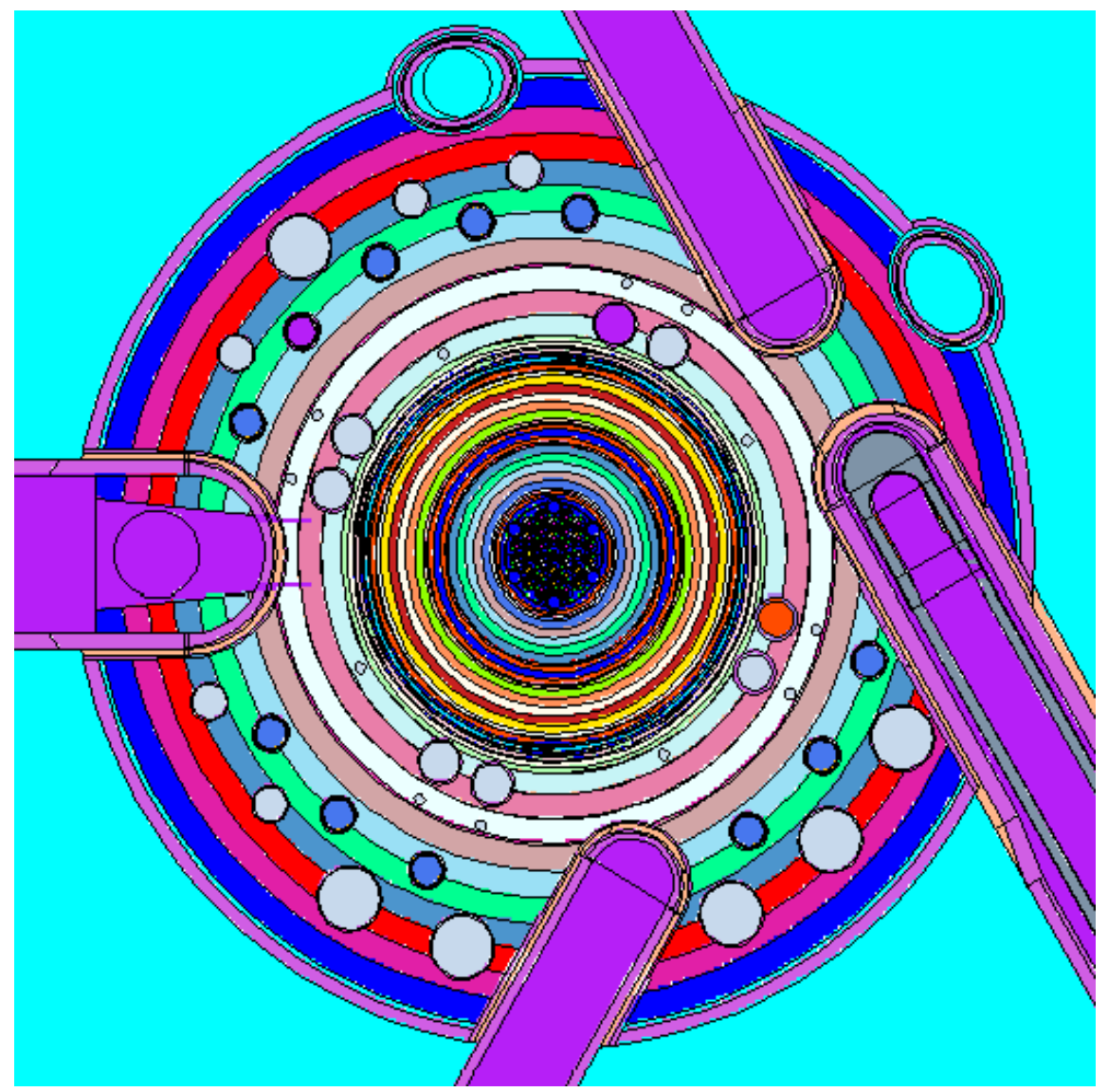

Fig. 3. Cross section of the MCNP model for HFIR LEU at core axial midline. 


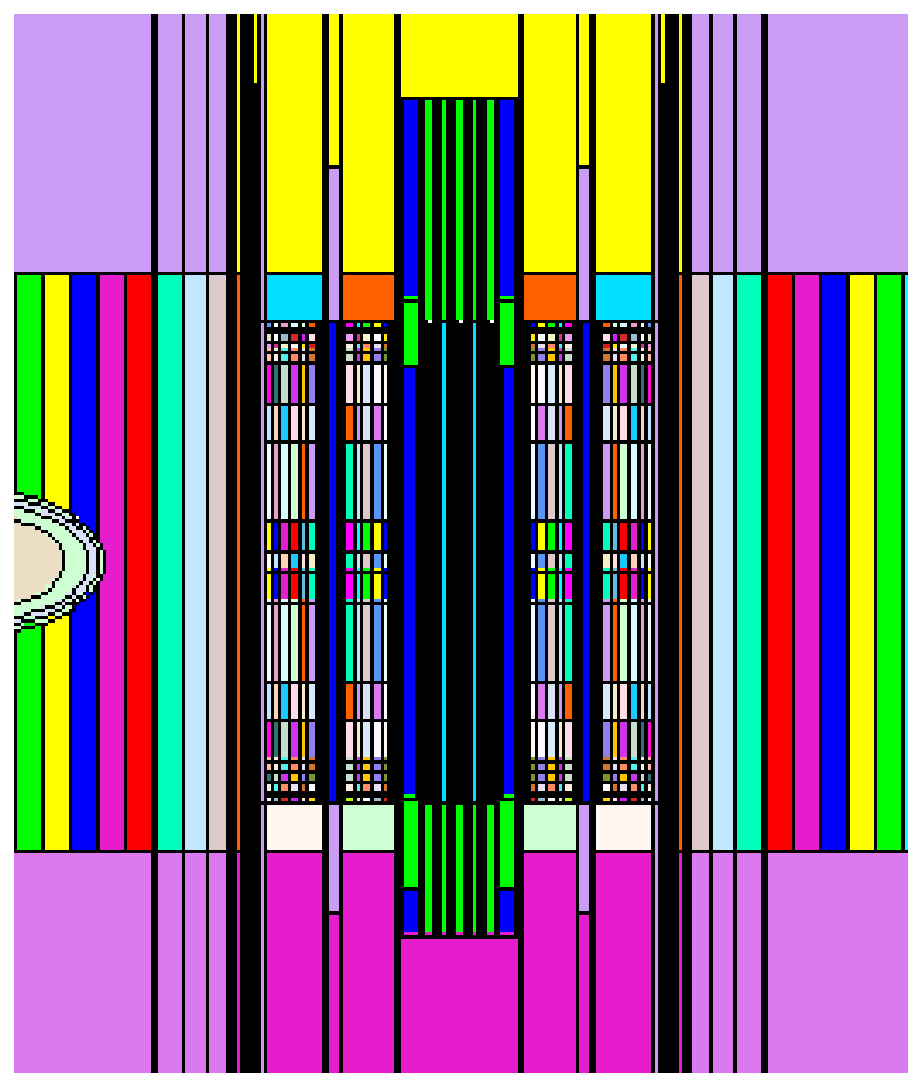

Fig. 4. Axial cross section of the MCNP model for HFIR LEU.

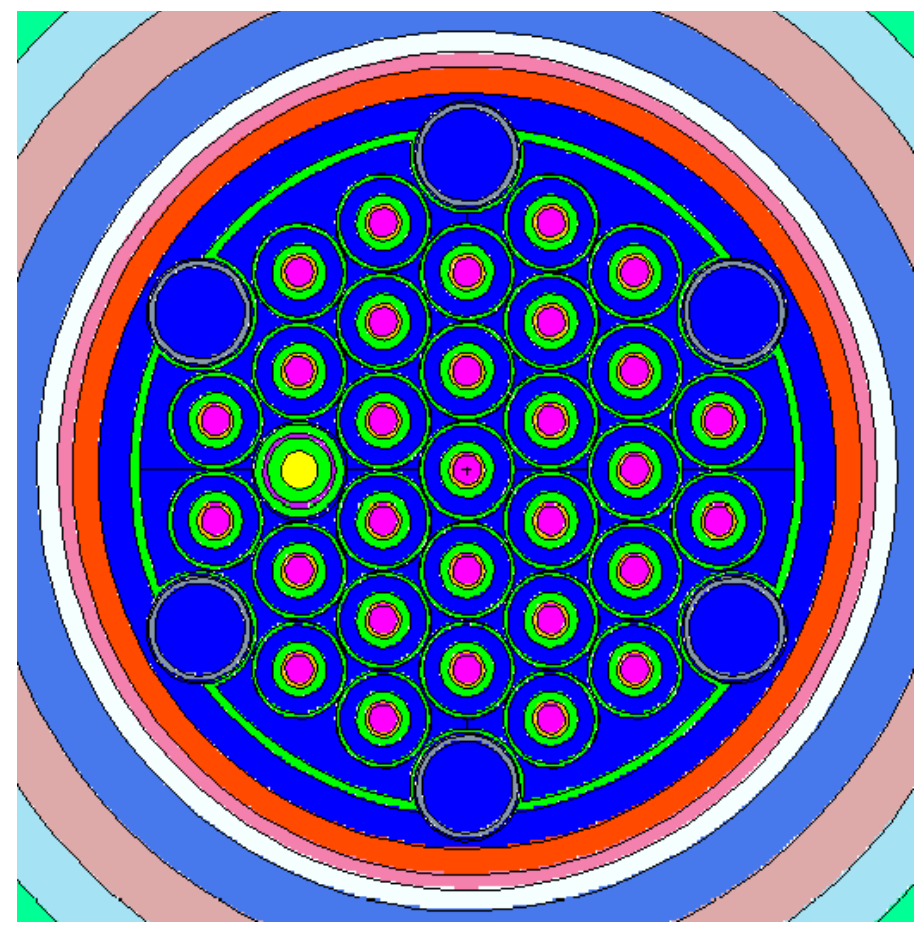

Fig. 5. Flux trap region in the LEU core model (radial view). 
As used in the MCNP model for cycle 400, the LEU fuel in the IFE and the OFE regions is modeled by homogenizing the fuel meat and aluminum cladding of the fuel plates and the water between the fuel plates. To approximate the variation of the ${ }^{235} \mathrm{U}$ content in the radial direction of the fuel plate (i.e., radial fuel grading), eight radial regions with different ${ }^{235} \mathrm{U}$ concentrations are used in the IFE modeling. A similar model is used for the OFE but with nine radial regions. The dimensions of the radial fuel regions in the IFE and OFE models are shown in Table 2. The concentration of ${ }^{235} \mathrm{U}$ in the axial direction was initially considered uniform, though axial grading was also used later. The axial layer dimensions were selected by studying the variation of the microscopic thermal fission cross section of ${ }^{235} U$ as a function of the axial location. ${ }^{13}$ The dimensions for the axial layers are shown in Table 3 . The acceptability of the approximations used in the MCNP model (i.e., homogenization of plates and water gaps) and the

Table 2. Radial fuel regions in the MCNP model for HFIR LEU

\begin{tabular}{cccccc}
\hline \multicolumn{2}{c}{$\begin{array}{c}\text { Inner fuel element } \\
\text { IFE }\end{array}$} & & \multicolumn{2}{c}{$\begin{array}{c}\text { Outer fuel element } \\
\text { OFE }\end{array}$} \\
\cline { 1 - 2 } \cline { 5 - 5 } Region \# & $\begin{array}{c}\text { Outer radius } \\
\text { (cm) }\end{array}$ & & Region \# & $\begin{array}{c}\text { Outer radius } \\
\text { (cm) }\end{array}$ \\
\hline $1^{a}$ & 7.50 & & 1 & 15.16 \\
2 & 8.50 & & 2 & 15.50 \\
3 & 9.50 & & 3 & 16.50 \\
4 & 10.50 & & 4 & 17.50 \\
5 & 11.50 & & 5 & 18.50 \\
6 & 12.50 & & 6 & 19.50 \\
7 & 12.59 & & 7 & 20.50 \\
8 & 12.60 & & 8 & 20.99 \\
& & & 9 & 21.00 \\
\hline
\end{tabular}

\footnotetext{
${ }^{a}$ Inner radii are $7.14 \mathrm{~cm}$ and $15.15 \mathrm{~cm}$ for IFE and OFE, respectively.

${ }^{b}$ Inner radii for the IFE and OFE in the HEU reference cycle 400 model are $7.14 \mathrm{~cm}$ and $15.129515 \mathrm{~cm}$, respectively, as documented in N. Xoubi and R. T. Primm III, Modeling of the High Flux Isotope Reactor Cycle 400, ORNL/TM2004-251 (2005). For the reference HEU model, the outer radii for the IFE are $7.5,8.0,8.5,9.5,10.5,11.5,12.0$, and $12.6 \mathrm{~cm}$; the outer radii for the OFE are 15.5, 16.0, 16.5, 17.5, 18.5, 19.5, 20.0, 20.5, and $20.978 \mathrm{~cm}$.
}

Table 3. Axial fuel regions in the MCNP model for HFIR LEU

\begin{tabular}{cccccc}
\hline Region \# & $\begin{array}{c}\text { Top edge } \\
\text { location }^{\mathbf{( c m})^{\boldsymbol{a}}}\end{array}$ & $\begin{array}{c}\text { Thickness }^{\boldsymbol{b}} \\
\mathbf{( \mathbf { c m } )}\end{array}$ & Region \# & $\begin{array}{c}\text { Top edge } \\
\text { location } \\
(\mathbf{c m})^{\boldsymbol{a}}\end{array}$ & $\begin{array}{c}\text { Thickness } \\
(\mathbf{c m})\end{array}$ \\
\hline 1 & 25.4 & 0.5 & 11 & -1.0 & 3.2 \\
2 & 24.9 & 0.5 & 12 & -4.2 & 8.4 \\
3 & 24.4 & 1.0 & 13 & -12.6 & 4.2 \\
4 & 23.4 & 1.0 & 14 & -16.8 & 4.2 \\
5 & 22.4 & 1.4 & 15 & -21.0 & 1.4 \\
6 & 21.0 & 4.2 & 16 & -22.4 & 1.0 \\
7 & 16.8 & 4.2 & 17 & -23.4 & 1.0 \\
8 & 12.6 & 8.4 & 18 & -24.4 & 0.5 \\
9 & 4.2 & 3.2 & 19 & -24.9 & 0.5 \\
10 & 1.0 & 2.0 & & & \\
\hline
\end{tabular}

${ }^{a}$ Location is with respect to the core midline (at axial location $0.0 \mathrm{~cm}$ ).

${ }^{b}$ Thicknesses for the axial fuel regions in the HEU cycle 400 depletion model are: $0.4,3.0$, 3.0, 3.0, 3.0, 3.0, 3.0, 3.0, 3.0, 2.0, 3.0, 3.0, 3.0, 3.0, 3.0, 3.0, 3.0, 3.0, and $0.4 \mathrm{~cm}$. 
adequacy of the radial and axial mesh definition have been demonstrated by validation studies based on this MCNP model to compare to measured activation rates, power profiles and spatially dependent, postirradiation uranium isotopic compositions. ${ }^{14-16}$

The material composition data assumed for the LEU fuel plates are presented in Appendix A. In addition to the material data used previously ${ }^{13}$ for the LEU fuel, the model studied during fiscal year (FY) 2010 includes a thin, zirconium diffusion barrier layer on the surfaces of the fuel meat region. This layer, $0.001 \mathrm{in}$. $(25.4 \mu \mathrm{m})$ thick in all directions, separates the fuel meat from the filler inside the fuel plate. Once the actual composition of the LEU material would become available (i.e., uranium isotopic composition, molybdenum isotopic composition, impurities), the model would need to be updated accordingly. Though it is expected that the change from assumed to actual LEU fuel data would not significantly impact the results of the current study, the actual effect remains to be quantified.

All regions located outside the IFE and OFE regions are represented as in the model for cycle 400, with the exception of the control element region. Compared to the HFIR HEU model for cycle 400 and the HFIR LEU core model described in Ref. 13, the composition of the materials in the control region has been changed to account for the irradiation history of the control elements (CEs). As summarized in Appendix B, a methodology has been developed ${ }^{17}$ to perform fast simulations of the HFIR CEs' irradiation history with the purpose of determining their material composition at a given time. This methodology has been applied to determine the CEs' material compositions at the beginning of cycle (BOC) 400 for use in HFIR HEU safety analysis. The source of an apparent burnup dependence of calculated $\mathrm{k}_{\mathrm{eff}}$ for cycle 400 has been removed by properly accounting for the CE irradiation history in HFIR HEU depletion simulations. ${ }^{17}$ The CE material composition for the LEU model, which is listed in Appendix A, was assumed to be the same as determined for BOC-400. The dimensions of the CEs and the $\mathrm{CE}$ movement during the irradiation cycle are presented in Appendix $\mathrm{C}$.

\subsection{DEPLETION MODEL FOR HFIR LEU IN VESTA}

In addition to the MCNP model of the configuration to be simulated, the input data for VEST A include information about the depletion mixtures (i.e., materials for which composition varies during simulation due to depletion and decay) and irradiation history. There are a total of 152 fuel regions in the IFE ( 8 radial by 19 axial) and 171 fuel regions ( 9 radial by 19 axial) in the OFE. For the initially considered studies with no variation of fuel composition in the axial direction, a total of 80 and 90 depletion mixtures are specified in the IFE and the OFE, respectively, for the purpose of flux calculation with MCNP; as previously mentioned, this flux serves to weight the pointwise cross-section data to obtain the effective one-group cross sections for use in the ORIGEN 2.2 depletion calculation. From the 80 depletion mixtures in the IFE, 8 mixtures are specified in the central (i.e., core midline) axial layer of the IFE, one for each of the 8 radial regions. A unique depletion mixture is specified for fuel regions with the same radial region number and with the same axial distance with respect to the core midline; for example, if a region in the $\operatorname{IFE}$ is identified as $\operatorname{IFE}(r, z)$, where $r=1, \ldots, 8$ and $z=1, \ldots, 19$, the same depletion mixture (i.e., material number in the MCNP input file) is used in fuel regions IFE $(r, 1)$ and $\operatorname{IFE}(r, 19)$. Similarly, there are 90 depletion mixtures in the OFE, which gives a total of 170 depletion mixtures in the fuel elements. Four depletion mixtures, two for each of the two control elements, are also included in the depletion model. One depletion mixture is also included for the curium targets in the central target region. The total number of depletion mixtures in this case would be therefore 175 .

The value used for power during the irradiation was $100 \mathrm{MW}$. As discussed in this report and in Ref. 18, the reactor power has to be increased from the $85 \mathrm{MW}$ for the current HEU core to $100 \mathrm{MW}$ for the LEU core to meet flux performance criteria (no changes from current operation) while meeting criteria for safe HFIR operation. The cross-section libraries used in the simulation are based on data from ENDF/B-VII release 0 . All cross sections were considered at $300 \mathrm{~K}$ temperature. VESTA allows changes in the configuration through the use of transformation cards in the MCNP model. This permits the modeling of the control element movement during the irradiation cycle. The location of the two HFIR control elements, identified as the inner control element (ICE) and the outer control element (OCE), can 
be changed for each of the depletion steps considered in the depletion simulation. The CE location as a function of irradiation time for the LEU core, as used in the depletion model, is discussed in Section 4 and Appendix $\mathrm{C}$ of this report. 


\section{LEU FUEL LOAD AND GRADING}

The design of an LEU fuel that would ensure the facility capabilities are maintained at current levels can be viewed as an optimization problem with a multi-objective function (core performance parameters similar to those for the HEU core, thermal hydraulic safety margins similar to the current HEU core) with multiple constraints (no changes to fuel plate basic geometry, same number of fuel plates in fuel element). ${ }^{2}$ As there is no fuel shuffling and the two fuel elements are required to have the same cycle time, the fuel management issues in HFIR are addressed at the design stage.

\subsection{SEARCH FOR AN OPTIMAL LEU FUEL}

To test whether a proposed LEU fuel design meets the HFIR conversion requirements, the following performance parameters were studied for the LEU core and compared with their values for the current HEU core: irradiation cycle length; core power distribution; neutron flux at the central target region, reflector, and cold source location; and thermal hydraulic safety margins. As illustrated in Fig. 6, iterative reactor core physics and thermal hydraulics calculations were performed to search for an optimal fuel load and fuel grading that would ensure a core performance similar to that of the currently operating HEU core. This iterative process, discussed in detail in Ref. 13, is summarized here for completeness.

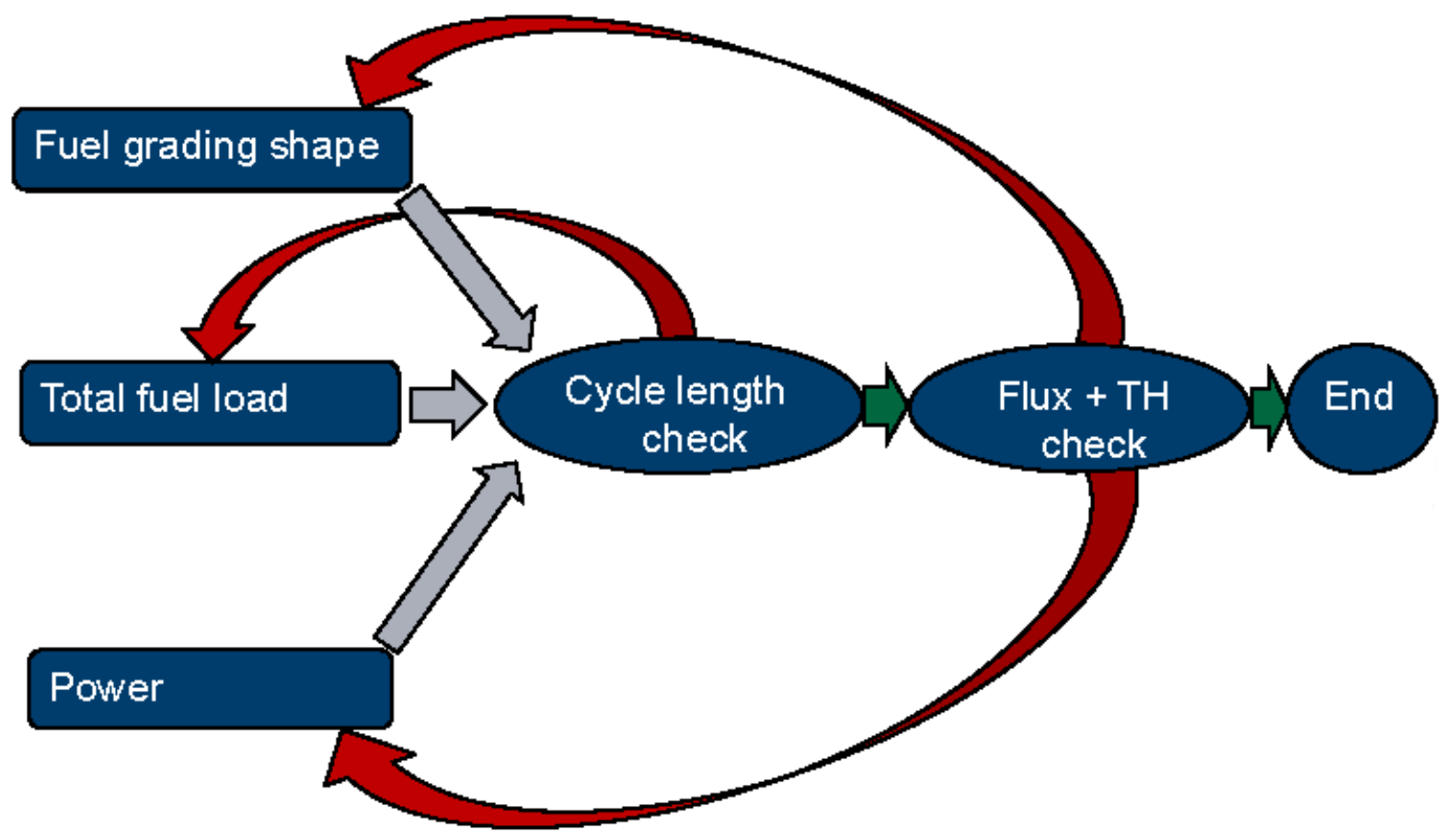

Fig. 6. Iterative search for an optimal LEU fuel design.

As the first step in the search for an optimal fuel design, the fuel load in the depletion model of the LEU core was varied to determine the loading that would ensure a core lifetime similar to that of the HFIR HEU core. It was found that the needed total loading of ${ }^{235} \mathrm{U}$ to meet this requirement is approximately $25 \mathrm{~kg}$. Then, iterations were carried out on both total ${ }^{235} \mathrm{U}$ load and radial fuel grading profile by searching around the $25 \mathrm{~kg}$ value for the total ${ }^{235} \mathrm{U}$ load. Depletion simulations were performed initially for a thermal operating power of $85 \mathrm{MW}$ as used in the current HEU core. The flux at important experiment locations was estimated and the corresponding core power distribution was applied in steady- 
state thermal hydraulics analysis to verify whether the thermal margins were maintained as for the HEU core. Later, the power had to be increased to $100 \mathrm{MW}$ to maintain the flux performance at the target locations similar to that for the HEU core at $85 \mathrm{MW}$, but still under the constraint of maintaining the same thermal margin (margin to incipient boiling) as for the HEU core at $85 \mathrm{MW}$.

Axial grading was also included later ${ }^{13,18}$ because of thermal hydraulics limits. The use of axial grading at the bottom of the fuel elements was based on the observation that, as the water coolant enters the top of the core and flows from the top to the bottom of the core, the occurrence of a power "spike" at the bottom of the fuel elements would cause that location to be the point at which the margin to incipient boiling was smallest; whereas a spike at the top of the fuel elements, as it is at the location of the coolant inlet to the core, would have a much larger margin to incipient boiling. Since the margin at the bottom of the fuel was less than that currently calculated for HEU fuel, grading of the fuel at the bottom of the core was needed.

In addition to the iterative process illustrated in Fig. 6, additional iterations were considered in the work performed during FY 2010. A first iteration was performed on control element movement to minimize the variation of the $k_{\text {eff }}$ during the cycle (keeping it at a constant value close to 1 ). A second iteration was performed on the boron concentration in the filler material in the IFE plates. This later iteration was necessary to optimize the power distribution in the fuel regions, which was affected by the update of the material composition in the control elements. During irradiation, the composition of the poison materials in the CEs changes due to neutron interactions, leading to a change in the properties (cross sections) of these materials. As discussed in detail in Ref. 17, a change of CEs material data from fresh composition to a composition that accounted for the irradiation history of the CEs' had a significant effect on $\mathrm{k}_{\text {eff }}$ variation for cycle 400 . The optimal amount of ${ }^{10} \mathrm{~B}$ in the IFE filler totals $5.4 \mathrm{~g}$, with a uniform boron distribution considered in the filler material. This amount is almost twice as much as the corresponding ${ }^{10} \mathrm{~B}$ content in IFE, of $2.8 \mathrm{~g}$, for the HEU cycle 400.

The boron is needed to shift power from the IFE to the OFE. The shift is needed to maximize the operating power of the reactor; that power determined by the margin to incipient boiling. The amount of boron, that is, the degree of needed power shift, is dependent on the results of the thermal hydraulic analysis. More discussion of this analysis will be provided later, but the authors note at this point that the assumptions inherent in the thermal hydraulic methodology of no heat conduction in the span-wise or axial directions and no turbulent mixing of the coolant water would lead to a larger amount of boron being required than would be the case if these phenomena were accurately modeled.

\subsection{OPTIMAL LEU FUEL LOAD AND GRADING}

The results of the search indicated as optimal an LEU core with a total ${ }^{235} \mathrm{U}$ load of $25.3 \mathrm{~kg}$, a radial fuel grading profile as illustrated in Fig. 7, and with axial grading applied to the bottom $3 \mathrm{~cm}$ of the fuel elements, as illustrated in Fig. 8. The corresponding uranium load would be approximately $127 \mathrm{~kg}$, a large increase compared with the current HEU uranium load of $10.1 \mathrm{~kg}$. A large increase in the fuel load when converting from HEU to LEU has been reported elsewhere, regarding the Massachusetts Institute of Technology (MIT) research reactor; ${ }^{19}$ in that case, the total uranium load is expected to increase from $11.5 \mathrm{~kg}$ to $107.9 \mathrm{~kg}$.

The current HEU fuel is composed of a pressed powder mixture of $\mathrm{U}_{3} \mathrm{O}_{8}$ and aluminum. Thus the manufacturing process easily accommodates the smoothly varying thicknesses shown in Fig. 2. However, the LEU/U-Mo fuel will be manufactured as "fully sized" metal foils to which clad will then be applied. Consultation with fuel fabricators yielded the request that for ease of manufacturing (minimizing cost), a straight-edge radial grading profile be considered for the LEU fuel. The constraints with respect to the fuel grading specified that the fuel meat thickness should be larger than a minimum value of $75 \mu \mathrm{m}$, indicated by the fuel fabricator, and smaller than a maximum value of $711.2 \mu \mathrm{m}$. The maximum thickness is dictated by the dimensions of the fuel plate and the thickness of the diffusion barrier layer ( $\mathrm{Zr}$ ). As seen in Fig. 7, one side of the LEU fuel meat region is flat as in the current HEU contour (see Fig. 2). 


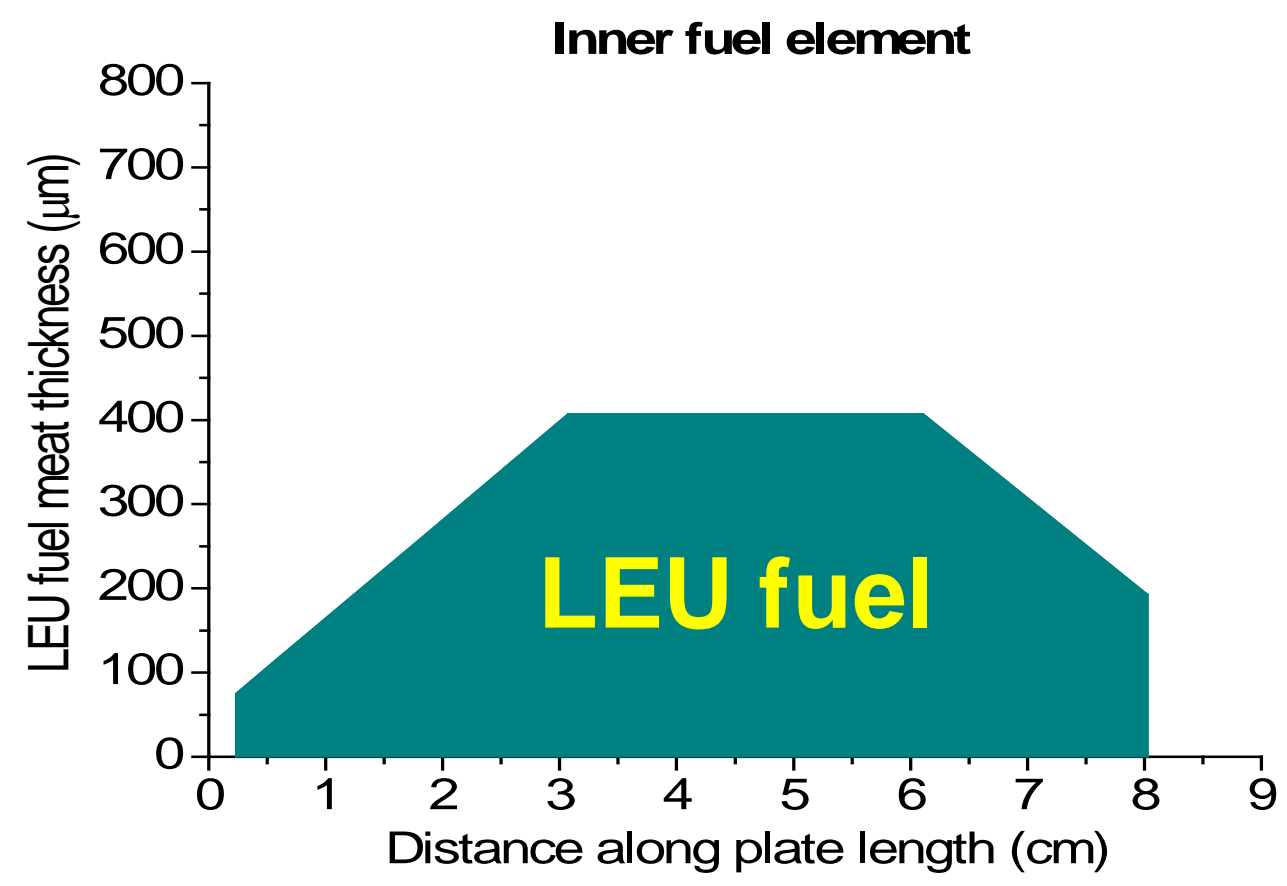

Outer fuel element

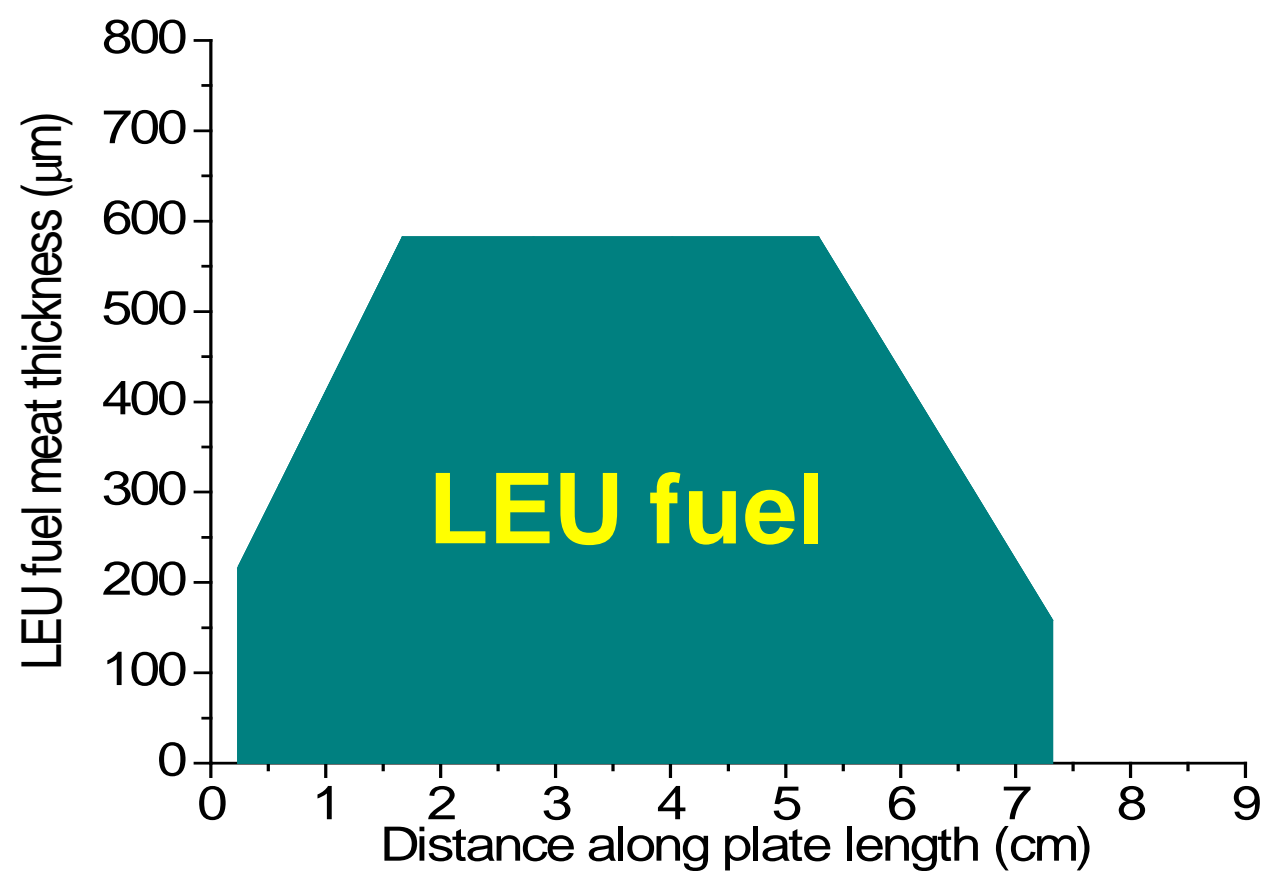

Fig. 7. Optimal radial grading profile for LEU fuel plates. 


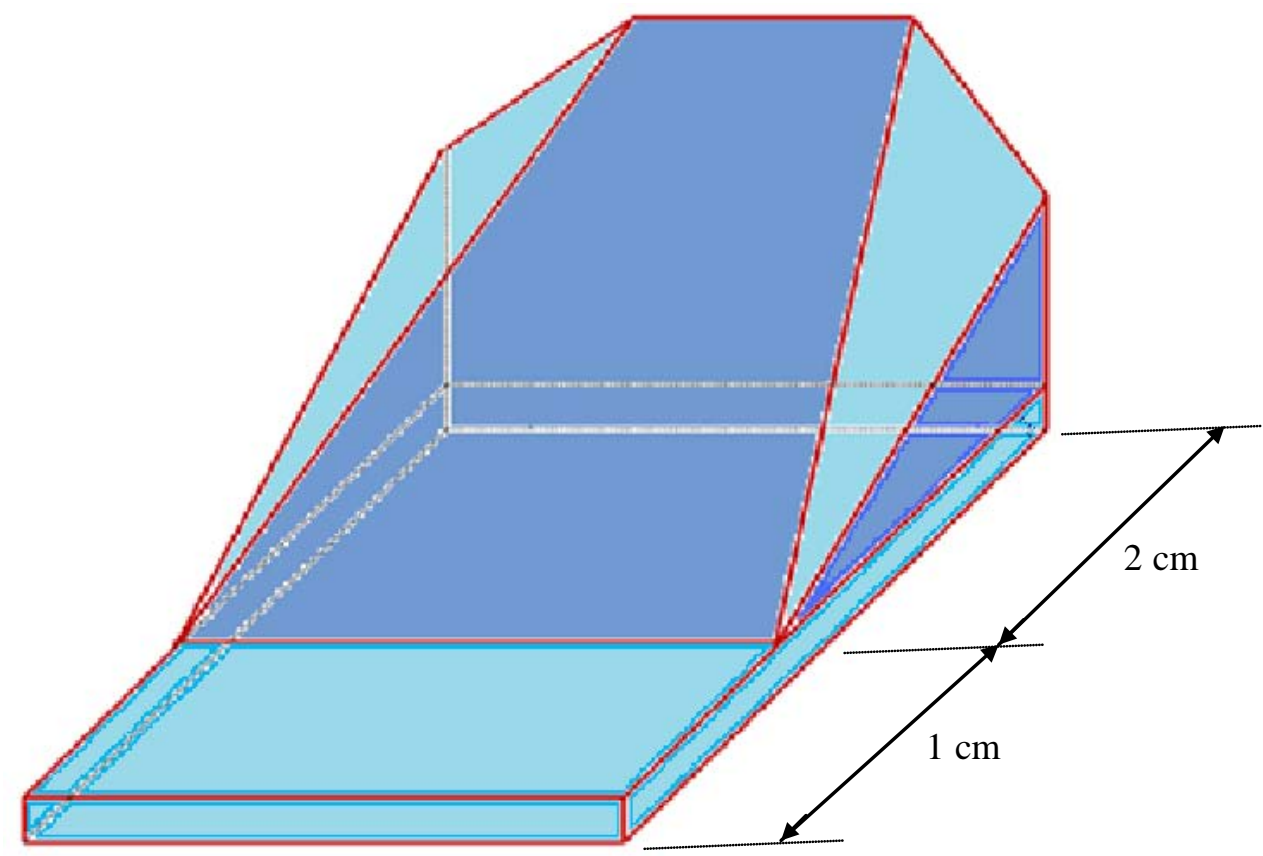

Fig. 8. Axial grading profiles for LEU fuel $(0-3 \mathrm{~cm}$ from bottom of fuel element).

However, the smooth curve profile of the other side for the HEU fuel plate is replaced by a threesegment shape in the case of the LEU grading. The dimensions characterizing the obtained LEU radial profiles are presented in Table 4.

Axial grading was applied to the bottom $3 \mathrm{~cm}$ of the fuel plate. Three cases were analyzed with different values for the concentration of ${ }^{235} \mathrm{U}$ in the bottom $3 \mathrm{~cm}$ of the fuel elements for a given radial location. ${ }^{13}$ It was found that all three cases met the thermal margins requirement. Consequently, a decision on tapering the bottom end of the fuel plates becomes a fabrication issue, decided by minimizing the cost of manufacturing. The axial grading shape found optimal, as illustrated in Fig. 8, consists of a flat radial grading on the bottom $1 \mathrm{~cm}$ (75 $\mu \mathrm{m}$ fuel meat thickness), with planes connecting the radially flat profile on the bottom $1 \mathrm{~cm}$ to the radial profile applied above $3 \mathrm{~cm}$ from the bottom.

Table 4. Radial fuel regions in the MCNP model for HFIR LEU

\begin{tabular}{cccccc}
\hline \multicolumn{2}{c}{ Inner fuel element } & & \multicolumn{2}{c}{ Outer fuel element } \\
\cline { 1 - 2 } \cline { 5 - 5 } $\begin{array}{c}\text { Distance al ong } \\
\text { plate length } \\
(\mathbf{c m})\end{array}$ & $\begin{array}{c}\text { Fuel meat } \\
\text { thickness } \\
(\boldsymbol{\mu m})\end{array}$ & & $\begin{array}{c}\text { Distance al ong } \\
\text { plate length } \\
(\mathbf{c m})\end{array}$ & $\begin{array}{c}\text { Fuel meat } \\
\text { thickness } \\
(\boldsymbol{\mu m})\end{array}$ \\
\hline 0.231 & 75 & & 0.234 & 216 \\
3.072 & 407 & & 1.667 & 582 \\
6.110 & 407 & & 5.286 & 582 \\
8.027 & 193 & & 7.323 & 158 \\
\hline
\end{tabular}




\section{PERFORMANCE AND SAFETY PARAMETERS FOR THE HFIR LEU CORE}

Depletion simulations were carried out with VEST A for the fuel grading and load established as discussed in Section 4.2 to calculate relevant performance parameters for the LEU core. A total of 26 depletion steps were used, each of one day duration. The control element movement was used as described in Appendix C. The power used for the depletion simulation was 100 MW. Performance and safety parameters for the HFIR LEU core are presented in this section and compared with the corresponding values for the HFIR HEU cycle 400 core. Both HEU and LEU core models employed cross sections based on ENDF/B-VII data.

\subsection{PERFORMANCE PARAMETERS FOR THE HFIR LEU CORE}

\subsubsection{Cycle Length and Time-Dependent Control Element Position}

The depletion simulation for the LEU core for a cycle length of 26 days showed that the variation of the effective multiplication factor is consistent with the corresponding curve for the reference HEU cycle 400 core (see Fig. 9). For both the LEU core and the HEU cycle 400 cores, the control elements were fully withdrawn at the end of cycle (EOC). The cycle length determined for the LEU core is similar to the cycle length of HFIR cycle 397 (26.15 days).

The time-dependent control element position for the LEU core was iterated on to obtain a value for $\mathrm{k}_{\mathrm{eff}}$ close to the critical condition. The control element movement during the LEU cycle that corresponds to the $k_{\text {eff }}$ variation shown in Fig. 9 is illustrated in Fig. 10. Details about the control elements modeling in both HEU and LEU cores are provided in Appendix C.

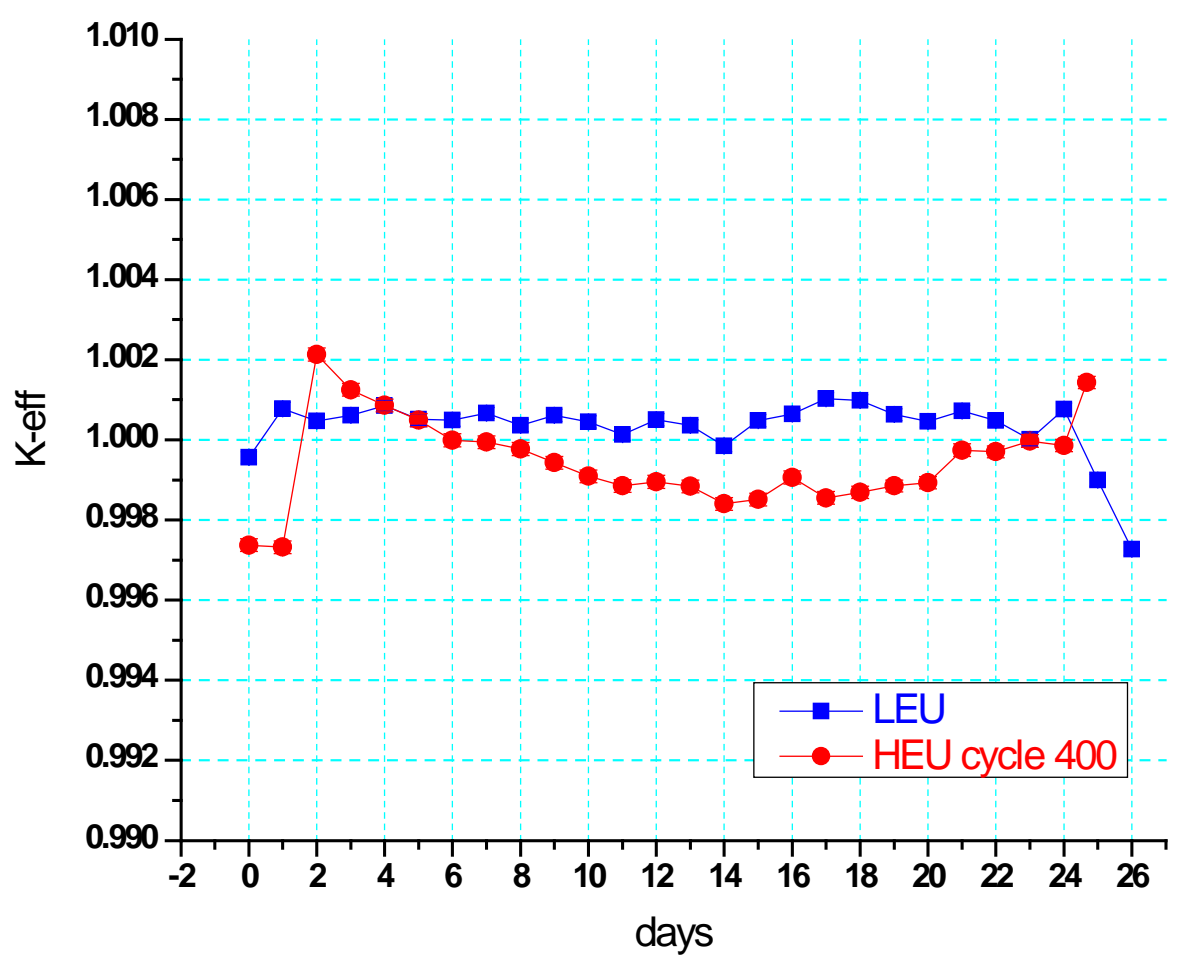

Fig. 9. Variation of $\mathbf{k}_{\mathrm{eff}}$ during irradiation. 


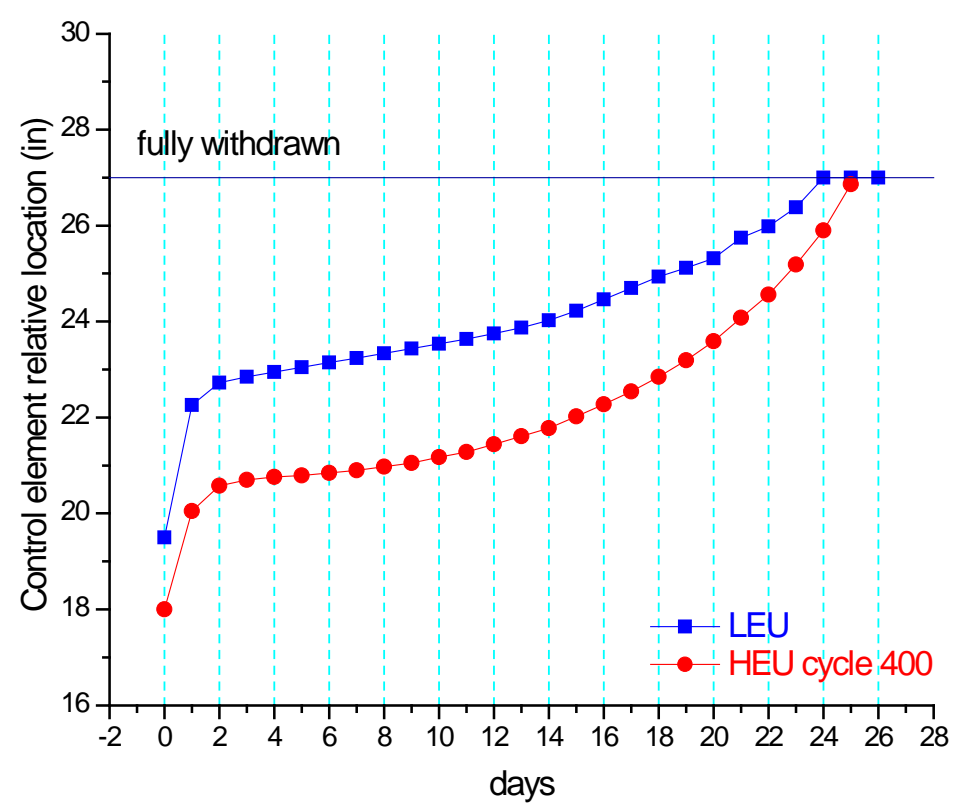

Fig. 10. Control element location during the irradiation cycle.

\subsubsection{Core Power Distribution}

The relative fission density data were calculated for each of the defined regions in the two fuel elements based on flux and fission density tallies in MCNP for BOC, EOC, and at selected intermediate times during the irradiation cycle. These data served as input for the thermal hydraulics analysis that showed that the corresponding operating power is 102.61 MW at BOC and 107.07 MW at EOC. These values preserve the same safety margin (margin to incipient boiling) as exists for the current HEU fuel cycle, as documented in the HFIR Safety Analysis Report. ${ }^{20}$ The relative fission density data for the LEU core at BOC and EOC are listed in Tables 5 and 6, respectively. Data from these tables are displayed in Figs. 11 and 12. The data corresponding to intermediate time points during the cycle are listed for days 1 , 5, 10, 15, 20, and 23 in Appendix D.

Compared to calculated power density profile for HEU fuel in HFIR cycle $400,{ }^{21}$ the power profile for the LEU fuel is "flatter," that is, smaller deviations of local power densities from the desired value of 1.0, than for the current HEU fuel. This desirable result is largely due to the minimum foil thickness for LEU fuel (3 mils) being significantly less than the minimum $\mathrm{HEU} \mathrm{U}_{3} \mathrm{O}_{8}$-Al thickness of 9 mils in an inner element fuel plate. 
Table 5. Relative fission density for HFIR LEU at BOC

\begin{tabular}{|c|c|c|c|c|c|c|c|c|c|c|c|c|c|c|c|c|c|}
\hline \multirow{2}{*}{$\begin{array}{c}\text { Axial } \\
\text { region \# }\end{array}$} & \multicolumn{8}{|c|}{ IFE } & \multicolumn{9}{|c|}{ OFE } \\
\hline & $r=1^{a}$ & $r=2$ & $r=3$ & $r=4$ & $r=5$ & $r=6$ & $r=7$ & $r=8$ & $r=1$ & $r=2$ & $r=3$ & $r=4$ & $r=5$ & $r=6$ & $r=7$ & $r=8$ & $r=9$ \\
\hline 1 & 0.994 & 1.311 & 1.564 & 1.561 & 1.483 & 1.339 & 1.140 & 1.144 & 1.215 & 1.239 & 1.388 & 1.330 & 1.158 & 1.042 & 0.791 & 0.470 & 0.351 \\
\hline 2 & 0.856 & 0.993 & 1.022 & 0.956 & 0.943 & 0.983 & 0.949 & 0.977 & 1.019 & 0.999 & 0.949 & 0.798 & 0.678 & 0.632 & 0.534 & 0.370 & 0.297 \\
\hline 3 & 0.789 & 0.850 & 0.801 & 0.731 & 0.737 & 0.825 & 0.833 & 0.850 & 0.888 & 0.859 & 0.798 & 0.636 & 0.530 & 0.503 & 0.443 & 0.322 & 0.265 \\
\hline 4 & 0.762 & 0.807 & 0.742 & 0.680 & 0.692 & 0.779 & 0.778 & 0.789 & 0.818 & 0.800 & 0.757 & 0.612 & 0.511 & 0.488 & 0.434 & 0.316 & 0.260 \\
\hline 5 & 0.775 & 0.827 & 0.771 & 0.710 & 0.724 & 0.795 & 0.775 & 0.789 & 0.807 & 0.796 & 0.781 & 0.649 & 0.545 & 0.522 & 0.468 & 0.339 & 0.273 \\
\hline 6 & 0.889 & 0.952 & 0.901 & 0.838 & 0.851 & 0.911 & 0.867 & 0.876 & 0.903 & 0.905 & 0.911 & 0.777 & 0.661 & 0.648 & 0.618 & 0.491 & 0.411 \\
\hline 7 & 1.083 & 1.163 & 1.101 & 1.029 & 1.045 & 1.112 & 1.052 & 1.066 & 1.092 & 1.098 & 1.121 & 0.966 & 0.832 & 0.839 & 0.853 & 0.731 & 0.626 \\
\hline 8 & 1.298 & 1.395 & 1.324 & 1.240 & 1.261 & 1.345 & 1.273 & 1.287 & 1.321 & 1.332 & 1.368 & 1.193 & 1.044 & 1.078 & 1.168 & 1.074 & 0.944 \\
\hline 9 & 1.406 & 1.510 & 1.434 & 1.345 & 1.373 & 1.464 & 1.385 & 1.399 & 1.448 & 1.456 & 1.498 & 1.318 & 1.169 & 1.248 & 1.474 & 1.486 & 1.345 \\
\hline 10 & 1.410 & 1.515 & 1.442 & 1.350 & 1.377 & 1.471 & 1.393 & 1.411 & 1.456 & 1.467 & 1.504 & 1.326 & 1.177 & 1.265 & 1.508 & 1.538 & 1.397 \\
\hline 11 & 1.388 & 1.489 & 1.420 & 1.332 & 1.358 & 1.447 & 1.367 & 1.384 & 1.430 & 1.439 & 1.479 & 1.304 & 1.159 & 1.240 & 1.470 & 1.491 & 1.351 \\
\hline 12 & 1.256 & 1.348 & 1.282 & 1.201 & 1.220 & 1.299 & 1.229 & 1.245 & 1.277 & 1.286 & 1.317 & 1.147 & 1.001 & 1.029 & 1.101 & 0.997 & 0.869 \\
\hline 13 & 1.020 & 1.092 & 1.033 & 0.961 & 0.976 & 1.039 & 0.983 & 0.996 & 1.021 & 1.026 & 1.043 & 0.901 & 0.776 & 0.772 & 0.774 & 0.651 & 0.554 \\
\hline 14 & 0.826 & 0.880 & 0.825 & 0.766 & 0.778 & 0.838 & 0.802 & 0.814 & 0.835 & 0.834 & 0.834 & 0.703 & 0.593 & 0.575 & 0.528 & 0.399 & 0.328 \\
\hline 15 & 0.723 & 0.768 & 0.714 & 0.664 & 0.680 & 0.754 & 0.743 & 0.757 & 0.782 & 0.770 & 0.743 & 0.609 & 0.505 & 0.468 & 0.382 & 0.241 & 0.184 \\
\hline 16 & 0.712 & 0.779 & 0.711 & 0.700 & 0.715 & 0.732 & 0.689 & 0.692 & 0.722 & 0.750 & 0.765 & 0.645 & 0.540 & 0.488 & 0.381 & 0.230 & 0.165 \\
\hline 17 & 0.749 & 0.715 & 0.535 & 0.508 & 0.505 & 0.552 & 0.548 & 0.529 & 0.547 & 0.636 & 0.603 & 0.496 & 0.419 & 0.365 & 0.296 & 0.212 & 0.137 \\
\hline 18 & 0.666 & 0.478 & 0.369 & 0.327 & 0.320 & 0.360 & 0.432 & 0.452 & 0.453 & 0.414 & 0.338 & 0.275 & 0.236 & 0.201 & 0.166 & 0.140 & 0.131 \\
\hline 19 & 0.768 & 0.604 & 0.497 & 0.447 & 0.429 & 0.449 & 0.502 & 0.512 & 0.515 & 0.485 & 0.421 & 0.360 & 0.312 & 0.264 & 0.212 & 0.168 & 0.152 \\
\hline
\end{tabular}

${ }^{a} \mathrm{r}=\mathrm{n}$ denotes the radial region number; $\mathrm{n}$ varies from 1 to 8 for the IFE and from 1 to 9 for the OFE. 
Table 6. Relative fission density for HFIR LEU at EOC

\begin{tabular}{|c|c|c|c|c|c|c|c|c|c|c|c|c|c|c|c|c|c|}
\hline \multirow{2}{*}{$\begin{array}{c}\text { Axial } \\
\text { region \# }\end{array}$} & \multicolumn{8}{|c|}{ IFE } & \multicolumn{9}{|c|}{ OFE } \\
\hline & $r=1$ & $r=2$ & $r=3$ & $r=4$ & $r=5$ & $r=6$ & $r=7$ & $r=8$ & $r=1$ & $r=2$ & $r=3$ & $r=4$ & $r=5$ & $r=6$ & $\mathbf{r}=7$ & $r=8$ & $r=9$ \\
\hline 1 & 0.735 & 1.162 & 1.502 & 1.502 & 1.441 & 1.276 & 1.024 & 1.032 & 1.098 & 1.136 & 1.394 & 1.416 & 1.316 & 1.325 & 1.247 & 0.949 & 0.792 \\
\hline 2 & 0.698 & 1.004 & 1.090 & 0.991 & 0.968 & 0.989 & 0.892 & 0.916 & 0.962 & 0.949 & 0.979 & 0.858 & 0.771 & 0.809 & 0.902 & 0.843 & 0.755 \\
\hline 3 & 0.668 & 0.888 & 0.868 & 0.753 & 0.752 & 0.832 & 0.794 & 0.820 & 0.852 & 0.826 & 0.803 & 0.665 & 0.589 & 0.639 & 0.793 & 0.818 & 0.752 \\
\hline 4 & 0.657 & 0.847 & 0.794 & 0.682 & 0.689 & 0.771 & 0.737 & 0.767 & 0.793 & 0.764 & 0.752 & 0.629 & 0.560 & 0.618 & 0.793 & 0.844 & 0.782 \\
\hline 5 & 0.671 & 0.862 & 0.812 & 0.704 & 0.707 & 0.773 & 0.727 & 0.755 & 0.780 & 0.753 & 0.767 & 0.659 & 0.590 & 0.652 & 0.844 & 0.897 & 0.831 \\
\hline 6 & 0.726 & 0.964 & 0.930 & 0.812 & 0.812 & 0.861 & 0.793 & 0.829 & 0.854 & 0.825 & 0.867 & 0.766 & 0.689 & 0.764 & 0.979 & 1.011 & 0.93 \\
\hline 7 & 0.808 & 1.126 & 1.116 & 0.970 & 0.964 & 1.008 & 0.916 & 0.963 & 0.993 & 0.956 & 1.022 & 0.909 & 0.820 & 0.910 & 1.156 & 1.137 & 1.024 \\
\hline 8 & 0.866 & 1.275 & 1.303 & 1.131 & 1.120 & 1.160 & 1.041 & 1.106 & 1.137 & 1.087 & 1.177 & 1.051 & 0.947 & 1.054 & 1.330 & 1.251 & 1.107 \\
\hline 9 & 0.882 & 1.334 & 1.390 & 1.207 & 1.193 & 1.233 & 1.101 & 1.170 & 1.202 & 1.146 & 1.250 & 1.115 & 1.006 & 1.122 & 1.408 & 1.301 & 1.146 \\
\hline 10 & 0.884 & 1.342 & 1.401 & 1.214 & 1.201 & 1.237 & 1.101 & 1.171 & 1.203 & 1.151 & 1.256 & 1.121 & 1.011 & 1.124 & 1.414 & 1.302 & 1.147 \\
\hline 11 & 0.879 & 1.328 & 1.385 & 1.203 & 1.188 & 1.224 & 1.095 & 1.164 & 1.196 & 1.142 & 1.244 & 1.112 & 1.002 & 1.116 & 1.402 & 1.295 & 1.141 \\
\hline 12 & 0.851 & 1.252 & 1.280 & 1.113 & 1.101 & 1.140 & 1.023 & 1.086 & 1.117 & 1.067 & 1.156 & 1.034 & 0.931 & 1.037 & 1.309 & 1.234 & 1.093 \\
\hline 13 & 0.783 & 1.087 & 1.077 & 0.937 & 0.933 & 0.974 & 0.886 & 0.934 & 0.961 & 0.923 & 0.986 & 0.877 & 0.792 & 0.881 & 1.126 & 1.113 & 1.003 \\
\hline 14 & 0.707 & 0.931 & 0.891 & 0.775 & 0.776 & 0.829 & 0.769 & 0.807 & 0.832 & 0.803 & 0.835 & 0.732 & 0.658 & 0.733 & 0.952 & 0.993 & 0.914 \\
\hline 15 & 0.664 & 0.854 & 0.811 & 0.708 & 0.716 & 0.793 & 0.759 & 0.789 & 0.814 & 0.785 & 0.790 & 0.669 & 0.598 & 0.661 & 0.858 & 0.912 & 0.846 \\
\hline 16 & 0.668 & 0.896 & 0.855 & 0.809 & 0.816 & 0.812 & 0.721 & 0.734 & 0.756 & 0.776 & 0.841 & 0.746 & 0.671 & 0.723 & 0.864 & 0.849 & 0.728 \\
\hline 17 & 0.695 & 0.827 & 0.670 & 0.632 & 0.619 & 0.634 & 0.580 & 0.562 & 0.557 & 0.653 & 0.665 & 0.592 & 0.548 & 0.563 & 0.637 & 0.690 & 0.53 \\
\hline 18 & 0.584 & 0.513 & 0.434 & 0.392 & 0.379 & 0.402 & 0.442 & 0.458 & 0.435 & 0.403 & 0.351 & 0.314 & 0.298 & 0.298 & 0.326 & 0.386 & 0.432 \\
\hline 19 & 0.609 & 0.563 & 0.506 & 0.473 & 0.455 & 0.462 & 0.484 & 0.492 & 0.474 & 0.450 & 0.415 & 0.388 & 0.372 & 0.368 & 0.381 & 0.414 & 0.441 \\
\hline
\end{tabular}

${ }^{a} \mathrm{r}=\mathrm{n}$ denotes the radial region number; $\mathrm{n}$ varies from 1 to 8 for the IFE and from 1 to 9 for the OFE. 


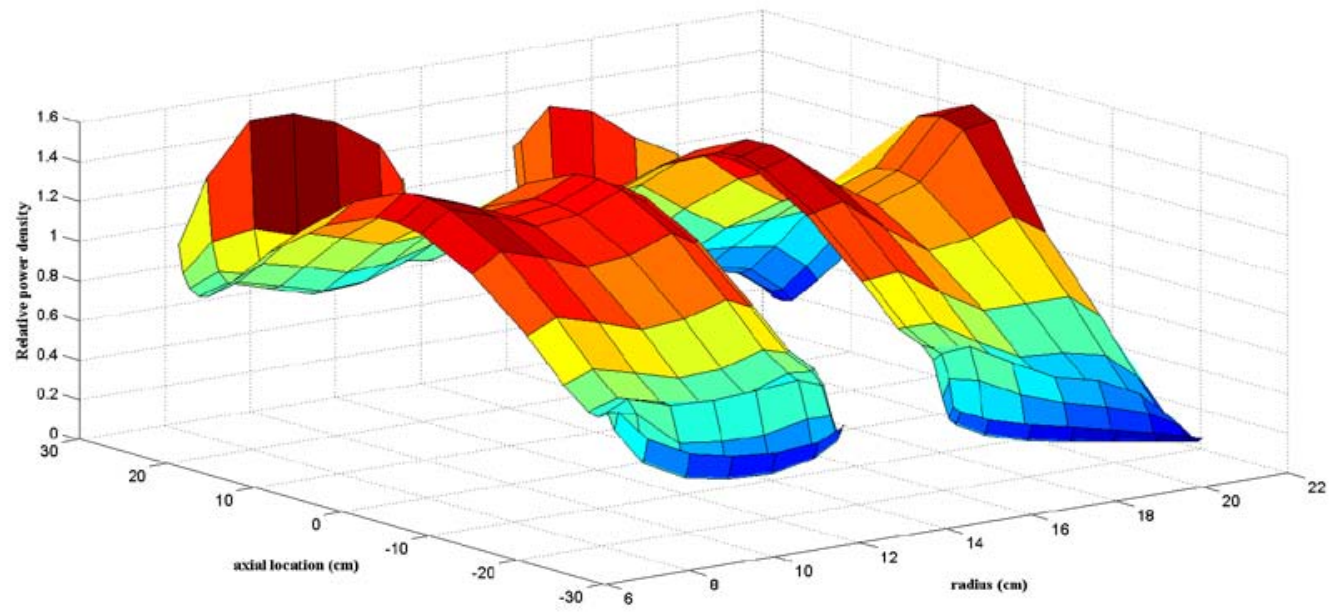

Fig. 11. Graphical representation of LEU BOC power profile (Table 5 data).

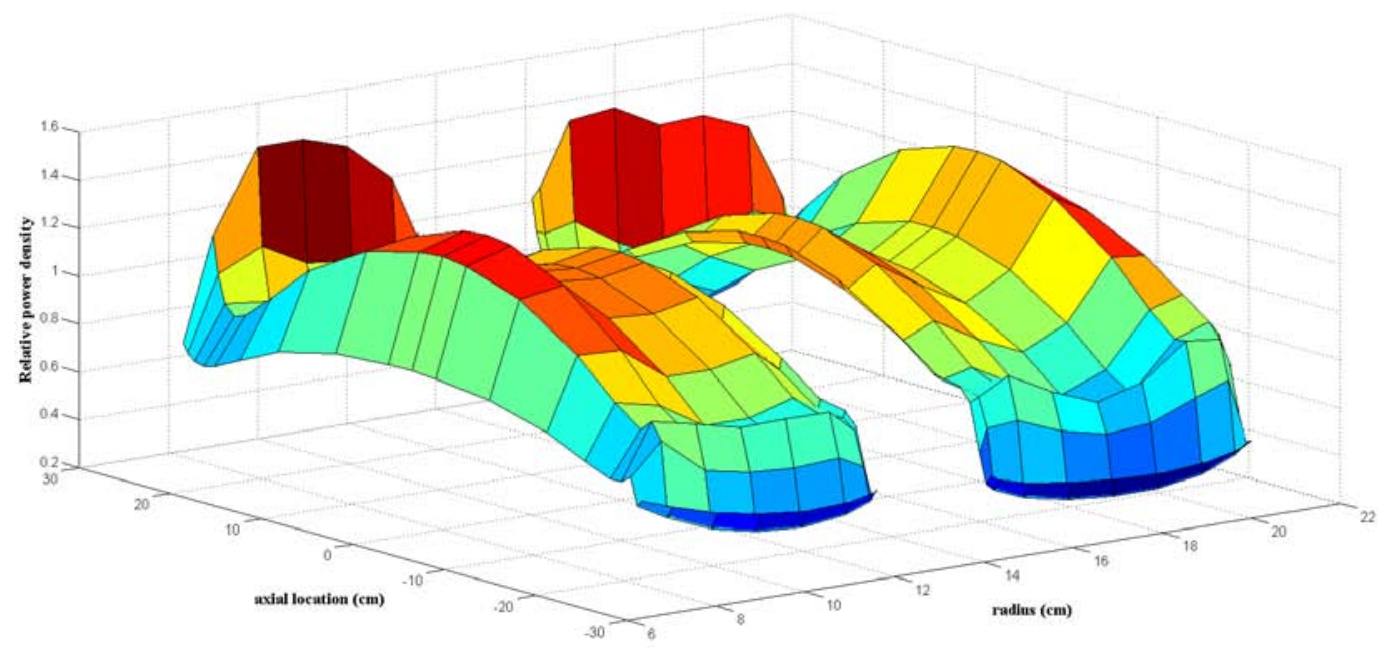

Fig. 12. Graphical representation of LEU EOC power profile (Table 6 data).

\subsubsection{Peak Physics Parameters Relevant to Irradiation Tests}

Fuel plate irradiations are expected to be conducted in the Advanced Test Reactor at Idaho National Laboratory for expected peak LEU fuel performance conditions. Table 7 provides estimates of peak fuel conditions; these estimates are derived from the same calculations that generated the results in Tables 5 and 6. The considered volume $\left(\mathrm{cm}^{3}\right)$ is the volume of the U-Mo fuel material and not of the whole plate or "combined water channel and plate" volume, and the reactor power level is $100 \mathrm{MW}$. Note that the values shown in Table 7 are nominal values for "perfectly manufactured" fuel plates for which all aspects of the fuel are known with "absolute certainty" (no errors and no uncertainty in measurements). Safety basis values would be larger than these, though the amount is currently unknown since the fabrication process is not quantified. 
Table 7. Peak performance parameters for LEU fuel in HFIR

\begin{tabular}{|c|c|c|}
\hline Parameter & Value & Comments \\
\hline Fission density & $\begin{array}{l}3.87 \times 10^{21} \text { fissions } / \\
\left(\mathrm{cm}^{3} \mathrm{U}-\mathrm{Mo}\right)\end{array}$ & A HFIR fuel plate has both fuel and filler regions \\
\hline $\begin{array}{l}\text { Fissions per initial } \\
\text { fissile atom (FIFA) }\end{array}$ & 0.499 & Different units, same location and burnup as fission density \\
\hline Fission rate density & $\begin{array}{l}2.25 \times 10^{15} \text { fissions/ } \\
\left(\mathrm{cm}^{3} \mathrm{~s}\right)\end{array}$ & The volume considered is the U/Mo fuel region \\
\hline $\begin{array}{l}\text { Nominal maximum } \\
\text { fuel plate surface } \\
\text { heat flux }\end{array}$ & $393 \mathrm{~W} / \mathrm{cm}^{2}$ & $\begin{array}{l}\text { Due to varying fuel thickness, the peak surface heat flux differs } \\
\text { from the peak fission rate density (value reported is core average } \\
\text { heat flux [251] }{ }^{*} \text { maximum local relative power density [1.504]; } \\
\text { i.e., does not include } 1.27 \text { hot spot factor) }\end{array}$ \\
\hline
\end{tabular}

Applying current HEU safety factors to these numbers would result in a maximum increase of $27 \%$ in the surface heat flux (the HEU fuel specification allows for a "hot spot" fuel thickness that is 1.27 times the nominal thickness), though it would not be correct to modify the number of fissions per initial fissile atom (FIFA) or the peak fission density by that factor, as both the numerator and denominator of that parameter would both be increased by the same factor. As documented in the safety analysis report for the current HFIR HEU fuel, the $85 \mathrm{MW}$ HEU hot spot heat flux value is $583 \mathrm{~W} / \mathrm{cm}^{2}$ (this value includes the hot spot safety factor noted above). It is noteworthy that the physics design for the LEU fuel has resulted in a fuel grading profile that reduces the hot spot heat flux from $583 \mathrm{~W} / \mathrm{cm}^{2}$ at $85 \mathrm{MW}$ to $499 \mathrm{~W} / \mathrm{cm}^{2}$ at $100 \mathrm{MW}$ - $17 \%$ improvement while increasing reactor power by $18 \%$.

\subsubsection{Neutron Flux}

As mentioned previously, the neutron flux level, one of the key parameters for characterizing core performance, should be maintained when replacing HEU with LEU so that facility missions will not be affected. A comparison of three-group flux data estimated based on MCNP flux tallies for the current HEU core at 85 MW power and the proposed LEU core at 100 MW power at BOC and EOC, respectively, is presented in Tables 8 and 9 for three locations considered as most relevant for the reactor performance and included in the criteria for the core performance assessment. The relative standard deviation for the tallied flux is less than $1 \%$ in all cases. The energy structure for the shown three-group data is thermal: $<0.625 \mathrm{eV}$; epithermal, $0.625 \mathrm{eV}-100 \mathrm{keV}$; and fast, $100 \mathrm{keV}-20 \mathrm{MeV}$. As the flux tallies provided by MCNP are normalized to the source (i.e., 1 fission neutron), the values for the flux in $\mathrm{n} / \mathrm{cm}^{2} \mathrm{~s}$ were obtained by multiplying the flux tally values by the total source. The total source $S$ was approximated as

$$
S=\frac{v P}{E e}
$$

where $v$ is the average number of neutrons per fission, $P$ is the reactor power in $M W, E$ is the average energy per fission in $\mathrm{MeV}$, and $e$ is a unit conversion factor $\left(1.6 \times 10^{-19}\right)$. An approximate value of $200 \mathrm{MeV}$ was used for $E$, whereas the value for $v$ was taken directly from the MCNP output. The value of the total source at BOC is $6.47 \times 10^{18} \mathrm{n} / \mathrm{s}$ for HEU at $85 \mathrm{MW}$ power and $7.66 \times 10^{18} \mathrm{n} / \mathrm{s}$ for LEU at $100 \mathrm{MW}$ power. The flux is shown for three important experiment locations: the maximum value in the central target in the flux trap, and at the edge of the cold source and in the beryllium reflector at $35 \mathrm{~cm}$ and $27 \mathrm{~cm}$ from the center at core midline, respectively. As observed, the fluxes corresponding to the LEU core are comparable to those for the HEU core. 
Table 8. Neutron flux at BOC-comparison of HEU

cycle 400 and LEU cores

\begin{tabular}{|c|c|c|c|c|}
\hline Location & Fuel & $\begin{array}{c}\text { Thermal flux } \\
\left(\mathbf{n} / \mathrm{cm}^{2} \mathbf{s}\right)\end{array}$ & $\begin{array}{c}\text { Epithermal } \\
\text { flux } \\
\left(\mathbf{n} / \mathbf{c m}^{2} \mathbf{s}\right)\end{array}$ & $\begin{array}{l}\text { Fast flux } \\
\left(\mathbf{n} / \mathbf{c m}^{2} \mathbf{s}\right)\end{array}$ \\
\hline $\begin{array}{l}\text { Central target } \\
\mathrm{r}=0 \mathrm{~cm}\end{array}$ & $\begin{array}{l}\text { HEU } \\
\text { LEU }\end{array}$ & $\begin{array}{l}2.2 \times 10^{15} \\
2.3 \times 10^{15}\end{array}$ & $\begin{array}{l}1.3 \times 10^{15} \\
1.3 \times 10^{15}\end{array}$ & $\begin{array}{l}1.1 \times 10^{15} \\
1.2 \times 10^{15}\end{array}$ \\
\hline $\begin{array}{l}\text { Cold source edge } \\
r=35 \mathrm{~cm}\end{array}$ & $\begin{array}{l}\text { HEU } \\
\text { LEU }\end{array}$ & $\begin{array}{l}6.5 \times 10^{14} \\
7.5 \times 10^{14}\end{array}$ & $\begin{array}{l}2.4 \times 10^{14} \\
2.8 \times 10^{14}\end{array}$ & $\begin{array}{l}9.3 \times 10^{13} \\
1.1 \times 10^{14}\end{array}$ \\
\hline $\begin{array}{l}\text { Reflector } \\
\mathrm{r}=27 \mathrm{~cm}\end{array}$ & $\begin{array}{l}\text { HEU } \\
\text { LEU }\end{array}$ & $\begin{array}{l}5.6 \times 10^{14} \\
6.3 \times 10^{14}\end{array}$ & $\begin{array}{l}6.3 \times 10^{14} \\
7.6 \times 10^{14}\end{array}$ & $\begin{array}{l}4.1 \times 10^{14} \\
4.8 \times 10^{14}\end{array}$ \\
\hline
\end{tabular}

Table 9. Neutron flux at EOC—comparison of HEU cycle 400 and LEU cores

\begin{tabular}{|c|c|c|c|c|}
\hline Location & Fuel & $\begin{array}{l}\text { Thermal flux } \\
\text { (n/cm²) }\end{array}$ & $\begin{array}{c}\text { Epithermal } \\
\text { flux } \\
\left(\mathbf{n} / \mathbf{c m}^{2} \mathbf{s}\right)\end{array}$ & $\begin{array}{l}\text { Fast flux } \\
\left(\mathbf{n} / \mathrm{cm}^{2} \mathbf{s}\right)\end{array}$ \\
\hline $\begin{array}{l}\text { Central target } \\
\mathrm{r}=0 \mathrm{~cm}\end{array}$ & $\begin{array}{l}\text { HEU } \\
\text { LEU }\end{array}$ & $\begin{array}{l}2.2 \times 10^{15} \\
2.5 \times 10^{15}\end{array}$ & $\begin{array}{l}1.1 \times 10^{15} \\
1.2 \times 10^{15}\end{array}$ & $\begin{array}{l}9.5 \times 10^{14} \\
1.1 \times 10^{15}\end{array}$ \\
\hline $\begin{array}{l}\text { Cold source edge } \\
\mathrm{r}=35 \mathrm{~cm}\end{array}$ & $\begin{array}{l}\text { HEU } \\
\text { LEU }\end{array}$ & $\begin{array}{l}8.3 \times 10^{14} \\
8.4 \times 10^{14}\end{array}$ & $\begin{array}{l}2.4 \times 10^{14} \\
2.7 \times 10^{14}\end{array}$ & $\begin{array}{l}9.4 \times 10^{13} \\
1.0 \times 10^{14}\end{array}$ \\
\hline $\begin{array}{l}\text { Reflector } \\
\mathrm{r}=27 \mathrm{~cm}\end{array}$ & $\begin{array}{l}\text { HEU } \\
\text { LEU }\end{array}$ & $\begin{array}{l}8.1 \times 10^{14} \\
7.2 \times 10^{14}\end{array}$ & $\begin{array}{l}6.5 \times 10^{14} \\
7.3 \times 10^{14}\end{array}$ & $\begin{array}{l}4.1 \times 10^{14} \\
4.6 \times 10^{14}\end{array}$ \\
\hline
\end{tabular}

Other parameters included in the HFIR Safety Analysis Report (SAR) for the HEU core refer to flux values at specific core locations. To facilitate a comparison of these values to the corresponding LEU core values, flux data were calculated based on MCNP flux tallies, as presented in Table 10. The neutron energy range for calculating the thermal flux is considered from 0 to $0.625 \mathrm{eV}$. The target average thermal flux for the central targets in the flux trap is determined as an average over all inner 31 target locations.

Table 10. Other neutron flux data-comparison of HEU cycle 400 and LEU cores

\begin{tabular}{lccc}
\hline \multicolumn{1}{c}{ Parameter } & Fuel & BOC & EOC \\
\hline $\begin{array}{l}\text { Average thermal flux in } \\
\text { central target region, n/cm }{ }^{2} \mathrm{~s}\end{array}$ & HEU & $1.6 \times 10^{15}$ & $1.6 \times 10^{15}$ \\
& LEU & $1.6 \times 10^{15}$ & $1.8 \times 10^{15}$ \\
$\begin{array}{l}\text { Maximum thermal flux at RB } \\
\text { locations in Be reflector, }\end{array}$ & HEU & $9.3 \times 10^{14}$ & $1.3 \times 10^{15}$ \\
n/cm cm $^{2}$ & LEU & $1.1 \times 10^{15}$ & $1.2 \times 10^{15}$ \\
$\begin{array}{l}\text { Average thermal flux in fuel } \\
\text { region (IFE + OFE), n/cm }{ }^{2} \mathrm{~s}\end{array}$ & HEU & $3.0 \times 10^{14}$ & $4.4 \times 10^{14}$ \\
& LEU & $1.4 \times 10^{14}$ & $1.6 \times 10^{14}$ \\
\hline
\end{tabular}




\subsubsection{Differential Control Element Worth}

Differential and integral control element worths for HFIR control elements for the HEU core were previously calculated using deterministic transport models of the core, as documented in Ref. 22. Differential worth for the HEU fuel at BOC was recalculated here for the HFIR cycle 400 using the MCNP model for this cycle. Differential worth for the LEU core at BOC was calculated using the MCNP model described in Section 4 of this report.

The differential worth $\mathrm{DW}_{i}$ at state $i$ corresponding to a position $p_{i}$ of the control element was calculated for each of the two control elements as

$$
D W_{i}=\frac{\left|k_{i}-k_{i, p}\right|}{\left|p_{i}-\left(p_{i}+\Delta p\right)\right|}
$$

where $k_{i}$ is the core effective multiplication constant corresponding to state $i$; $p_{i}$ is the control element location in state $i ; k_{i, p}$ is the core effective multiplication constant corresponding to a perturbed state; $p_{i}+\Delta p$ is the perturbed location for one control element in the perturbed state; and $\Delta p$ is the perturbation of the location on one control element location, used as $0.5 \mathrm{in}$. for all cases. In initial state $i$, both control elements are located symmetrically with respect to the core axial centerline. In the perturbed state, position of one control element only is perturbed.

Compositions of control element materials were the same at BOC for both HEU and LEU cores, though, of course, initial critical configuration differed for the two cores. Differential worth for HEU cycle 400 and LEU cores are presented in Table 11 and illustrated in Fig. 13. Data are expressed in cents/in. The values used for the effective delayed neutron fraction are discussed in Section 5.3.4 of this report.

The MCNP-calculated maximum differential worth for HEU fuel occurs at 18 in. withdrawn and has a value of 277 cents/in. This value is $9 \%$ below the nominal value of 310 cents/in. that is the basis for predicting startup control/safety plate positions for the current HEU fuel. The difference, at least in part, is attributed to the fact that current calculations are performed with predicted "depleted" control and safety plate isotopics and the 310 cents/in. value is based on extrapolations from measurements conducted with fresh safety and control plates. For these studies, the most important aspect is not the actual value of the calculated differential worth but the values of the differences between the calculated worths for LEU and HEU fuels at given control/safety plate locations.

Table 11. Differential worth of control elements

\begin{tabular}{|c|c|c|c|c|}
\hline \multirow{3}{*}{$\begin{array}{c}\text { Position } \\
\text { (in.) }\end{array}$} & \multicolumn{4}{|c|}{ Differential worth (cents/in.) ${ }^{a}$} \\
\hline & \multicolumn{2}{|c|}{ Inner control element } & \multicolumn{2}{|c|}{ Outer control element } \\
\hline & LEU & HEU & LEU & HEU \\
\hline 15 & 79 & 103 & 67 & 81 \\
\hline 16 & 85 & 120 & 75 & 101 \\
\hline 17 & 98 & 131 & 93 & 110 \\
\hline 18 & 118 & 150 & 113 & 127 \\
\hline 19 & 122 & 137 & 108 & 128 \\
\hline 20 & 102 & 127 & 102 & 112 \\
\hline 21 & 91 & 104 & 88 & 96 \\
\hline 22 & 78 & 85 & 71 & 80 \\
\hline 23 & 60 & 66 & 57 & 62 \\
\hline 24 & 51 & 54 & 44 & 50 \\
\hline 25 & 35 & 38 & 35 & 36 \\
\hline 26 & 30 & 29 & 23 & 27 \\
\hline
\end{tabular}

${ }^{a}$ Calculated standard deviation is less than 3 cents/in. 


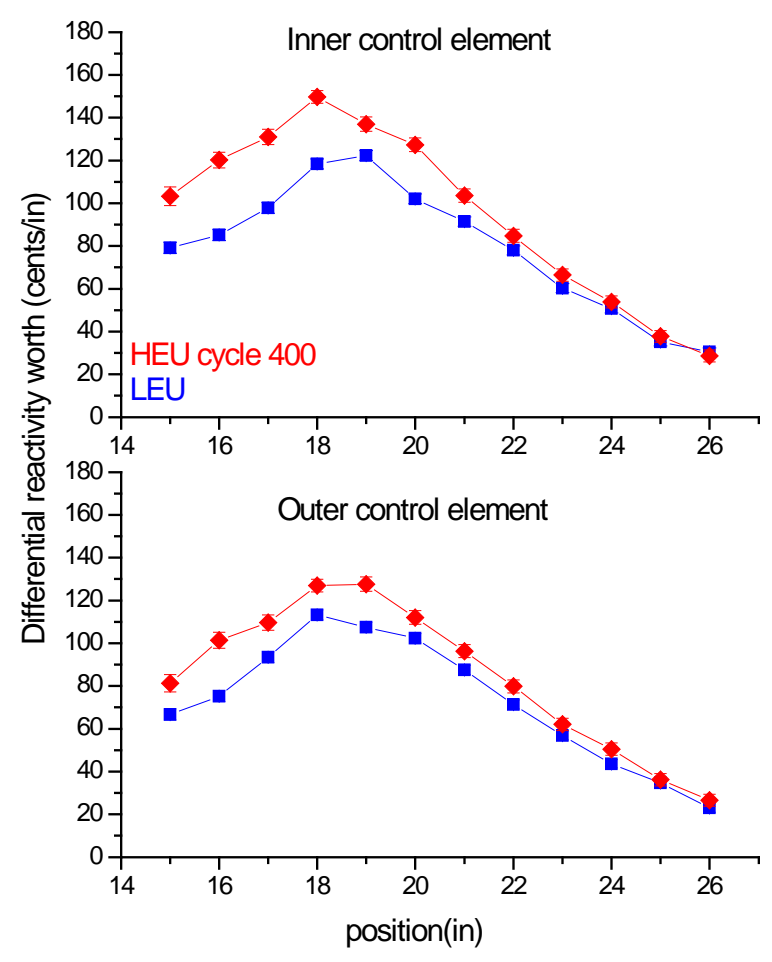

Fig. 13. Differential worth of control elements.

\subsection{THERMAL HYDRAULICS CHARACTERISTICS OF THE LEU CORE}

Relative fission density data were calculated for each of the defined regions in the two fuel elements based on flux and fission density tallies in MCNP for BOC, EOC, and at selected intermediate times during the irradiation cycle. Power profiles at selected times during an irradiation cycle were then used as input to the HFIR Steady State Heat Transfer Code (HSSHTC) ${ }^{22}$ to determine the maximum allowable operating power, under assumptions currently applicable to the HEU fuel core. It is emphasized that it is currently unknown if the HEU assumptions are applicable to LEU fuel analyses because LEU fuel fabrication and performance data do not exist.

A review of the input data that are employed in the calculation of the maximum operating power for both the HEU operating core and the LEU core is provided in this section. For the HEU core, two sets of burnup-dependent heat transfer data are provided, that from the current version of the HFIR Safety Analysis Report (SAR) ${ }^{20}$ and the second set being that calculated for HFIR cycle 400 using the same methodology as employed for the analysis of the LEU core. Details about the use of HSSHTC spatial mesh with the power density data corresponding to the MCNP fuel zones for the HEU cycle 400 and LEU core models are presented in Appendix D.

\subsubsection{Review of Input to Maximum Operating Power Calculation}

Though limited manufacturing data were reported in Ref. 23 (Appendix B, Table B.5), a fuel specification and associated inspection parameters have not been created for HFIR LEU fuel plates. ${ }^{24}$ Consequently, uncertainties in manufacturing parameters that are input to safety-related analyses, also 
discussed in Appendix B of Ref. 23, remain unknown. Consistent with the definition of HFIR LEU studies established in Ref. 3, uncertainties for the current HEU HFIR fuel have been adopted in order to assess the maximum permissible operating power for HFIR. The only parameters for LEU fuel that differ from the HEU parameters documented in Ref. 3 are enumerated in Table 12. Intervening mesh intervals, as discussed in Appendix D, have a zero thickness.

The upper limit for the reactor power level is defined as the maximum power level at which none of the local heat fluxes in the fuel elements exceed the corresponding values of the burnout heat fluxes. The flux-to-flow ratio limiting control setting (LCS) is 1.3 times the normal operating power level as indicated by the neutron flux channels above a coolant flow rate of 11,000 gpm. (Normal coolant flow rate is in the 16,500 to 17,000 -gpm range.) This implies that the reactor should be able to operate at $130 \%$ of its normal power level for short periods of time without damage to the fuel elements (condensed from Pg. 4.4-10 of Ref. 20). For the calculations reported here, onset of incipient boiling heat flux rather than burnout heat flux is determined.

Table 12. HSSHTC input parameters for LEU that differ from HEU

\begin{tabular}{cccccc}
\hline \multirow{2}{*}{$\begin{array}{c}\text { Radial } \\
\text { mesh } \\
\text { number }\end{array}$} & \multicolumn{2}{c}{ Inner element } & & \multicolumn{2}{c}{ Outer element } \\
\cline { 2 - 3 } \cline { 5 - 6 } & $\begin{array}{c}\text { Radial spatial } \\
\text { increment }(\mathbf{c m})\end{array}$ & $\begin{array}{c}\text { End plate power } \\
\text { peaking factor }\end{array}$ & & $\begin{array}{c}\text { Radial spatial } \\
\text { increment (cm) }\end{array}$ & $\begin{array}{c}\text { End plate power } \\
\text { peaking factor }\end{array}$ \\
\hline 4 & 0.3599 & 1.25 & & 0.01 & 1.23 \\
6 & 1.0 & 1.41 & & 0.3401 & 1.26 \\
8 & 1.0 & 1.44 & & 1.0 & 1.35 \\
10 & 1.0 & 1.43 & & 1.0 & 1.35 \\
12 & 1.0 & 1.43 & & 1.0 & 1.35 \\
14 & 1.0 & 1.30 & & 1.0 & 1.35 \\
16 & 0.0899 & 1.20 & & 1.0 & 1.35 \\
18 & 0.01 & 1.20 & & 0.0899 & 1.31 \\
20 & 0.0 & 1.00 & & 0.01 & 1.25 \\
\hline
\end{tabular}

The coolant nominal inlet temperature for HFIR is $120^{\circ} \mathrm{F}$. A high-temperature alarm will sound when this temperature reaches $125^{\circ} \mathrm{F}$, and the reactor will scram at $130^{\circ} \mathrm{F}$. For calculations reported here-both HEU and LEU - the inlet temperature input to the HSSHTC was assumed to be $130^{\circ} \mathrm{F}$.

The nominal core inlet pressure for HFIR is 468 psig. The low-pressure scram set point is 368 psig, vessel pressure. Coolant enters the fuel assembly from an annulus formed by the inner shroud and the target tower. At rated flow, there is an approximate 8 psi pressure entrance loss associated with the annulus. Hence, when converted to psia (for use in the HFIR SSHTC), the coolant inlet pressure (in psia) is roughly 7 psi greater than the vessel pressure (in psig); that being 375 psia (368 - $8+15$ ). (Pg. 4.4-11 of Ref. 20) For calculations reported here-both HEU and LEU - the inlet pressure input to the HSSHTC was assumed to be 375 psia.

The thermal hydraulic parameters contained in the current version of the HFIR SAR ${ }^{20}$ are provided in Table 13. The power profile values that were input to the HSSHTC to generate the numbers shown in Table 13 are interpolations and extrapolations from measured local power densities at selected locations in the reactor core. Note that the hot spot in the core may or may not be located in the hot streak. Also, the location that limits the reactor power - the point at which the incipient boiling temperature equals the clad surface temperature-will not be at the hot spot.

Table 14 provides thermal hydraulic parameters that are based on a power profile generated for HFIR cycle 400 using data from the VESTA depletion simulation for this cycle. The same VESTA code version 
and nuclear data libraries were used to generate the HEU power densities as were used to generate the power profile for the LEU core. The maximum allowable operating power for HEU fuel based on verified and validated MCNP calculations is $85 \mathrm{MW}$, the same as derived from historic data.

The thermal hydraulic parameters for the LEU fuel design that was documented in a previous section of this report are presented in Table 15. Whereas Tables 13 and 14 show parameters of the HEU core for an operating power of $85 \mathrm{MW}$, in order to maintain parity with the current HEU fuel performance, the LEU fuel must operate at a reactor power of $100 \mathrm{MW}$ (as shown in the table).

The "onset of incipient boiling power" (the first entry in Tables 13 through 15) is defined as the reactor power that yields-somewhere in the reactor core-a local surface temperature that is equivalent to the incipient boiling temperature of the water at the pressure at that location. The pressure drop across the reactor core is approximately 100 psia. Hence the incipient boiling temperature is continually decreasing as a function of axial distance from the top of the core.

For the LEU fuel calculation, the incipient boiling temperature as a function of distance "down the core" is shown in Fig. 14 (where 0.0 is the top of the fueled region of the core). The axial variation in the surface temperature- directly proportional to the axial variation in the local power density (see Figs. 10 and 11) - for the LEU case is shown in Fig. 15. Note that the peak in surface temperature occurs at the axial location at which the poison regions of the control and safety plates are not between the reactor core and the Be reflector. Determination of the "onset of incipient boiling power" is determined by taking the ratio of the data shown in Fig. 15 to the data shown in Fig. 14 and determining the power at which, at some point in the core, the value of the ratio is 1.0. This spatially dependent ratio is shown in Fig. 16.

Table 13. Current HEU fuel burnup-dependent heat transfer data-incipient boiling criteria ${ }^{a}$ (Ref. $3^{b}$ with cycle time corrected)

\begin{tabular}{|c|c|c|c|c|c|}
\hline Time into cycle (d) & 0 (BOC) & 1.19 & 13.61 & 26.73 & 29.41 \\
\hline Onset of incipient boiling power, MW & 110.63 & 120.89 & 116.51 & 116.34 & 120.35 \\
\hline Maximum potential operating power, MW & 85 & 93 & 90 & 89 & 93 \\
\hline \multicolumn{6}{|l|}{ Limiting heat flux } \\
\hline $\begin{array}{l}\text { Fuel plate and mesh location } \\
\text { (along span with } 0.0 \text { at fuel edge, axial } \\
\text { with } 0.0 \text { at top of fuel), cm }\end{array}$ & $\begin{array}{c}\text { Outer } \\
(0.19,50.1)\end{array}$ & $\begin{array}{c}\text { Inner } \\
(1.77,50.1)\end{array}$ & $\begin{array}{c}\text { Inner } \\
(1.77,50.1)\end{array}$ & $\begin{array}{c}\text { Inner } \\
(1.77,50.1)\end{array}$ & $\begin{array}{c}\text { Outer } \\
(0.19,50.1)\end{array}$ \\
\hline [QAH] Heat flux, Btu/h-ft ${ }^{2}$ & $2.80 \times 10^{6}$ & $2.81 \times 10^{6}$ & $2.79 \times 10^{6}$ & $2.87 \times 10^{6}$ & $2.70 \times 10^{6}$ \\
\hline$[\mathrm{BWT}]$ Bulk water temperature, ${ }^{\circ} \mathrm{F}$ & 274 & 276 & 278 & 275 & 286 \\
\hline [TSHS] Surface temperature, ${ }^{\circ} \mathrm{F}$ & 422 & 422 & 422 & 422 & 422 \\
\hline$[\mathrm{HH}]$ Heat transfer coefficient, Btu/h- $\mathrm{ft}^{2},{ }^{\circ} \mathrm{F}$ & 18,920 & 19,250 & 19,375 & 19,525 & 19,850 \\
\hline $\begin{array}{l}\text { [FLOWR] Average channel flow rate, } \\
\text { lb/s * in width of interval }\end{array}$ & 0.7473 & 0.6754 & 0.6468 & 0.6421 & 0.6684 \\
\hline [PABS] Pressure, psia & 264 & 264 & 264 & 263 & 263 \\
\hline
\end{tabular}

${ }^{a}$ Reactor conditions based on $130^{\circ} \mathrm{F}$ coolant inlet temperature and 368 psig reactor pressure (equivalent to 375 psia fuel assembly inlet pressure). Coolant inlet temperature uncertainty factor $\mathrm{U}_{6}$ is set to 1.0.

${ }^{b}$ BOC calculations originally published in W. E. Thomas, Bases for the Scram Setpoints, the Limiting Safety System Settings and the Safety Limits of the High Flux Isotope Reactor for Mode 1 Operation at 85 Mw(th), ORNL/RRD/INT22, December 22, 1987, Table 2, pg. 17. 
Table 14. Current HEU fuel burnup-dependent heat transfer data based on power profile for cycle 400 -incipient boiling criteria ${ }^{a}$

\begin{tabular}{|c|c|c|c|c|c|}
\hline Time into cycle (d) & $\mathbf{0}$ (BOC) & 1 & 11 & 22 & 24.67 (EOC) \\
\hline Onset of incipient boiling power, MW & 111.4 & 116.3 & 115.9 & 119.7 & 120.5 \\
\hline Maximum potential operating power, MW & 85.7 & 89.5 & 89.2 & 92.0 & 92.7 \\
\hline \multicolumn{6}{|c|}{ Limiting heat flux location parameters (incipient boiling temperature equal to surface temperature) } \\
\hline $\begin{array}{l}\text { Mesh location fuel plate (along span } \\
\text { with zero at fuel edge, axial with zero } \\
\text { at top of fuel), cm }\end{array}$ & $\begin{array}{l}\text { Inner } \\
(0.61 \\
50.6)\end{array}$ & & & & $\begin{array}{l}\text { Inner } \\
(3.07,50.6)\end{array}$ \\
\hline [QAH] Heat flux, Btu/h-ft ${ }^{2}$ & $2.27 \times 10^{6}$ & & & & $2.46 \times 10^{6}$ \\
\hline$[\mathrm{BWT}]$ Bulk water temperature, ${ }^{\circ} \mathrm{F}$ & 279 & & & & 276 \\
\hline [TSHS] Surface temperature, ${ }^{\circ} \mathrm{F}$ & 399 & & & & 398 \\
\hline$[\mathrm{HH}]$ Heat transfer coefficient, Btu/h- $\mathrm{ft}^{2},{ }^{\circ} \mathrm{F}$ & 17,932 & & & & 19,103 \\
\hline $\begin{array}{l}\text { [FLOWR] Average channel flow rate, } \\
\mathrm{lb} / \mathrm{s} * \text { in width of interval }\end{array}$ & 0.7581 & & & & 0.7006 \\
\hline [PABS] Pressure, psia & 264 & & & & 261 \\
\hline
\end{tabular}

${ }^{a}$ Reactor conditions based on $130^{\circ} \mathrm{F}$ coolant inlet temperature and 368-psig reactor pressure (equiva lent to 375 -psia fuel assembly inlet pressure). Coolant inlet temperature uncertainty factor $\mathrm{U}_{6}$ is set to 1.0. Brackets [] contain variable name in HFIR steady state heat transfer code, Part 3 results.

Table 15. LEU fuel burnup-dependent heat transfer data-incipient boiling criteria ${ }^{a}$

\begin{tabular}{|c|c|c|c|c|c|c|c|c|}
\hline Time into cycle (d) & $\begin{array}{c}\mathbf{0} \\
(\mathbf{B O C})\end{array}$ & 1 & 5 & 10 & 15 & 20 & 23 & $\begin{array}{c}26 \\
(\mathrm{EOC})\end{array}$ \\
\hline Onset of inc. boiling power, MW & 133.8 & 131.1 & 131.5 & 133.5 & 133.8 & 137.2 & 139.9 & 139.6 \\
\hline Max. potential op. power, MW & 102.9 & 100.8 & 101.2 & 102.7 & 103.0 & 105.5 & 107.6 & 107.4 \\
\hline \multicolumn{9}{|c|}{ Limiting heat flux location parameters (incipient boiling temperature equal to surface temperature) } \\
\hline $\begin{array}{l}\text { Mesh location, fuel plate (along } \\
\text { span with zero at fuel edge, axial } \\
\text { with zero at top of fuel), } \mathrm{cm}\end{array}$ & $\begin{array}{l}\text { Inner } \\
(0.61 \text {, } \\
33.8)\end{array}$ & $\begin{array}{l}\text { Outer } \\
(6.96 \\
33.8)\end{array}$ & & & & & & $\begin{array}{l}\text { Outer } \\
(5.95, \\
33.8)\end{array}$ \\
\hline [QAH] Heat flux, Btu/h-ft ${ }^{2}$ & $2.61 \times 10^{6}$ & $3.24 \times 10^{6}$ & & & & & & $3.12 \times 10^{6}$ \\
\hline$[\mathrm{BWT}]$ Bulk water temperature, ${ }^{\circ} \mathrm{F}$ & 265 & 261 & & & & & & 280 \\
\hline [TSHS] Surface temperature, ${ }^{\circ} \mathrm{F}$ & 403 & 430 & & & & & & 430 \\
\hline $\begin{array}{l}{[\mathrm{HH}] \text { Heat transfer coefficient, }} \\
\text { Btu/h- } \mathrm{ft}^{2},{ }^{\circ} \mathrm{F}\end{array}$ & 17,598 & 17,672 & & & & & & 19,380 \\
\hline $\begin{array}{l}\text { [FLOWR] Average channel flow } \\
\text { rate, lb/s * in width of interval }\end{array}$ & 0.7617 & 0.7628 & & & & & & 0.7188 \\
\hline [PABS] Pressure, psia & 286 & 286 & & & & & & 286 \\
\hline
\end{tabular}

${ }^{a}$ Reactor conditions based on $130^{\circ} \mathrm{F}$ coolant inlet temperature and 368-psig reactor pressure (equivalent to 375 -psia fuel assembly inlet pressure). Coolant inlet temperature uncertainty factor $\mathrm{U}_{6}$ is set to 1.0. 

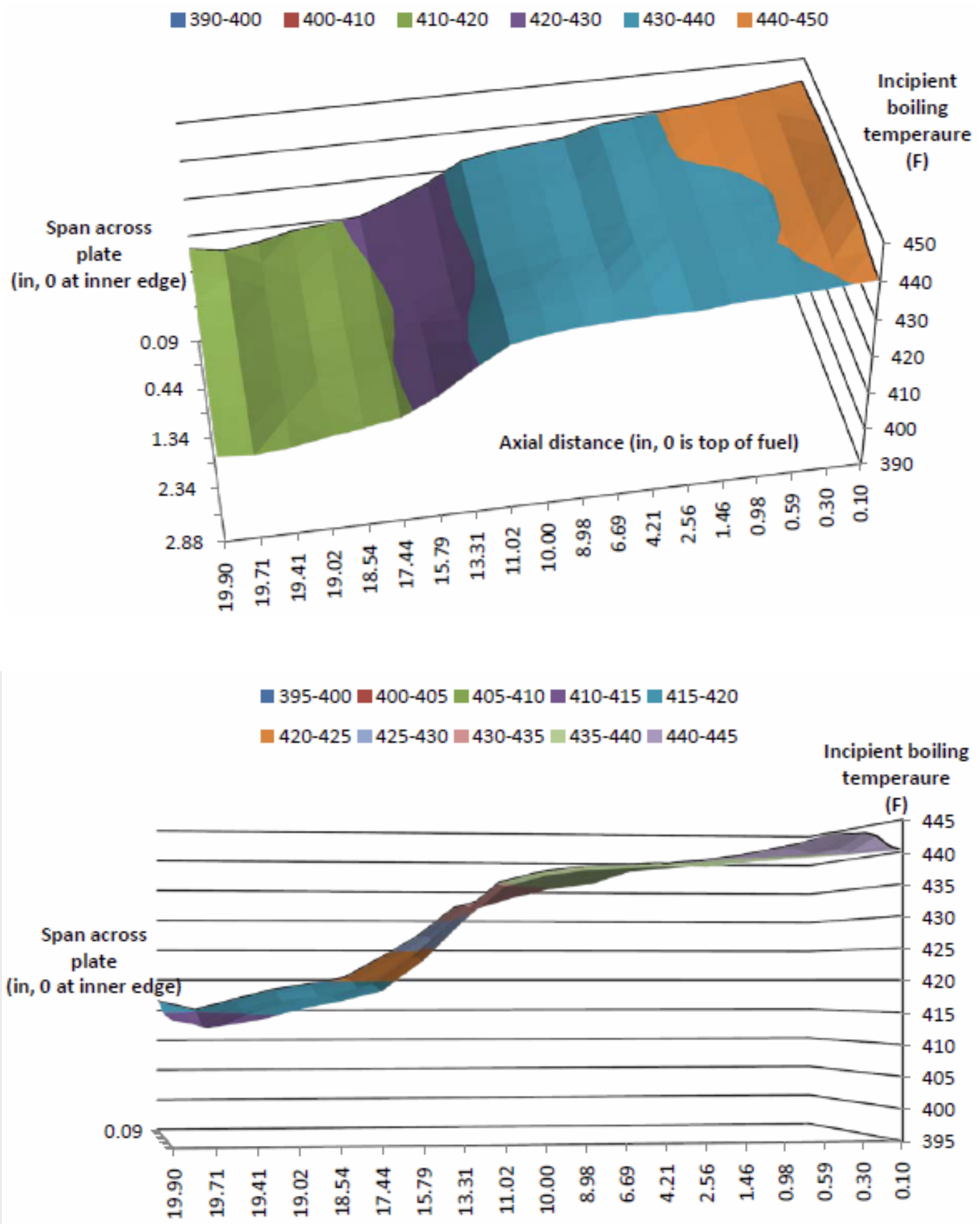

Axial distance (in, 0 is top of fuel)

Fig. 14. Incipient boiling temperature for LEU fuel, outer element plate (same data, two views), after 1 day of irradiation at $100 \mathrm{MW}$. 


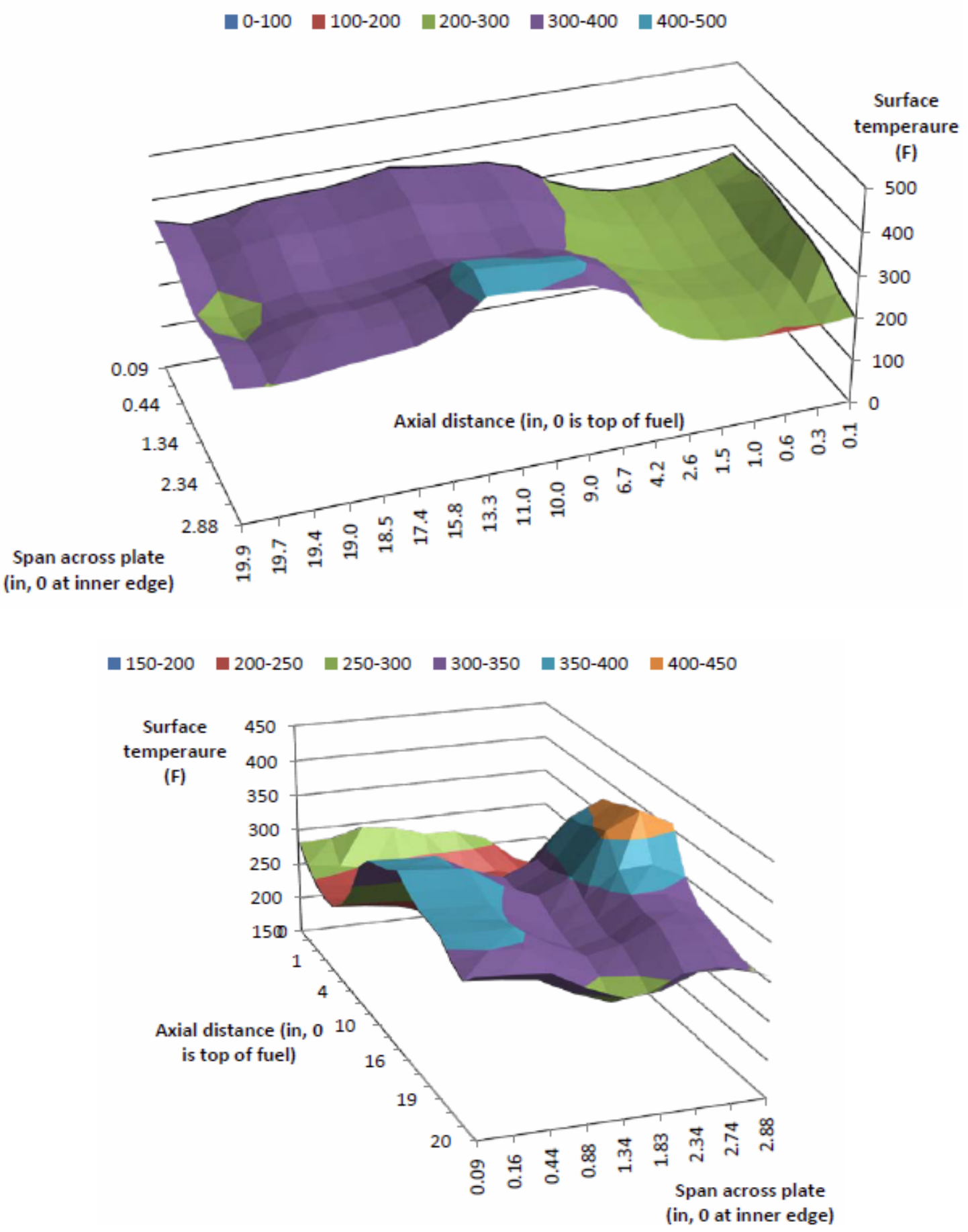

Fig. 15. Hot spot surface temperatures for LEU fuel, outer element fuel plate after 1 day of irradiation at $100 \mathrm{MW}$ (two views). 


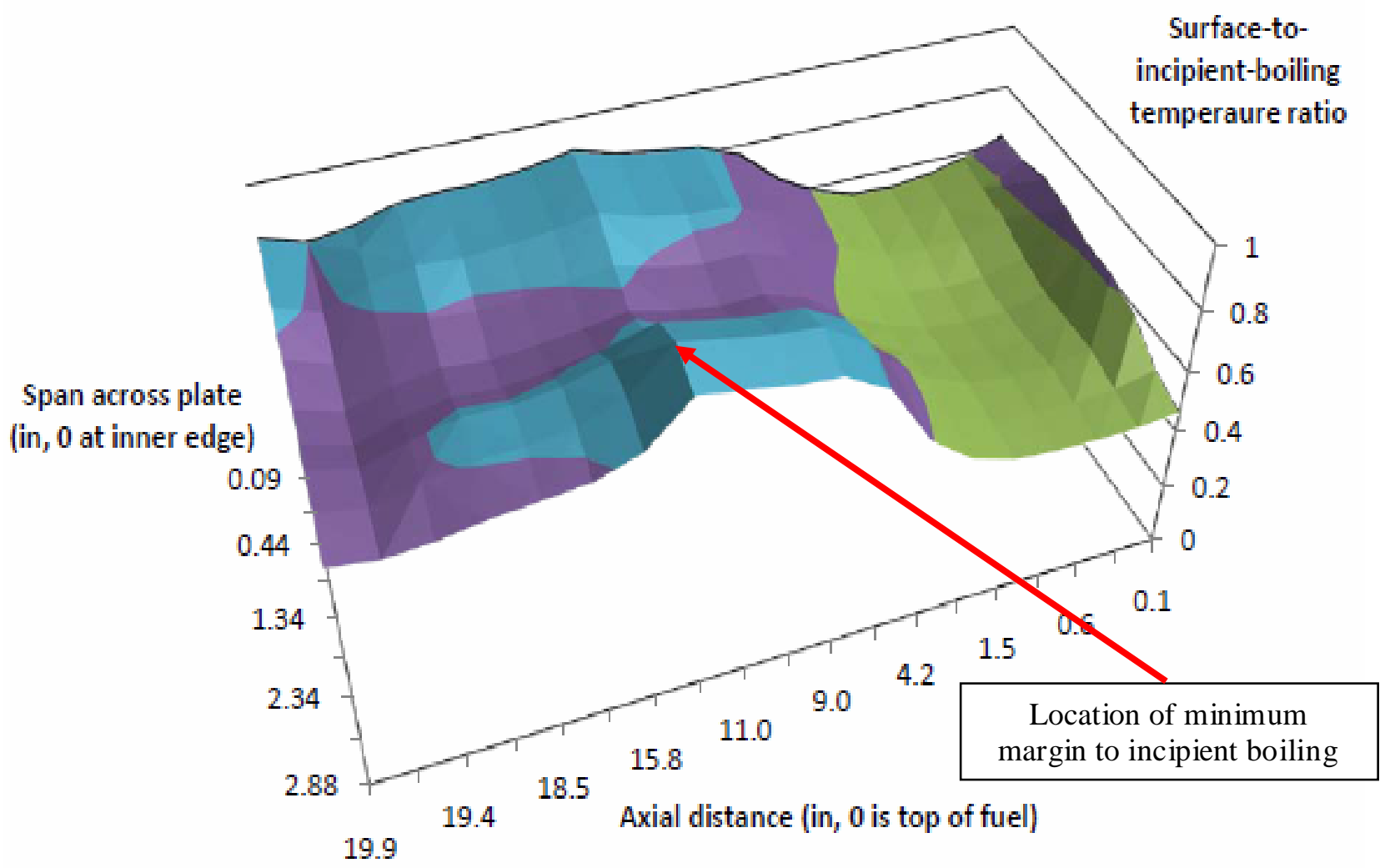

Fig. 16. Surface-to-incipient boiling temperature ratio for LEU fuel, outer element (Fig. 15/Fig. 14).

For the LEU fuel, the location that determines the maximum operating power is in the outer fuel element after one day of operation (not at beginning-of-life as found for the HEU fuel). While not immediately obvious from the Fig. 16, the limiting spot that determines the operating power for the LEU core is close to the axial mid-plane of the reactor core. This is the desired location for achieving maximum reactor operating power. The limit occurs near the location of the maximum "cosine shape" power distribution rather than being driven by edge effects at the lower region of the core. This observation confirms that the LEU fuel was sufficiently graded axially to minimize end-plate peaking but difference between the values of the ratios at plate end and mid-plane is small indicating that no more grading was performed than needed to shift the power-limiting spot.

The ratio of surface temperature to incipient boiling temperature for HEU fuel is shown in Fig. 17the calculation being the current safety basis case for the Safety Analysis Report. The spot that determines the reactor operating power (85 MW) is found at the lower edge of the outer fuel element plate.

Fig. 18 shows the "surface-to-incipient-boiling" ratio for an HSSHTC case that uses as input MCNPcalculated local power densities for HFIR cycle 400 (same neutronics methodology as used for LEU studies). The operating power for an HEU-fueled HFIR is the same as the basis calculation for the HFIR Safety Analysis Report, but the location of the power-limiting point is in the inner element rather than the outer element. Despite differing locations, both the SAR-basis analyses and the current, MCNP-based, cycle 400 analyses lead to the same conclusion: a maximum potential operating power of $85 \mathrm{MW}$ for the current HEU fuel.

Performance with the LEU fuel equals that of the HEU fuel because of advances in fuel grading. Metal foils, as will be used with the LEU fuel, can achieve minimum thicknesses that are smaller than that achievable with $\mathrm{U}_{3} \mathrm{O}_{8} / \mathrm{Al}$ compacts present in the $\mathrm{HEU}$ fuel. Furthermore, axial grading significantly 
$\square$ 0-0.2 $\square 0.2-0.4 \square 0.4-0.6 \square 0.6-0.8 \square 0.8-1$

Span along plate (in, $0=$ inside edge)

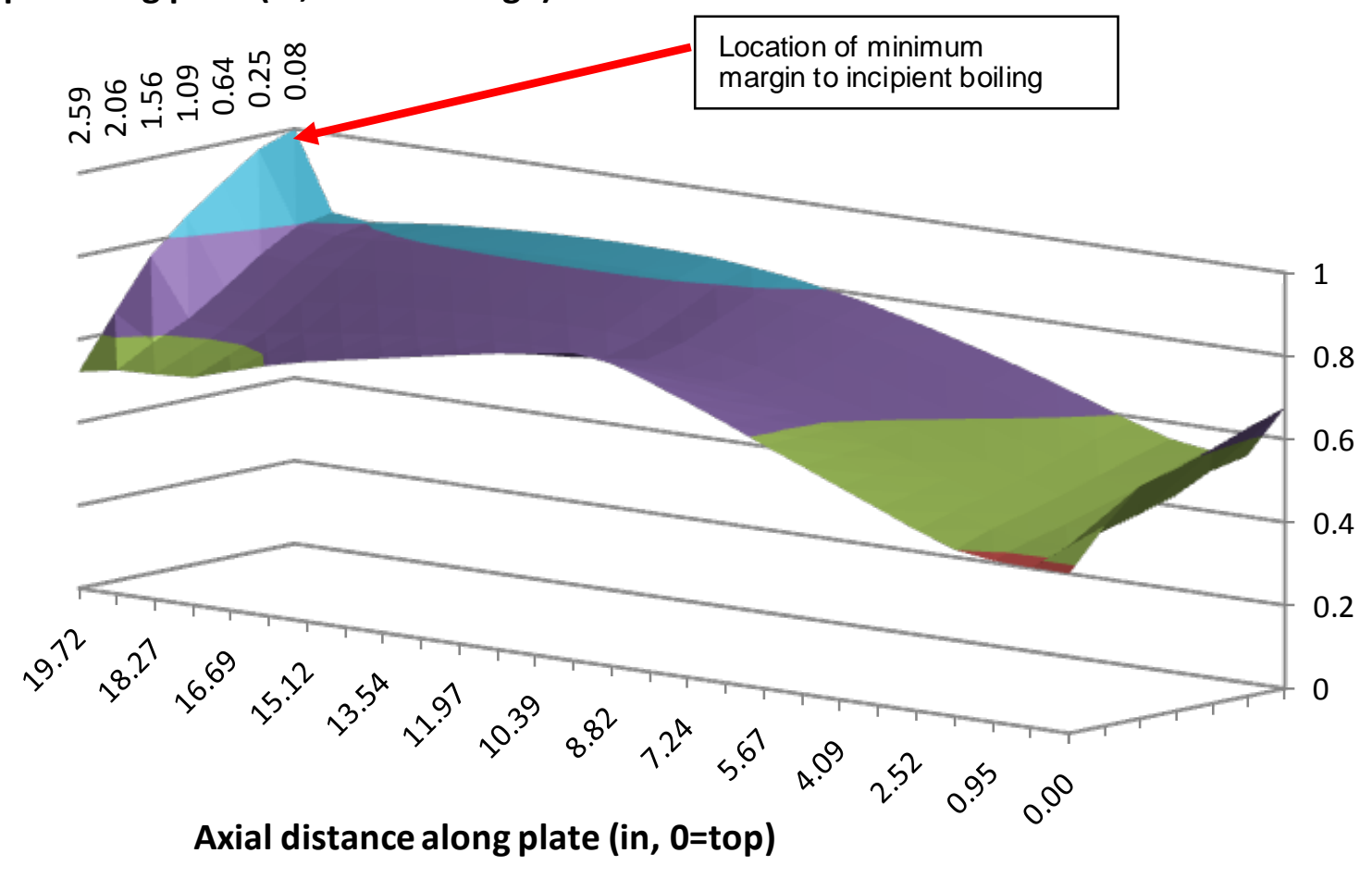

Fig. 17. Surface-to-incipient boiling temperature ratio for HEU fuel, outer element fuel plate, SAR safety basis case. 


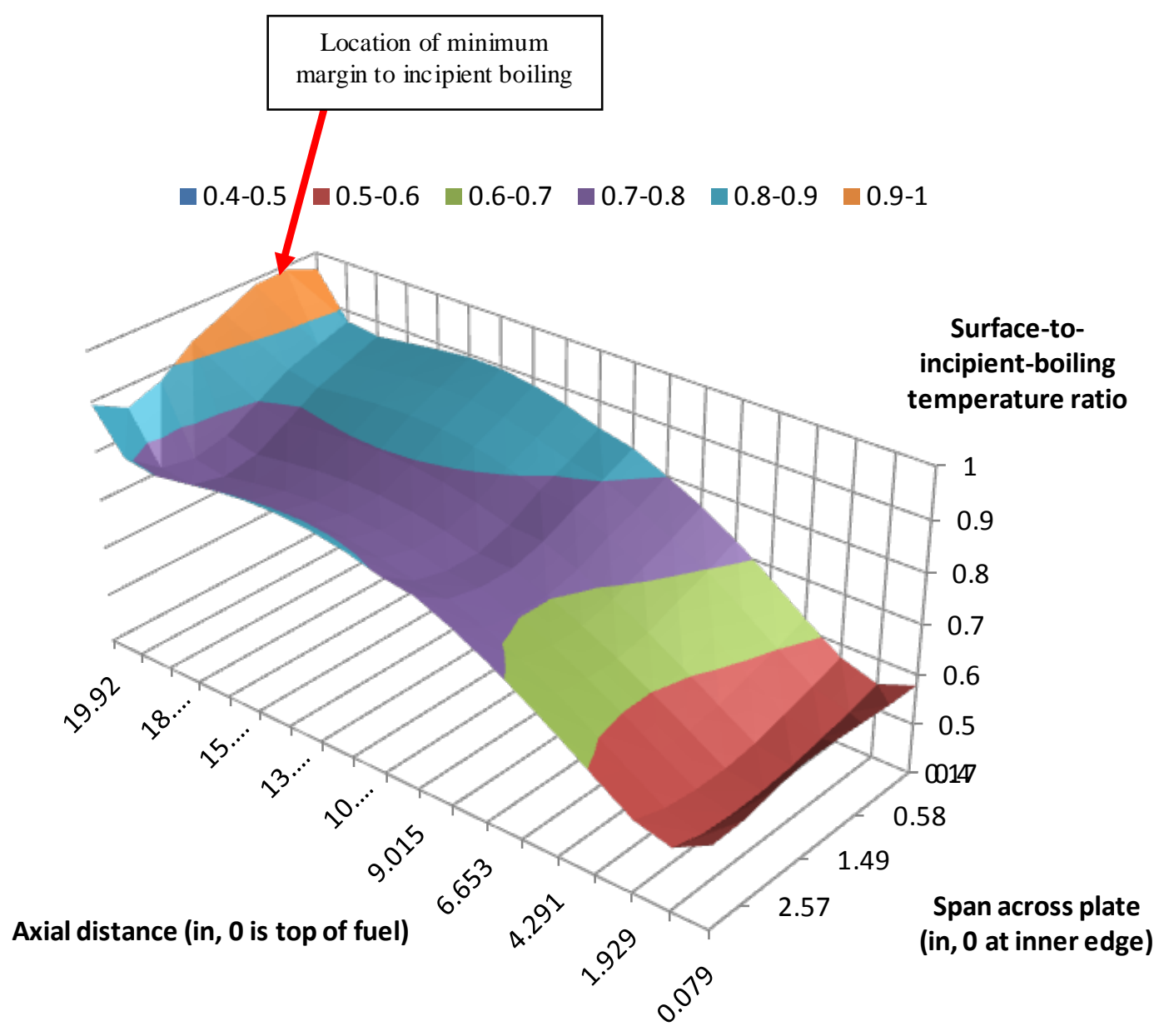

Fig. 18. Surface-to-incipient boiling temperature ratio for HEU fuel, inner element (current MCNP-based methodology, cycle 400). 
reduces the "spike" in power density that occurs at the base of the LEU fuel relative to the value that occurs in the HEU fuel. The HEU fuel design yields this spike for two reasons-reflection of neutrons from the water below the core and misalignment of the bottom edge of the fuel zones in adjacent fuel plates due to manufacturing variances. Both of these factors combine to yield a minimum incipientboiling-temperature-to-surface-temperature ratio that occurs at the base of the HEU fuel (see Figs. 17 and 18).

With axial grading, reflection of neutrons to the core is compensated by reduction in the local fuel thickness (as is done radially for both the HEU and LEU fuels). Manufacturing variability (misalignment of adjacent fuel plates) of the same order as HEU can also be compensated in LEU by the proper degree of axial grading. Even though the LEU fuel design operates at a higher power density than the HEU design, the two fuel designs have the same maximum surface-to-incipient-boiling temperature ratios (each 1.0) because these maxima occur at different locations in the HEU and the LEU cores.

\subsection{SAFETY AND SAFEGUARDS PARAMETERS FOR THE HFIR LEU CORE}

\subsubsection{Decay Heat in Used Fuel Elements}

A procedure was developed to extract the depleted fuel composition data from the VESTA output and feed it into the ORIGEN-ARP sequence in SCALE for source term characterization. The total mass of used fuel from the core (as a sum of the IFE and OFE compositions) was considered as one source. The calculated decay heat for the used LEU fuel corresponding to values of the cooling time from reactor shutdown to 100 years cooling time is presented in Table 16 . In addition to the total decay heat value, the component of the decay heat due to the actinides present in the used fuel is shown. A comparison of the total decay heat from LEU and HEU used fuel as a function of the decay time is illustrated in Fig. 19.

The total decay heat for LEU fuel is slightly larger than the corresponding value for the HEU fuel, as expected, given the larger production of transuranic nuclides in the LEU than in the HEU fuel. At 10 years cooling time, the total decay heat decreases by almost four orders of magnitude, becoming less than $80 \mathrm{~W}$, and becomes less than $11 \mathrm{~W}$ after 100 years of decay. The top 20 nuclides contributing to the decay heat at the normal discharge time (1 day decay time) and the corresponding decay heat for the HEU and LEU core are shown in Table 17.

Table 16. Decay heat for used fuel-comparison of HEU cycle 400 and LEU cores

\begin{tabular}{lccccc}
\hline \multirow{2}{*}{$\begin{array}{c}\text { Decay } \\
\text { time }\end{array}$} & \multicolumn{2}{c}{$\begin{array}{c}\text { Total decay heat } \\
\text { (W) }\end{array}$} & & \multicolumn{2}{c}{$\begin{array}{c}\text { Actinides decay heat } \\
\text { (W) }\end{array}$} \\
\cline { 2 - 3 } \cline { 5 - 6 } & LEU & HEU & & LEU & HEU \\
\hline $0 \mathrm{~s}$ & $9.58 \times 10^{6}$ & $8.02 \times 10^{6}$ & & $9.83 \times 10^{4}$ & $4.70 \times 10^{3}$ \\
$10 \mathrm{~s}$ & $5.10 \times 10^{6}$ & $4.27 \times 10^{6}$ & & $9.80 \times 10^{4}$ & $4.69 \times 10^{3}$ \\
$10^{2} \mathrm{~s}$ & $2.82 \times 10^{6}$ & $2.33 \times 10^{6}$ & & $9.58 \times 10^{4}$ & $4.61 \times 10^{3}$ \\
$10^{3} \mathrm{~s}$ & $1.68 \times 10^{6}$ & $1.37 \times 10^{6}$ & & $7.82 \times 10^{4}$ & $3.97 \times 10^{3}$ \\
$10^{4} \mathrm{~s}$ & $7.61 \times 10^{5}$ & $6.14 \times 10^{5}$ & & $4.55 \times 10^{4}$ & $2.77 \times 10^{3}$ \\
$1 \mathrm{day}$ & $3.25 \times 10^{5}$ & $2.48 \times 10^{5}$ & & $3.48 \times 10^{4}$ & $2.25 \times 10^{3}$ \\
$1 \mathrm{yr}$ & $1.59 \times 10^{3}$ & $1.37 \times 10^{3}$ & & $1.61 \times 10^{0}$ & $3.44 \times 10^{-1}$ \\
$3 \mathrm{yr}$ & $2.83 \times 10^{2}$ & $2.42 \times 10^{2}$ & $1.68 \times 10^{0}$ & $3.45 \times 10^{-1}$ \\
$10 \mathrm{yr}$ & $7.82 \times 10^{1}$ & $6.72 \times 10^{1}$ & & $1.92 \times 10^{0}$ & $3.50 \times 10^{-1}$ \\
$30 \mathrm{yr}$ & $4.79 \times 10^{1}$ & $4.03 \times 10^{1}$ & & $2.26 \times 10^{0}$ & $3.41 \times 10^{-1}$ \\
$50 \mathrm{yr}$ & $3.07 \times 10^{1}$ & $2.51 \times 10^{1}$ & & $2.35 \times 10^{0}$ & $3.18 \times 10^{-1}$ \\
$100 \mathrm{yr}$ & $1.10 \times 10^{1}$ & $7.85 \times 10^{0}$ & $2.29 \times 10^{0}$ & $2.57 \times 10^{-1}$ \\
\hline
\end{tabular}




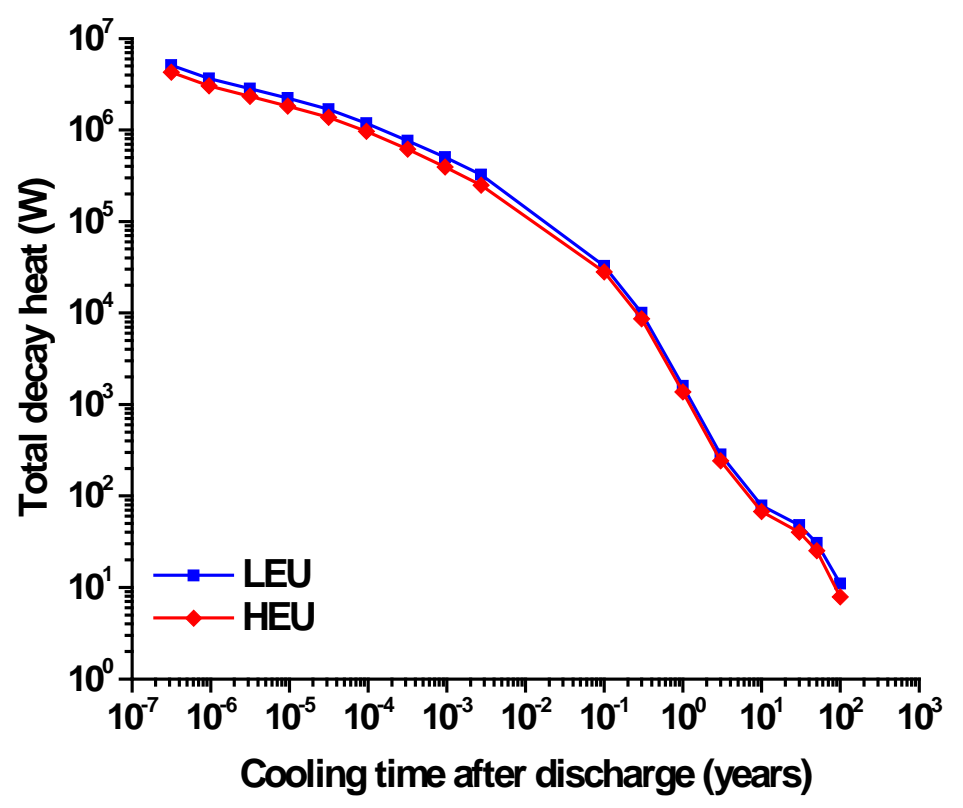

Fig. 19. Decay heat for used fuel-comparison of HEU cycle 400 and LEU cores.

Table 17. Major contributors to total decay heat at 1 daycomparison of HEU cycle 400 and LEU cores

\begin{tabular}{ccccccc}
\hline & \multicolumn{2}{c}{ HEU } & & \multicolumn{2}{c}{ LEU } \\
\cline { 2 - 3 } \cline { 6 - 7 }$\#$ & Nuclide ID & $\begin{array}{c}\text { Decay heat } \\
\text { (W) }\end{array}$ & & Nuclide ID & $\begin{array}{c}\text { Decay heat } \\
\text { (W) }\end{array}$ \\
\hline 1 & & ${ }^{140} \mathrm{La}$ & $5.35 \mathrm{E}+04$ & & ${ }^{140} \mathrm{La}$ & $6.18 \mathrm{E}+04$ \\
2 & ${ }^{132} \mathrm{I}$ & $4.16 \mathrm{E}+04$ & & ${ }^{132} \mathrm{I}$ & $4.95 \mathrm{E}+04$ \\
3 & ${ }^{97} \mathrm{Zr}$ & $1.62 \mathrm{E}+04$ & & ${ }^{97} \mathrm{Zr}$ & $1.90 \mathrm{E}+04$ \\
4 & ${ }^{133} \mathrm{I}$ & $1.30 \mathrm{E}+04$ & & ${ }^{133} \mathrm{I}$ & $1.53 \mathrm{E}+04$ \\
5 & ${ }^{97} \mathrm{Nb}$ & $1.12 \mathrm{E}+04$ & & ${ }^{97} \mathrm{Nb}$ & $1.31 \mathrm{E}+04$ \\
6 & ${ }^{143} \mathrm{Ce}$ & $1.05 \mathrm{E}+04$ & & ${ }^{99} \mathrm{Mo}$ & $1.28 \mathrm{E}+04$ \\
7 & ${ }^{99} \mathrm{Mo}$ & $1.03 \mathrm{E}+04$ & & ${ }^{143} \mathrm{Ce}$ & $1.22 \mathrm{E}+04$ \\
8 & ${ }^{140} \mathrm{Ba}$ & $9.14 \mathrm{E}+03$ & & ${ }^{140} \mathrm{Ba}$ & $1.06 \mathrm{E}+04$ \\
9 & ${ }^{93} \mathrm{Y}$ & $6.64 \mathrm{E}+03$ & & ${ }^{93} \mathrm{Y}$ & $7.62 \mathrm{E}+03$ \\
10 & ${ }^{91} \mathrm{Sr}$ & $5.76 \mathrm{E}+03$ & & ${ }^{131} \mathrm{I}$ & $6.88 \mathrm{E}+03$ \\
11 & ${ }^{131} \mathrm{I}$ & $5.71 \mathrm{E}+03$ & & ${ }^{91} \mathrm{Sr}$ & $6.54 \mathrm{E}+03$ \\
12 & ${ }^{95} \mathrm{Zr}$ & $5.57 \mathrm{E}+03$ & & ${ }^{95} \mathrm{Zr}$ & $6.42 \mathrm{E}+03$ \\
13 & ${ }^{143} \mathrm{Pr}$ & $5.37 \mathrm{E}+03$ & & ${ }^{143} \mathrm{Pr}$ & $6.28 \mathrm{E}+03$ \\
14 & ${ }^{132} \mathrm{Te}$ & $4.91 \mathrm{E}+03$ & & ${ }^{132} \mathrm{Te}$ & $5.84 \mathrm{E}+03$ \\
15 & ${ }^{133} \mathrm{Xe}$ & $4.62 \mathrm{E}+03$ & & ${ }^{133} \mathrm{Xe}$ & $5.54 \mathrm{E}+03$ \\
16 & ${ }^{135} \mathrm{I}$ & $4.05 \mathrm{E}+03$ & & ${ }^{135} \mathrm{I}$ & $4.76 \mathrm{E}+03$ \\
17 & ${ }^{91} \mathrm{Y}$ & $3.97 \mathrm{E}+03$ & & ${ }^{91} \mathrm{Y}$ & $4.52 \mathrm{E}+03$ \\
18 & ${ }^{89} \mathrm{Sr}$ & $3.47 \mathrm{E}+03$ & & ${ }^{135} \mathrm{Xe}$ & $4.02 \mathrm{E}+03$ \\
19 & ${ }^{135} \mathrm{Xe}$ & $3.20 \mathrm{E}+03$ & & ${ }^{89} \mathrm{Sr}$ & $3.94 \mathrm{E}+03$ \\
& ${ }^{103} \mathrm{Ru}$ & $2.88 \mathrm{E}+03$ & & ${ }^{103} \mathrm{Ru}$ & $3.50 \mathrm{E}+03$ \\
\hline
\end{tabular}




\subsubsection{Isotopic Compositions in Used Fuel Elements}

The isotopic compositions of the used fuel, the plutonium inventory in particular, need to be assessed for the LEU fuel, because they are important to safeguards, reactor safety, and waste management. A comparison of the HEU and LEU cores with respect to the total mass of the main actinides uranium and plutonium at EOC in the core, as well as in each of the two fuel elements, is presented in Table 18. As expected, the production of plutonium increases, given the large fraction of ${ }^{238} \mathrm{U}$ present in the LEU fuel. The total amount of plutonium at EOC is about $15 \mathrm{~g}$ for the HEU core and $464 \mathrm{~g}$ for the LEU core.

Table 18. Major actini des inventory (in grams) for HEU and LEU cores at EOC

\begin{tabular}{|c|c|c|c|c|c|c|}
\hline \multirow{2}{*}{ Nuclide } & \multicolumn{3}{|c|}{ HEU cycle 400} & \multicolumn{3}{|c|}{ LEU } \\
\hline & Core & IFE & OFE & Core & IFE & OFE \\
\hline U-234 & 87.55 & 23.29 & 64.26 & 231.68 & 57.22 & 174.46 \\
\hline U-235 & 6596.08 & 1564.79 & 5031.29 & 22048.07 & 5263.72 & 16784.35 \\
\hline U-236 & 534.53 & 185.87 & 348.65 & 786.85 & 253.15 & 533.70 \\
\hline U-238 & 530.49 & 145.60 & 384.90 & 101637.18 & 25642.59 & 75994.59 \\
\hline Pu-238 & 0.34 & 0.15 & 0.19 & 0.37 & 0.15 & 0.22 \\
\hline Pu-239 & 12.04 & 3.44 & 8.60 & 425.22 & 132.65 & 292.57 \\
\hline $\mathrm{Pu}-240$ & 1.60 & 0.58 & 1.02 & 28.48 & 11.37 & 17.11 \\
\hline $\mathrm{Pu}-241$ & 0.73 & 0.29 & 0.44 & 9.43 & 4.33 & 5.10 \\
\hline $\mathrm{Pu}-242$ & 0.07 & 0.04 & 0.03 & 0.37 & 0.22 & 0.15 \\
\hline
\end{tabular}

\subsubsection{Reactivity Coefficients}

Flux trap void

Fig. 20 shows the variation in $\mathrm{k}_{\mathrm{eff}}$ with the reduction of water density in flux trap region. Points shown for experimental data were digitized from Figs. 4.3.6 and 4.3.7 in the HFIR SAR. ${ }^{20}$

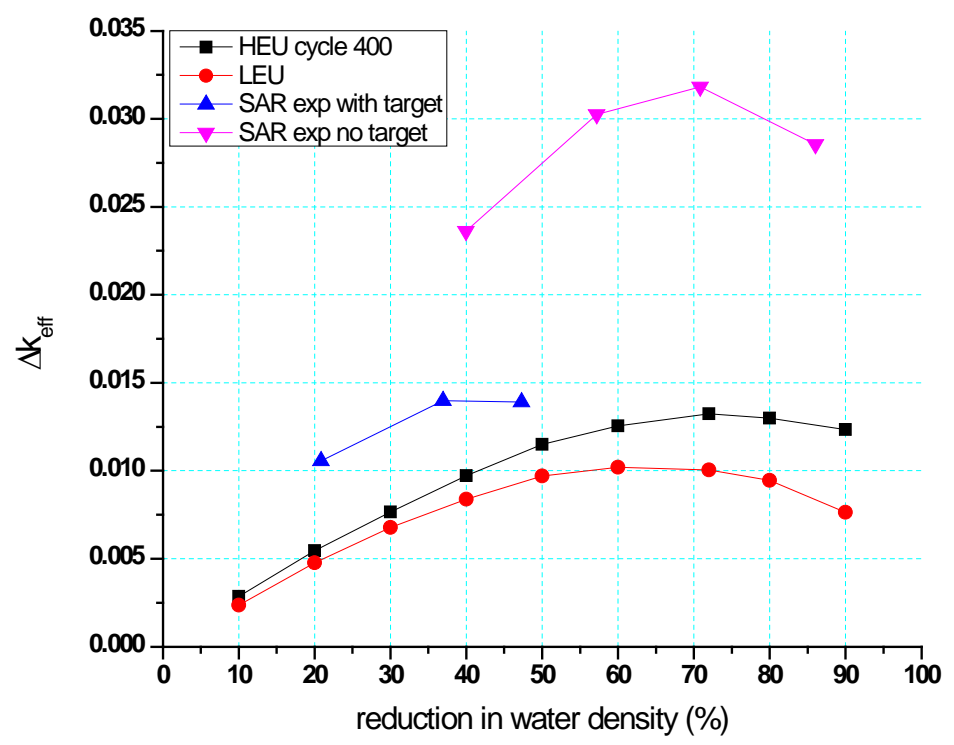

Fig. 20. Variation of $k_{\text {eff }}$ in with reduction of water density in flux trap region. 
Both the HEU cycle 400 and LEU data are less than the $1.5 \% \Delta \mathrm{k} / \mathrm{k}$ value that was adopted in SAR as a design basis reactivity event for protection system design and evaluation. Note that at the time the SAR measurements and calculations were prepared, the assumed target loading differed from the design present in the computational models for cycle 400 and LEU. As observed from Fig. 20, the LEU values on the y-axis are always smaller than the corresponding data for the HEU core. The HEU and LEU data were calculated for the BOC state.

\section{Coolant void}

The coolant void reactivity coefficient (CVR) for the coolant in the fuel region was calculated for the BOC and EOC conditions using the MCNP models for these two state points. Two CVR values were calculated for the fuel region for each state point, for consistency with the reporting in the HFIR SAR, ${ }^{20}$ one for each of the two fuel elements (IFE and OFE). Two values were used for the coolant density: the nominal (reference) value and a perturbed value at $90 \%$ of the nominal density. A large number of neutron histories were used in the MCNP calculations for improved convergence and to reduce the standard deviation in the value for $k_{\text {eff. }}$ As the $k_{\text {eff }}$ variation due to the change in the coolant density is small, it is desired to obtain a standard deviation in $\mathrm{k}_{\text {eff }}$ sufficiently small compared to the value of this variation. The CVR value was calculated as

$$
C V R=\frac{\Delta k_{e f f} / k_{e f f}}{\Delta V_{c} / V_{c}}
$$

where $V_{c}$ is the volume of the coolant in the region of interest, and $\Delta$ signifies the variation in the value for eigenvalue or volume. The CVR results for the LEU core are shown in Table 19, along with the corresponding values calculated for the HEU cycle 400 core.

Table 19. Coolant void reactivity coefficients (in $(\Delta \mathbf{k} / \mathbf{k}) / \Delta \mathbf{V})$

\begin{tabular}{ccccccc}
\hline \multirow{2}{*}{$\begin{array}{c}\text { Core } \\
\text { state }\end{array}$} & \multirow{2}{*}{ Region } & \multicolumn{2}{c}{ LEU } & \multicolumn{2}{c}{ HEU cycle 400 } \\
\cline { 3 - 4 } \cline { 6 - 7 } & & CVR & $\sigma_{\text {CVR }}$ & & CVR & $\sigma_{\text {CVR }}$ \\
\hline BOC & IFE & -0.082 & 0.001 & & -0.102 & 0.001 \\
& OFE & -0.153 & 0.001 & & -0.218 & 0.001 \\
EOC & IFE & -0.064 & 0.001 & & -0.069 & 0.001 \\
& OFE & -0.108 & 0.001 & -0.146 & 0.001 \\
\hline
\end{tabular}

\section{Temperature coefficients}

Two temperatures were considered for the calculation of temperature coefficients of reactivity: $300 \mathrm{~K}$ (reference) and 600K. Three perturbed cases were studied at both BOC and EOC states: (1) the cross sections for all materials in fuel regions were modified to correspond to 600K; (2) the cross sections for all materials in the flux trap region were modified to correspond to 600K; and (3) the cross sections for all materials in the MCNP model were modified to correspond to $600 \mathrm{~K}$. No changes were made to material number densities. Temperature coefficients (TC) were calculated for all three perturbed states considered as

$$
T C=\frac{k_{p}-k_{r}}{k_{p} k_{0}\left(T_{p}-T_{r}\right)}
$$

where indices $p$ and $r$ correspond to perturbed state and reference state, respectively; $k$ is the core effective multiplication constant; and $T$ is the temperature. 
The calculated temperature coefficients (in units $\Delta \mathrm{k} / \mathrm{k} / \mathrm{K}$ ) are shown in Table 20. The calculated values for HFIR HEU cycle 400 in cases (1) and (2) at BOC and EOC are in the range of data from Fig. 4.3.5 of the HFIR Safety Analysis Report. ${ }^{20}$ It is noted in Ref. 20 that "The isothermal coefficient measured in the actual HFIR facility (with the target installed) was slightly positive over the temperature range of 80 to $120^{\circ} \mathrm{F}$." In all cases the absolute values of the LEU temperature coefficients are equal to or less than the HEU values.

Table 20. Temperature coefficients of reactivity (in $\Delta \mathbf{k} / \mathbf{k} / \mathbf{K}$ )

\begin{tabular}{|c|c|c|c|c|c|}
\hline \multirow{2}{*}{$\begin{array}{c}\text { Case } \\
\#\end{array}$} & \multirow{2}{*}{ Region } & \multicolumn{2}{|c|}{ HEU cycle 400} & \multicolumn{2}{|c|}{ LEU } \\
\hline & & BOC & EOC & BOC & EOC \\
\hline 1 & Fuel region & $-6.2 \times 10^{-5}$ & $-8.9 \times 10^{-5}$ & $-5.2 \times 10^{-5}$ & $-5.3 \times 10^{-5}$ \\
\hline 2 & Flux trap region & $5.7 \times 10^{-5}$ & $4.7 \times 10^{-5}$ & $3.4 \times 10^{-5}$ & $3.6 \times 10^{-5}$ \\
\hline 3 & All regions in the model & $3.0 \times 10^{-5}$ & $7.1 \times 10^{-5}$ & $2.4 \times 10^{-5}$ & $5.9 \times 10^{-5}$ \\
\hline
\end{tabular}

\subsubsection{Effective Delayed Neutron Fraction}

The effective delayed neutron fractions for the HFIR HEU and LEU cores were calculated using the MCNP core models with ENDF/B-VII cross-section data. The method used for the calculation is discussed in Appendix F of this report. The calculated values for both BOC and EOC states are presented in Table 21. The value currently accepted in the safety basis for HFIR (Ref. 20) is 0.0076 for both BOC and EOC states. As observed, the newly calculated values at BOC and EOC for HFIR HEU are within two standard deviations from the current safety basis value.

Table 21. Effective delayed neutron fraction

\begin{tabular}{ccccc}
\hline \multicolumn{2}{c}{ HEU cycle 400 } & & \multicolumn{2}{c}{ LEU } \\
\cline { 1 - 2 } \cline { 5 - 6 } BOC & EOC & BOC & EOC \\
\hline $0.00736 \pm 0.00011$ & $0.00740 \pm 0.00011$ & & $0.00756 \pm 0.00008$ & $0.00707 \pm 0.00010$ \\
\hline
\end{tabular}

\subsubsection{Total Gamma Source}

For HEU fuel, deterrence from diversion is achieved from the high dose rate from spent fuel. Thus recent dose rate studies for HFIR HEU, reported in Ref. 25, focused on expected dose rates for times approaching or exceeding the expected lifetime of the HFIR facility. For LEU, due to the relatively small plutonium content as compared to residual ${ }^{235} \mathrm{U}$, the security-related concerns are mitigated and engineering interest is focused on dose rates for times shortly following discharge from the reactor-that is, determination of hazards due to handling and shipment of irradiated fuel.

For both HEU and LEU, the depleted fuel composition data at EOC were extracted from the VESTA output files and used in a decay calculation with the ORIGEN-S code in SCALE 6.1. The calculated total gamma source calculated with ORIGEN-S for various decay times up to 100 years after discharge from the reactor is presented in Table 22. The gamma spectra from spent LEU fuel as a function of decay time are provided in Appendix G.

\subsubsection{Safeguards Category for LEU Fuel}

Nuclear materials are controlled and accounted for on the basis of the classification dividing such materials into categories according to their strategic or financial importance and their potential environmental threat (Ref. 26). Table 23 shows a five-level classification system of material "attractiveness" defined by the corresponding U.S. DOE directive (Ref. 27). According to Table 23, fresh 
LEU fuel would be attractiveness level E, category IV. To maintain parity with spent HEU fuel, spent LEU fuel elements should have attractiveness level D. Due to the high plutonium content in spent LEU fuel (see Table 18), discharged LEU HFIR elements still must be shown to have a high radiation field in order to be unattractive for diversion. Given that the dose rate from LEU elements is the same or greater than from HEU elements, spent LEU fuel elements would be attractiveness level D, category IV, which is the same as for spent HEU fuel assemblies. ${ }^{28}$

The strategic significance of nuclear material is distinguished from the attractiveness level. According to Tables 24 and 25 from Ref. 26, fresh LEU fuel would be classified as "material of moderate strategic significance." This classification is "less" than for the current HEU fuel elements which, if inner and outer elements are taken together, would be strategic special nuclear material. (If considered separately, the inner element would be moderate strategic significance and the outer element would be strategic special nuclear material.) Restrictions on the movement and storage of this classification are defined in 10 CFR Part 74.

Table 22. Total gamma source (photons/s) vs. cooling time

\begin{tabular}{|c|c|c|c|c|c|c|}
\hline \multirow{2}{*}{$\begin{array}{c}\text { Decay } \\
\text { time }\end{array}$} & \multicolumn{3}{|c|}{ LEU } & \multicolumn{3}{|c|}{ HEU cycle 400} \\
\hline & IFE & OFE & IFE + OFE & IFE & OFE & IFE + OFE \\
\hline $1 \mathrm{~d}$ & $1.134 \times 10^{18}$ & $2.146 \times 10^{18}$ & $3.280 \times 10^{18}$ & $7.884 \times 10^{17}$ & $1.415 \times 10^{18}$ & $2.204 \times 10^{18}$ \\
\hline $1 \mathrm{yr}$ & $3.488 \times 10^{15}$ & $6.371 \times 10^{15}$ & $9.859 \times 10^{15}$ & $3.144 \times 10^{15}$ & $5.337 \times 10^{15}$ & $8.481 \times 10^{15}$ \\
\hline $10 \mathrm{yr}$ & $1.535 \times 10^{14}$ & $2.801 \times 10^{14}$ & $4.336 \times 10^{14}$ & $1.409 \times 10^{14}$ & $2.382 \times 10^{14}$ & $3.791 \times 10^{14}$ \\
\hline $30 \mathrm{yr}$ & $9.151 \times 10^{13}$ & $1.676 \times 10^{14}$ & $2.591 \times 10^{14}$ & $8.352 \times 10^{13}$ & $1.421 \times 10^{14}$ & $2.256 \times 10^{14}$ \\
\hline $50 \mathrm{yr}$ & $5.712 \times 10^{13}$ & $1.046 \times 10^{14}$ & $1.617 \times 10^{14}$ & $5.199 \times 10^{13}$ & $8.848 \times 10^{13}$ & $1.405 \times 10^{14}$ \\
\hline $100 \mathrm{yr}$ & $1.781 \times 10^{13}$ & $3.252 \times 10^{13}$ & $5.033 \times 10^{13}$ & $1.605 \times 10^{13}$ & $2.731 \times 10^{13}$ & $4.336 \times 10^{13}$ \\
\hline
\end{tabular}

Table 23. Attractiveness levels and safeguards categories

\begin{tabular}{|c|c|c|c|c|c|c|c|c|c|}
\hline \multirow{3}{*}{$\begin{array}{l}\text { Material } \\
\text { type }\end{array}$} & \multirow{3}{*}{$\begin{array}{l}\text { Level of } \\
\text { attractive- } \\
\text { ness }\end{array}$} & \multicolumn{8}{|c|}{$\begin{array}{l}\text { Safeguards category ( } \mathrm{I} \text { = max. concern) as a function of the amount } \\
\text { of material contained (kg) }\end{array}$} \\
\hline & & \multicolumn{4}{|c|}{ Plutonium or Uranium-233 } & \multicolumn{4}{|c|}{ Uranium-235 } \\
\hline & & $\mathbf{I}$ & II & III & IV & I & II & III & IV \\
\hline Weapon $^{a}$ & $\mathrm{~A}$ & \multicolumn{4}{|c|}{ Any amount—category I } & \multicolumn{4}{|c|}{ Any amount—category I } \\
\hline $\begin{array}{l}\text { Pure } \\
\text { product }^{b}\end{array}$ & B & $>2$ & $0.4-2$ & $0.2-0.4$ & $<0.2$ & $>5$ & $1-5$ & $0.4-1$ & $<0.4$ \\
\hline $\begin{array}{l}\text { High-grade } \\
\text { material }^{c}\end{array}$ & $\mathrm{C}$ & $>6$ & $2-6$ & $0.4-2$ & $<0.4$ & $>20$ & $6-20$ & $2-6$ & $<2$ \\
\hline $\begin{array}{l}\text { Low-grade } \\
\text { material }^{d}\end{array}$ & $\mathrm{D}$ & - & $>16$ & $3-16$ & $<3$ & - & $>50$ & $8-50$ & $<8$ \\
\hline All other ${ }^{e}$ & E & \multicolumn{4}{|c|}{ Any reportable quantities ${ }^{f}$ - category IV } & \multicolumn{4}{|c|}{ Any reportable quantities — category IV } \\
\hline 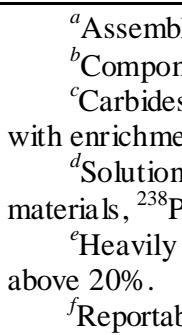 & $\begin{array}{l}\text { led weapon or to } \\
\text { lents, disks, ing } \\
\text {, oxides, soluti } \\
\text { nt greater than } \\
\text { s with concentr } \\
\text { u (except waste } \\
\text { irradiated form }\end{array}$ & $\begin{array}{l}\text { st devic } \\
\text { ts, re-m } \\
\text { ons with } \\
50 \% \text {. } \\
\text { ation fro } \\
\text { s), UF } \\
\text {, solutio }\end{array}$ & $\begin{array}{l}\text { metal, d } \\
\text { ntration } \\
25 \mathrm{~g} / \mathrm{L} \\
\mathrm{F}_{6} \text { with } \\
\text { h conce }\end{array}$ & $\begin{array}{l}\text { tly conver } \\
\text { ater than } \\
\text { cess resic } \\
\text { chment fr } \\
\text { tion belor }\end{array}$ & $\begin{array}{l}\text { e mater } \\
\mathrm{g} / \mathrm{L} \text {, nitr } \\
\\
\text { sequiri } \\
20 \text { to } 50 \\
\mathrm{~g} / \mathrm{L} \text {, ura }\end{array}$ & $\begin{array}{l}\text { etc., fu } \\
\text { extensiv } \\
m \text { in an }\end{array}$ & $\begin{array}{l}\text { s and as } \\
\text { ocessing } \\
\text { n and an }\end{array}$ & $\begin{array}{l}\text { blies, U } \\
\text { oderate } \\
\text { nt with e }\end{array}$ & $\begin{array}{l}\mathrm{d} \mathrm{UF}_{6} \\
\text { idiated } \\
\text { ment }\end{array}$ \\
\hline
\end{tabular}


Table 24. Strategic significance of special nuclear material [Ref. 26, part 74.4]

\begin{tabular}{|c|c|c|c|c|c|}
\hline \multirow{4}{*}{$\begin{array}{l}\text { Material } \\
\text { significance }\end{array}$} & \multicolumn{5}{|c|}{ Amount of material (g) } \\
\hline & \multirow{3}{*}{ Plutonium } & \multirow{3}{*}{ Uranium-233 } & \multirow{2}{*}{\multicolumn{3}{|c|}{$\begin{array}{c}\text { Uranium-235 } \\
\text { Enrichment (A), \% }\end{array}$}} \\
\hline & & & & & \\
\hline & & & $0.7<\mathrm{A}<\mathbf{1 0}$ & $10<\mathrm{A}<20$ & $A>20$ \\
\hline \multirow{4}{*}{$\begin{array}{l}\text { Material of low } \\
\text { strategic significance }\end{array}$} & $>15$ & - & - & - & - \\
\hline & - & 15 & - & - & - \\
\hline & - & - & - & - & $<15$ \\
\hline & \multicolumn{5}{|c|}{$\left.\left[m_{1}(\mathrm{Pu})+\mathrm{m}_{2}\left({ }^{235} \mathrm{U}\right)+\mathrm{m}_{3}{ }^{235} \mathrm{U}\right)\right]>15$} \\
\hline \multirow{3}{*}{$\begin{array}{l}\text { Material of moderate } \\
\text { strategic significance }\end{array}$} & $>500$ & - & - & - & - \\
\hline & - & 500 & - & - & $>500$ \\
\hline & \multicolumn{5}{|c|}{$\left[\mathrm{m}_{1}(\mathrm{Pu})+\mathrm{m}_{2}\left({ }^{235} \mathrm{U}\right)+\mathrm{m}_{3}\left({ }^{235} \mathrm{U}\right)\right]>500$} \\
\hline $\begin{array}{l}\text { Strategic special } \\
\text { nuclear material }\end{array}$ & \multicolumn{5}{|c|}{$\begin{array}{l}\text { Nuclear materials in any combination totaling } 5000 \mathrm{~g} \text { or more, defined as } \\
2.5\left[\mathrm{~m}_{1}(\mathrm{Pu})+\mathrm{m}_{2}\left({ }^{235} \mathrm{U}\right)\right]+\mathrm{m}_{3}\left({ }^{235} \mathrm{U}\right) \geq 5000 \text {. }\end{array}$} \\
\hline
\end{tabular}

Table 25. U.S. version, strategic significance of special nuclear material [Ref. 26, part 74.4]

\begin{tabular}{|c|c|c|c|c|c|}
\hline \multirow{4}{*}{$\begin{array}{l}\text { Material } \\
\text { significance }\end{array}$} & \multicolumn{5}{|c|}{ Amount of material (g) } \\
\hline & \multirow{3}{*}{ Plutonium } & \multirow{3}{*}{ Uranium-233 } & \multicolumn{3}{|c|}{ Uranium-235 } \\
\hline & & & \multicolumn{3}{|c|}{ Enrichment (A), \% } \\
\hline & & & $0.7<\mathrm{A}<\mathbf{1 0}$ & $10<\mathrm{A}<20$ & $A \geq 20$ \\
\hline \multirow{2}{*}{$\begin{array}{l}\text { Material of low } \\
\text { strategic significance }\end{array}$} & $>15$ & $>15$ & $\geq 10,000$ & $1,000<\mathrm{x}<10,000$ & $>15$ \\
\hline & \multicolumn{5}{|c|}{ For mixtures: $\left[m_{1}(\mathrm{Pu})+\mathrm{m}_{2}\left({ }^{235} \mathrm{U}\right)+\mathrm{m}_{3}\left({ }^{235} \mathrm{U}\right)\right]>15$} \\
\hline \multirow{2}{*}{$\begin{array}{l}\text { Material of moderate } \\
\text { strategic significance }\end{array}$} & $>500$ & $>500$ & - & $\geq 10,000$ & $1000<x<5000$ \\
\hline & \multicolumn{5}{|c|}{ For mixtures: $2\left[\mathrm{~m}_{1}(\mathrm{Pu})+\mathrm{m}_{2}\left({ }^{235} \mathrm{U}\right)\right]+\mathrm{m}_{3}\left({ }^{235} \mathrm{U}\right) \geq 1000$} \\
\hline $\begin{array}{l}\text { Strategic special } \\
\text { nuclear material }\end{array}$ & \multicolumn{5}{|c|}{$\begin{array}{l}\text { Nuclear materials in any combination totaling } 5000 \mathrm{~g} \text { or more, defined as } 2.5\left[\mathrm{~m}_{1}(\mathrm{Pu})+\right. \\
\left.\left.\left.\mathrm{m}_{2}{ }^{235} \mathrm{U}\right)\right]+\mathrm{m}_{3}{ }^{235} \mathrm{U}\right) \geq 5000 \text { where } \mathrm{A} \geq 20 \text {. }\end{array}$} \\
\hline
\end{tabular}

\subsection{SUMMARY OF PERFORMANCE AND SAFETY PARAMETERS}

A summary of the performance and safety parameters for the HFIR LEU core calculated from the neutronics and thermal hydraulics analyses is presented in Table 26. This table is formatted for consistency with the data included in the current HFIR Safety Analysis Report (SAR). ${ }^{20}$ Two sets of values are shown in the table for the parameters considered: (1) values for the HFIR HEU core as listed in the current HFIR SAR and (2) values calculated for the HFIR LEU core. Table 26 facilitates a comparison between the HEU and the LEU cores and shows the values and locations of the physics and thermal hydraulics parameters that will need to be changed when the SAR is updated for LEU fuel. 
Table 26. Summary of performance and safety parameters

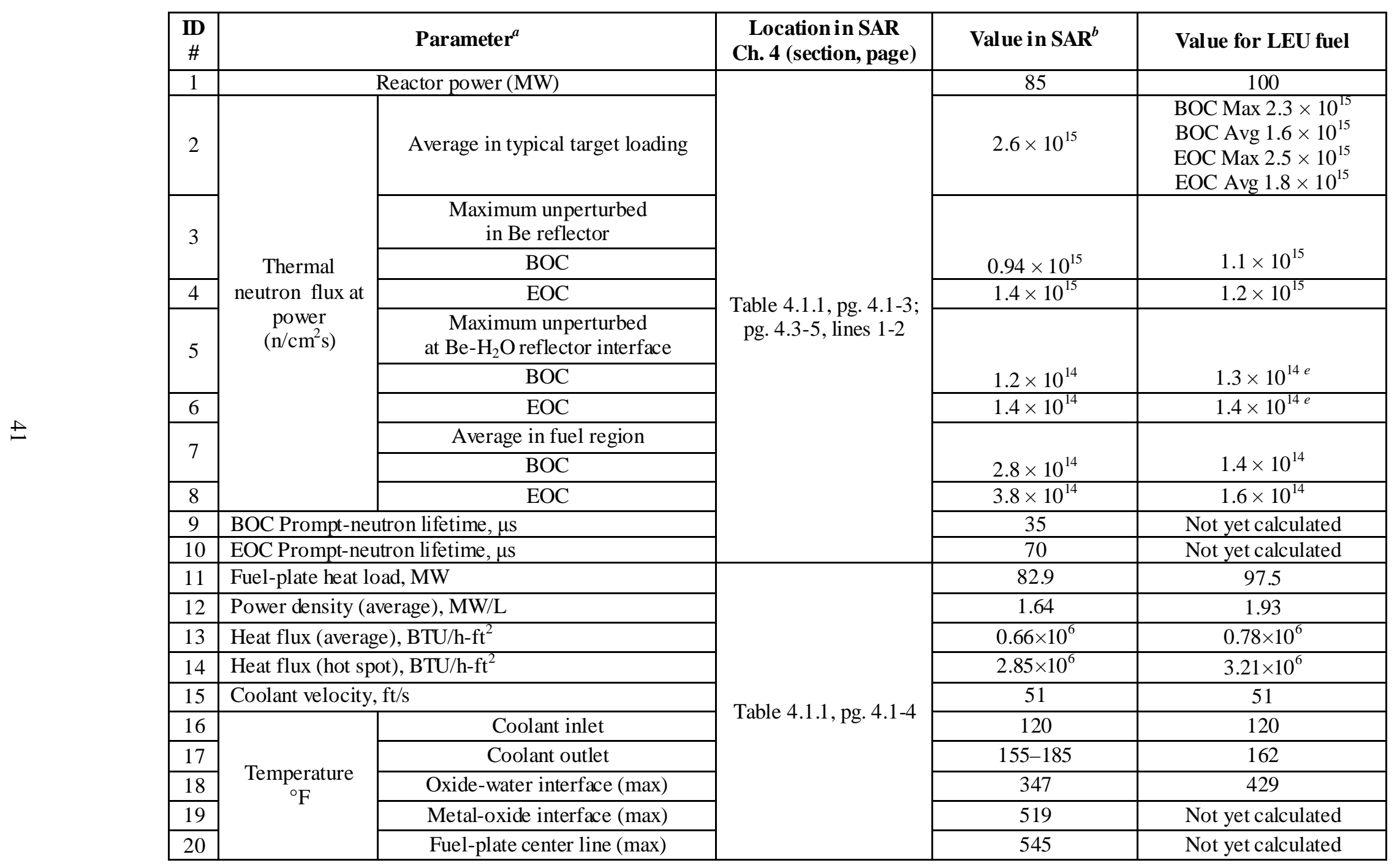


Table 26. (continued)

\begin{tabular}{|c|c|c|c|c|}
\hline ID & Parameter ${ }^{a}$ & $\begin{array}{c}\text { Location in SAR } \\
\text { Ch. } 4 \text { (section, page) }\end{array}$ & Value in $\mathrm{SAR}^{b}$ & Value for LEU fuel \\
\hline 21 & Critical velocity & pg. $4.2-4$, pg. $4.2-16$ & $\begin{array}{l}\text { Inner element - } \\
49.8 \mathrm{~m} / \mathrm{s} \text {; } \\
\text { Outer element - } 47.1 \\
\mathrm{~m} / \mathrm{s}\end{array}$ & unknown \\
\hline 22 & Thermally induced deflection & pg. 4.2-5, lines 39-41 & Single sine wave & unknown \\
\hline 23 & Creep behavior & pg. 4.2-6, lines 3-4 & "included in analyses" & unknown \\
\hline 24 & Modulus of elasticity & pg. 4.2-6, lines 17-18 & $\begin{array}{l}\text { " assumed to be the } \\
\text { same as aluminum" }\end{array}$ & unknown \\
\hline 25 & Gap reduction due to oxide formation and swelling, in. & pg. 4.2-6, line 21 & 0.0015 & 0.0015 \\
\hline 26 & $\begin{array}{l}\text { Maximum ("hot plate") metal temperature, EOC, } 100 \mathrm{MW} \text {, } \\
{ }^{\circ} \mathrm{F}\end{array}$ & pg. 4.2-7, line 8 & 480 & 430 \\
\hline 27 & Total fuel loading, kg of $\mathrm{U}^{235}$ & \multirow{7}{*}{$\begin{array}{l}\text { Table 4.2.1, pg. 4.2- } \\
\text { 15; } \\
\text { pg. 4.3-1, line } 41 \text {; } \\
\text { pg. 4.3-2, line 8; } \\
\text { pg. 4.3-13, lines 24- } \\
25\end{array}$} & 9.40 & 25.27 \\
\hline 28 & Inner element fuel loading, $\mathrm{kg}$ of $\mathrm{U}^{235}$ & & 2.60 & 6.39 \\
\hline 29 & Outer element fuel loading, kg of $\mathrm{U}^{235}$ & & 6.80 & 18.88 \\
\hline 30 & Burnable poison loading (inner element), grams of ${ }^{10} \mathrm{~B}$ & & 2.8 & 5.4 \\
\hline 31 & Average power density (82.9 MW in fuel region), MW/L & & 1.64 & 1.93 \\
\hline 32 & $\begin{array}{l}\text { Average heat flux (82.9 MW conducted to coolant), Btu h } \\
\mathrm{ft}^{-2}\end{array}$ & & $0.66 \times 10^{5}$ & $0.78 \times 10^{6}$ \\
\hline 33 & Hot spot, BOC, heat flux, Btu h $\mathrm{h}^{-1} \mathrm{ft}^{-2}$ & & $2.15 \times 10^{6}$ & $3.02 \times 10^{6}$ \\
\hline 34 & Operating cycle length, MWD & $\begin{array}{l}\text { pg. 4.3-1, line 26; } \\
\text { pg. 4.3-2, line 9; } \\
\text { pg. 4.3-5, lines } 8,11\end{array}$ & 2100 to 2400 & 2615 \\
\hline 35 & Design basis refueling shutdown margin, \$ & pg. 4.3-1, line 28 & 10.4 & $\sim \$ 9$ \\
\hline 36 & Minimum shutdown margin (3 plate scram) & pg. 4.3-1, line 39 & 3 & Not yet calculated \\
\hline 37 & Effective delayed neutron fraction & pg. 4.3-4, line 38 & 0.0076 & $\begin{array}{l}0.00756 \pm 0.00008 \\
\text { at BOC }\end{array}$ \\
\hline 38 & Measured power distributions & pg. 4.3-5, lines 30-43 & pg. 4.3-23 through -27 & NA \\
\hline 39 & Local fuel nonuniformity & pg. 4.3-6, lines 9-23 & $\begin{array}{l}27 \% \text { point, } 12 \% \\
\text { average }\end{array}$ & unknown \\
\hline 40 & Axial fuel plate misalignment power density factors & pg. 4.3-6, lines 14-23 & $\begin{array}{l}\text { various between } \\
1.20 \text { and } 1.44\end{array}$ & $\begin{array}{c}\text { Assumed same as HEU } \\
\text { fuel, various between } \\
1.20 \text { and } 1.44 \\
\end{array}$ \\
\hline
\end{tabular}


Table 26. (continued)

\begin{tabular}{|c|c|c|c|c|c|}
\hline$\underset{\#}{\text { ID }}$ & \multicolumn{2}{|c|}{ Parameter $^{a}$} & $\begin{array}{l}\text { Location in SAR } \\
\text { Ch. } 4 \text { (section, } \\
\text { page) }\end{array}$ & Value in SAR ${ }^{b}$ & Value for LEU fuel \\
\hline 41 & \multicolumn{2}{|c|}{ Nuclear power distribution uncertainties } & $\begin{array}{l}\text { pg. 4.3-6, lines 24- } \\
36\end{array}$ & $\begin{array}{c}1.10 \text { (power shape) } * \\
1.05 \text { (cent. Target expt. effects) OR } \\
1.10 * 1.09 \text { (ref. target effects) }\end{array}$ & 1.155 or 1.199 \\
\hline 42 & \multicolumn{2}{|c|}{ Isothermal core temperature coefficient $\left(\Delta \mathrm{k} / \mathrm{k}\right.$ per $\left.{ }^{\circ} \mathrm{F}\right)$} & $\begin{array}{c}\text { pg. 4.3-7, lines } 12- \\
13\end{array}$ & $\begin{array}{l}\text { "slightly positive over the } \\
\text { temperature range of } 80 \text { to } 120^{\circ} \mathrm{F} \text {, } \\
\text { with the maximum reactivity } \\
\text { addition being about } 10 \text { cents" }\end{array}$ & $\begin{array}{l}2.4 \times 10^{-5} \\
\text { at } \mathrm{BOC}\end{array}$ \\
\hline 43 & \multicolumn{2}{|c|}{$\begin{array}{l}\text { Isothermal fuel region water temperature coefficient } \\
\left(\Delta \mathrm{k} / \mathrm{k} \text { per }{ }^{\circ} \mathrm{F}\right)\end{array}$} & pg. 4.3-7, line 17 & $-1.15 \times 10^{-4}$ & $-5.2 \times 10^{-5}$ \\
\hline 44 & \multicolumn{2}{|c|}{$\begin{array}{l}\text { Isothermal target region water temperature } \\
\text { coefficient }\left(\Delta \mathrm{k} / \mathrm{k} \text { per }{ }^{\circ} \mathrm{F}\right)\end{array}$} & pg. 4.3-7, line 33 & $6 \times 10^{-5}$ & $3.4 \times 10^{-5}$ at $\mathrm{BOC}$ \\
\hline 45 & \multirow{2}{*}{$\begin{array}{l}\text { Void coefficient } \\
\text { BOC zero power }(\Delta \mathrm{k} / \mathrm{k})\end{array}$} & Inner & \multirow{4}{*}{ pg. 4.3-8, line 17} & -0.086 & -0.082 \\
\hline 46 & & Outer & & -0.196 & -0.153 \\
\hline 47 & \multirow{2}{*}{$\begin{array}{l}\text { Void coefficient } \\
\text { equilibrium xenon }(\Delta \mathrm{k} / \mathrm{k})\end{array}$} & Inner & & -0.067 & -0.064 at EOC \\
\hline 48 & & Outer & & -0.143 & -0.108 at EOC \\
\hline 49 & \multicolumn{2}{|c|}{ Max water void coefficient in reflector $(\Delta \mathrm{k} / \mathrm{k})$} & pg. 4.3-8, line 22 & 0.005 & Not yet calculated \\
\hline 50 & \multicolumn{2}{|c|}{ Max. refueling void worth, \$ } & pg. 4.3-11, line 7 & 4.3 & Not yet calculated \\
\hline 51 & \multirow{4}{*}{ Reactivity addition rate, $\$ / \mathrm{s}$} & Cyl, reg. mode & \multirow{4}{*}{ pg. 4.3-12, line 7} & 0.425 & \multirow{4}{*}{ Similar per Table 11} \\
\hline 52 & & Cyl shim. mode & & 0.16 & \\
\hline 53 & & 4 saf. shim mode & & 0.14 & \\
\hline 54 & & All 5, shim & & 0.30 & \\
\hline 55 & \multirow{4}{*}{ Expected 20-year fast fluence } & HB 1 \& 4 nozzles & \multirow{4}{*}{ pg. 4.3-15, line 24} & $1.1 \times 10^{18}$ & \multirow{4}{*}{$\begin{array}{c}\text { Same per Tables 8- } \\
10\end{array}$} \\
\hline 56 & & HB 2 nozzle & & $2.9 \times 10^{18}$ & \\
\hline 57 & & HB 3 nozzle & & $2.3 \times 10^{18}$ & \\
\hline 58 & & Shell & & $<1 \times 10^{18}$ & \\
\hline
\end{tabular}


Table 26. (continued))

\begin{tabular}{|c|c|c|c|c|c|c|}
\hline ID & \multicolumn{2}{|r|}{ Parameter $^{a}$} & Location in SAR & \multicolumn{2}{|c|}{ Value in $\mathrm{SAR}^{b}$} & Value for LEU \\
\hline 59 & \multirow{8}{*}{$\begin{array}{l}\text { Reactivity balance } \\
\text { (units of } \Delta \mathrm{K} / \mathrm{K} \text {; } \\
\text { first column is } \\
\mathrm{BOC} \text { at } 8.5 \mathrm{MW} \text {; } \\
\text { second column is } \\
\text { EOC at } 85 \mathrm{MW} \text { ) }\end{array}$} & Fuel & \multirow{8}{*}{ Table 4.3-3, pg. 4.3-28 } & 0.135 & 0.073 & \multirow{17}{*}{$\begin{array}{l}\text { Not yet } \\
\text { calculated }\end{array}$} \\
\hline 60 & & Burnable poison & & -0.05 & 0.0 & \\
\hline 61 & & Target worth & & +0.007 & +0.007 & \\
\hline 62 & & Xe and $\mathrm{Sm}$ & & 0.0 & -0.034 & \\
\hline 63 & & Other fission products & & 0.0 & -0.038 & \\
\hline 64 & & Power defect $^{\mathrm{a}}$ & & 0.0 & -0.004 & \\
\hline 65 & & Equilibrium Be poisons & & 0.0 & -0.004 & \\
\hline 66 & & $\begin{array}{l}\text { Inserted control worth, with respect } \\
\text { to full-out condition }\end{array}$ & & -0.092 & 0.0 & \\
\hline 67 & \multirow{4}{*}{$\begin{array}{l}\text { Shutdown margin } \\
\text { (Case ID; flux } \\
\text { trap condition), \$ }\end{array}$} & I; Optimum void, no target & \multirow{4}{*}{ Table 4.3-4, pg. 4.3-29; pg. 4.6-11 } & \multicolumn{2}{|c|}{7.5} & \\
\hline 68 & & II; Target, plus optimum void & & \multicolumn{2}{|c|}{3.3} & \\
\hline 69 & & III; Target, plus optimum void & & \multicolumn{2}{|c|}{2.5} & \\
\hline 70 & & IV; Target, no void & & \multicolumn{2}{|c|}{1.5} & \\
\hline 71 & \multirow{5}{*}{$\begin{array}{l}\text { Shutdown margin } \\
\text { (at refueling with } \\
\text { worst case } \\
\text { manufacture } \\
\text { tolerances), \$ }\end{array}$} & Normal (design) shutdown margin & \multirow{5}{*}{ Table 4.3-5, pg. 4.3-29; pg. 4.6-10 } & \multicolumn{2}{|c|}{10.3} & \\
\hline 72 & & Worst-case void in flux trap & & \multicolumn{2}{|c|}{6.0} & \\
\hline 73 & & $\begin{array}{l}\text { Withdrawn shim/regulating } \\
\text { cylinder }\end{array}$ & & \multicolumn{2}{|c|}{6.5} & \\
\hline 74 & & Withdrawn shim/safety plates (4) & & \multicolumn{2}{|c|}{8.7} & \\
\hline 75 & & $\begin{array}{l}\text { Complete absence of burnable } \\
\text { poison }\end{array}$ & & \multicolumn{2}{|c|}{2.9} & \\
\hline 76 & \multicolumn{2}{|c|}{ Fuel thickness profile inside plates } & Fig. 4.3-2, pg. 4.3-30 & \multicolumn{2}{|c|}{ various } & $\begin{array}{l}\text { Figs. } 7 \text { and } 8 \text {, } \\
\text { Table } 4 \text { this } \\
\text { report }\end{array}$ \\
\hline 77 & \multicolumn{2}{|c|}{ Control plate withdrawal curve } & Fig. 4.3-8, pg. 4.3-36 & \multicolumn{2}{|c|}{-} & $\begin{array}{l}\text { Table 11, } \\
\text { Fig. 13, this } \\
\text { report }\end{array}$ \\
\hline 78 & \multicolumn{2}{|c|}{ Differential rod worth curve } & Fig. 4.3-9, pg. 4.3-37 & \multicolumn{2}{|c|}{-} & $\begin{array}{l}\text { Table 11, } \\
\text { Fig. 13, this } \\
\text { report }\end{array}$ \\
\hline 79 & \multicolumn{2}{|c|}{ Calculated flux profiles } & $\begin{array}{l}\text { Figs. 4.3-10 through } 13 \text {, } \\
\text { pgs. } 4.3-38 \text { through } 41\end{array}$ & \multicolumn{2}{|c|}{-} & Tables 8-10 \\
\hline 80 & \multicolumn{2}{|c|}{$\begin{array}{l}\text { Fuel temperature at hot spot for } 121^{\circ} \mathrm{F} \text { coolant inlet, } \\
\text { EOC }\end{array}$} & pg. 4.4-1, lines 40-41 & \multicolumn{2}{|c|}{$600^{\circ} \mathrm{F}$ at $100 \mathrm{MW}$} & $\begin{array}{c}\text { Not yet } \\
\text { calculated }\end{array}$ \\
\hline
\end{tabular}


Table 26. (continued)

\begin{tabular}{|c|c|c|c|c|c|}
\hline ID & \multicolumn{2}{|c|}{ Parameter $^{a}$} & $\begin{array}{c}\text { Location in SAR } \\
\text { Ch. } 4 \text { (section, page) }\end{array}$ & Value in $\mathrm{SAR}^{b}$ & Value for LEU fuel \\
\hline 81 & \multicolumn{2}{|l|}{ Peak-to-average heat generation rate } & Pg. 4.4-3, Line 40 & 1.3 & Appendix E \\
\hline 82 & \multicolumn{2}{|l|}{ Reactor heat transferred to pool, MW } & Pg. 4.4-5, Line 21 & 0.4 & $\begin{array}{l}\text { Not yet calculated, } \\
\text { expected slightly } \\
\text { greater than } 0.4\end{array}$ \\
\hline 83 & \multicolumn{2}{|c|}{$\begin{array}{l}\text { Fraction of reactor heat deposited in fuel elements and core } \\
\text { coolant }\end{array}$} & Pg. 4.4-9, Line 28 & 0.975 & $\begin{array}{l}\text { Assumed } 0.975 \text {, but } \\
\text { could be slightly larger }\end{array}$ \\
\hline 84 & \multicolumn{2}{|c|}{ LCS value } & Pg. 4.4-10, Line 4 & 1.3 & 1.3 \\
\hline 85 & \multirow{4}{*}{$\begin{array}{l}\text { Low-low flow SL and LCS, } \\
\text { Mode 1; IB power, power-to-flow } \\
\text { ratio }\end{array}$} & $\begin{array}{l}\text { Case 1-Inlet temperature } \\
\text { at SL }\end{array}$ & \multirow{4}{*}{$\begin{array}{l}\text { Pg. 4.4-12, Lines 19- } \\
\text { 31; } \\
\text { Pg. 4.4-14, Lines 5-9; } \\
\text { Table 4.4-5; Table 4.4- } \\
1\end{array}$} & $24.26,1.79$ & \multirow{7}{*}{ Not yet calculated } \\
\hline 86 & & $\begin{array}{l}\text { Case 2-Flux (power) to } \\
\text { flow at SL }\end{array}$ & & $24.70,1.82$ & \\
\hline 87 & & Case 3-Pressure at SL & & $24.1,1.76$ & \\
\hline 88 & & $\begin{array}{l}\text { Case 4-Low-low flow at } \\
\text { SL }\end{array}$ & & $13.59,1.90$ & \\
\hline 89 & \multirow{3}{*}{$\begin{array}{l}\text { Mode } 2 \text { calculated IB power, } \\
\text { MW }\end{array}$} & 2550 gpm, $135^{\circ} \mathrm{F}$ & \multirow{3}{*}{$\begin{array}{l}\text { Pg. 4.4-14, Lines 29- } \\
31 ; \\
\text { Table 4.4-6 }\end{array}$} & 8.56 & \\
\hline 90 & & 2550 gpm, $140^{\circ} \mathrm{F}$ & & 8.16 & \\
\hline 91 & & $1350 \mathrm{gpm}, 135^{\circ} \mathrm{F}$ & & 4.77 & \\
\hline 92 & \multicolumn{2}{|c|}{ Maximum calculated permissible power level (mW) } & $\begin{array}{l}\text { Pg. 4.4-15, Lines 3-4; } \\
\text { Table 4.4-3 }\end{array}$ & $\begin{array}{l}123.6(\mathrm{BOC}) \\
135.3(\mathrm{EOC})\end{array}$ & $\begin{array}{l}133.4 \text { (BOC), } \\
139.2 \text { (EOC) }\end{array}$ \\
\hline 93 & \multicolumn{2}{|l|}{ Uncertainty factors in TH analyses } & Table 4.4-9 & Various & Assumed same as HEU \\
\hline 94 & \multicolumn{2}{|l|}{ Tolerances for dimensions } & Table 4.4-10 & Various & Assumed same as HEU \\
\hline 95 & \multicolumn{2}{|l|}{ Maximum size of blister } & Pg. 4.4-24, Line 27 & $1 / 16$ in & Assumed same as HEU \\
\hline 96 & \multicolumn{2}{|c|}{ Minimum average manufactured coolant channel thickness } & $\begin{array}{l}\text { Pg. 4.4-25; Table 4.4- } \\
4\end{array}$ & 0.044 in. & Assumed same as $\mathrm{HEU}$ \\
\hline 97 & \multicolumn{2}{|c|}{ Results of physics startup tests (cycle 288) } & Pg. 4.4-25 and Ch. 14 & Various & \multirow{4}{*}{$\begin{array}{c}\text { Not yet } \\
\text { measured/calculated }\end{array}$} \\
\hline 98 & \multicolumn{2}{|c|}{ Heat flux peaking due to non-bonds } & Fig. 4.4-7 and 4.4-8 & Various & \\
\hline 99 & \multicolumn{2}{|c|}{ Reactivity worth of poison injection system } & Pg. 4.6-3, 4.6-12 & $\begin{array}{l}\sim \$ 5,0.6 \mathrm{~g} / \mathrm{L} \text { of } \\
\text { gadolinium }\end{array}$ & \\
\hline 100 & \multicolumn{2}{|c|}{ Maximum reactivity available to servo system } & Pg. 4.6-16, Lines 6-7 & $\$ 1.6$ & \\
\hline
\end{tabular}




\section{SUPPLEMENTAL DOCUMENTATION AND RETENTION OF RECORDS}

At the time this document was being written, preparation was underway to document further discussion of the VEST A and MCNP computational models in two Research Reactors Division (RRD) Calculations and to store all input and output datasets on the RRD quality assurance (QA) server (fea8.ornl.gov at the time this document was written) in the compressed file designated in the RRD calculations. Likewise, preparation was underway to document discussion of the HSSHTC computational models in an RRD Calculation and input and output datasets to be stored on the RRD QA server in the compressed file designated in the RRD Calculation. These documents and files are to be reviewed and approved under RRD procedure SBP-1000, Preparation, Review, and Handling of Calculations. Though these documents and files will be designated "internal communication", they are retained as quality assurance-related records and distribution can be made to individuals upon request to and approval by the division director of the ORNL RRD. Conceptual design drawings based on Figs. 7 and 8 of this report have been prepared, assigned the numbers D42114A, Rev. 0 for the inner element fuel plate and D42122A, Rev. 0 for the outer element fuel plate, and are stored in the RRD drawings database. 



\section{SUMMARY AND CONCLUSIONS}

The computational models developed in FY 2010 to search for an LEU fuel design that would meet the requirements for the HEU to LEU conversion study, and the results obtained with these models, are documented and discussed in this report. Estimates of relevant reactor performance parameters for the LEU fuel core are presented and compared with the corresponding data for the currently operating HEU fuel core. No degradation of the HFIR performance parameters was observed as a result of the change of the fuel to LEU.

A 3-D Monte Carlo-based depletion model with VEST A has been developed for performing burnup simulations of the HFIR LEU core and for serving as an engine in the search of an optimal fuel design and core configuration details. This model is documented in the current report. The use of the new depletion tool VEST A facilitates improvements to the depletion model, such as making it possible to account for the irradiation of nonfissile materials (e.g., control elements, beryllium reflector, or nonfissile targets) during the reactor cycle. In addition, VESTA can be used with an extended set of nuclear cross sections, including those that are based on the most recent nuclear data evaluations. Cross sections based on ENDF/B-VII nuclear data evaluations were used for the studies documented in this report. Data for individual molybdenum is otopes in the ENDF/B-VII files should provide a better treatment of the molybdenum isotopes than in previous studies.

The LEU fuel design considered has 2-D grading, both radial and axial, with the axial grading applied only to the bottom $3 \mathrm{~cm}$ of the fuel elements. Compared to the studies carried out during FY 2009, changes in FY 2010 included modeling a zirconium interlayer between the U-10Mo foil and the filler region of the fuel plate, accounting for the irradiation history of the materials in the control elements, and changing the quantity of boron in the inner fuel element for optimizing the power distribution in the core. In addition, an optimal control element movement was determined ("control element withdrawal curve") that would minimize the variation of the $k_{\text {eff }}$ during the cycle (time-dependent depletion calculations conducted with fluxes from critical configurations). Additional changes to this design will be made, using the established methodology and models, for consistency with the proposed manufacturing methodology ${ }^{29}$ as it continues to be developed and to include, when these become available, the actual fuel specifications (e.g., uranium isotopic content, impurities levels). The impact of these fuel design changes on the core performance remains to be assessed. The reduction in control element worth due to the reduced neutron leakage from the LEU fuel relative to the HEU fuel is noteworthy but the assessment of importance requires consideration of the response of the reactor to transients (reactivity coefficients also change), which is a subject beyond the scope of the studies documented in the current report.

The performance and safety parameters calculated for the HFIR LEU core are summarized along with the corresponding data as listed in the current HFIR HEU SAR. This facilitates an "at a glance" comparison between the HEU and the LEU cores for physics and thermal hydraulics parameters that will need to be changed when the SAR is updated for LEU fuel. 



\section{REFERENCES}

1. R. D. Cheverton and T. M. Sims, HFIR Core Nuclear Design, ORNL-4621, Oak Ridge National Laboratory (1971).

2. R. T. Primm III, R. J Ellis, J. C. Gehin, D. L. Moses, J. L. Binder, and N. Xoubi, “Assumptions and criteria for performing a feasibility study of the conversion of the High Flux Isotope Reactor core to use low-enriched uranium fuel,” CD Proceedings, PHYSOR 2006, Vancouver, Canada (2006).

3. R. T. Primm III, R. J Ellis, J. C. Gehin, D. L. Moses, J. L. Binder, and N. Xoubi, Assumptions and Criteria for Performing a Feasibility Study of the Conversion of the High Flux Isotope Reactor Core to Use Low-Enriched Uranium Fuel, ORNL/TM-2005/269, Oak Ridge National Laboratory (2006).

4. HFIR Technical Safety Requirements, ORNL/TM-12841, Rev. 16C, Oak Ridge National Laboratory (2005).

5. X-5 Monte Carlo Team, MCNP-A General Monte Carlo N-Particle Transport Code, Version 5, LACP-03-0245, Los Alamos National Laboratory (2003).

6. D. R Vondy, T. B. Fowler, G. W. Cunningham III, The BOLD VENTURE Computation System for Nuclear Reactor Core Analysis, Version III, ORNL-5711, Oak Ridge National Laboratory (1981).

7. SCALE: A Modular Code System for Performing Standardized Computer Analyses for Licensing Evaluation, ORNL/TM-2005/39, Version 6, Vols. I-III, January 2009. (Available from Radiation Safety Information Computational Center at Oak Ridge National Laboratory as CCC-750).

8. W. Haeck, An Optimum Approach to Monte Carlo Burnup, Ph.D. thesis, Ghent University, Belgium (2007).

9. R. T. Primm III, D. Chandler, G. Ilas, B.C. Jolly, J. H. Miller, and J. D. Sease, Design Study for a Low-Enriched Uranium Core for the High Flux Isotope Reactor, Annual Report for FY 2008, ORNL/TM-2009/87, Oak Ridge National Laboratory (2009).

10. N. Xoubi and R. T. Primm III, Modelling of the High Flux Isotope Reactor Cycle 400, ORNL/TM2004-251 (2005).

11. W. Haeck, VESTA User's Manual-Version 2.0.0, IRSN Report DSU/SEC/T/2008-331 Indice A, France (2009).

12. RSICC Computer Code Collection CCC-371, ORIGEN 2.2. Available from RSICC, Oak Ridge National Laboratory (2002).

13. G. Ilas and R. T. Primm III, Fuel Grading Study on a Low-Enriched Uranium Fuel Design for the High Flux Isotope Reactor, ORNL/TM-2009/223/R1, Oak Ridge National Laboratory (2010).

14. D. Chandler, R. T. Primm III, G. I. Maldonado, Validating MCNP for LEU Fuel Design via Power Distribution Comparisons, ORNL/TM-2008/126, Oak Ridge National Laboratory (2008).

15. D. Chandler, R. T. Primm III, and G. I. Maldonado, Validation of a Monte Carlo Based Depletion Methodology with HFIR Post-Irradiation Examination Data, ORNL/TM-2009/123, Oak Ridge National Laboratory (2009).

16. D. Chandler, R. T. Primm III, and G. I. Maldonado, "HFIR Post-Irradiation Curium Target Rod Nuclide Inventory Calculations,” ANS Transactions 102, 560-561 (2010).

17. G. Ilas and R. T. Primm III, "Methodology for simulating the irradiation of the control elements in HFIR,” ANS Transactions, 103, 696-698 (2010).

18. R. T. Primm III and G. Ilas, "Reference (axially graded) low enriched uranium fuel design for the High Flux Isotope Reactor (HFIR),” CD Proceedings, Test, Research and Training Reactors Meeting TRTR 2010, Knoxville, TN (September 2010).

19. T. H. Newton, Jr., Development of a Low Enrichment Uranium Core for the MIT Reactor, Ph.D. thesis, Massachusetts Institute of Technology (2006).

20. HFIR Updated Safety Analysis Report, Rev. 6B, ORNL/HFIR/USAR/2344.

21. R. T. Primm III, D. Chandler, G. Ilas, B. C. Jolly, J. H. Miller, and J. D. Sease, Design Study for a Low-Enriched Uranium Core for the High Flux Isotope Reactor, Annual Report for FY 2009, ORNL/TM-2009/313, Oak Ridge National Laboratory (2010). 
22. R. T. Primm III, Reactor Physics Studies of Reduced-Tantalum-Content Control and Safety Elements for the High Flux Isotope Reactor, ORNL/TM-2003/65, Oak Ridge National Laboratory (2003).

23. H. A. Mclain, HFIR Fuel Element Steady State Heat Transfer Analysis, Revised Version, ORNL/TM1904, Oak Ridge National Laboratory, 1967, as appended by T. E. Cole, L. F. Parsly, and W. E. Thomas, Revisions to the HFIR Steady State Heat Transfer Analysis Code, ORNL/CF-85/68 (1986).

24. R. T. Primm III, D. L. Pinkston, J. D. Sease, and D. G. Renfro, Establishing Specifications for Low Enriched Uranium Fuel Operations Conducted Outside the High Flux Isotope Reactor, ORNL/TM-2010/241 (2010).

25. R. T. Primm III, Dose Rate from Spent Fuel Elements and Security Classification of Fresh Fuel, C-HFIR-2005-146, May 2005 (archived, internal document available upon request to the division director, Research Reactors Division, Oak Ridge National Laboratory).

26. V. G. Terentiev, U.S. National Nuclear Material Control and Accounting System, UCRL-CR-132636, Moscow, Russia (1998).

27. U.S. Department of Energy, Control and Accounting of Nuclear Materials, DOE Order 5633.3A, (February 12, 1993).

28. Code of Federal Regulations / Energy, 10, Parts 51 to 199, Washington: U.S. Government Printing Office (1994).

29. G. A. Moore et al., "Monolithic Fuel Fabrication Process Development at the Idaho National Laboratory,” RERTR-2008 International Meeting on Reduced Enrichment for Research and Test Reactors, Washington, D.C. (2008).

30. R. W. Knight and A. E. Richt, "Evaluation of Absorber Materials Performance in HFIR Control Cylinders," Nuclear Technology 15, 384 (1972).

31. J. D. Sease, Fabrication of Control Rods for the High Flux Isotope Reactor, ORNL/TM-9365/R1 (1998).

32. G. D. Spriggs, R. D. Busch, and J. M. Campbell, "Calculation of the Delayed Neutron Effectiveness Factor Using Ratios of k-Eigenvalues,” Annals of Nuclear Energy 28, 477 (2001).

33. R. K. Meulekamp and S. C. van der Marck, "Calculating the Effective Delayed Neutron Fraction with Monte Carlo,” Nuclear Science and Engineering 152, 142 (2006).

34. G. Chiba, "Calculation of Effective Delayed Neutron Fraction Using a Modified k-Ratio Method," Journal of Nuclear Science and Technology 152, 142 (2006).

35. M. M. Bretscher, "Evaluation of Reactor Kinetic Parameters without the Need for Perturbation Codes,” Proceedings of RERTR 1997, Jackson Hole, Wyoming (October 5-10, 1997). 


\section{APPENDIX A. MATERIAL COMPOSITION FOR LEU CORE}

The LEU fuel material considered, as mentioned previously in this report, is a metallic alloy containing $90 \mathrm{wt} \%$ uranium and $10 \mathrm{wt} \%$ molybdenum. The density of the fuel is $17.02 \mathrm{~g} / \mathrm{cm}^{3}$ and the enrichment is $19.75 \mathrm{wt} \%{ }^{235} \mathrm{U}$. The material composition data for fuel, fuel diffusion barrier layer, clad, and filler as used in the model are shown in Table A.1. The isotopic composition assumed for uranium, molybdenum, and zirconium in the fuel material and the fuel diffusion barrier layer are presented in Table A.2. As in the HEU fuel plate design, a filler material is used between the fuel meat and the clad; boron in the form of $\mathrm{B}_{4} \mathrm{C}$ is included in the filler for the IFE only. No detailed specifications are available at this time for the actual composition of the LEU fuel material (isotopic content, impurities), as mentioned before. When these specifications become available, the model will be updated accordingly.

The composition of the curium targets in the HFIR LEU core model is listed in Table A.3. The material composition for the "black" and "gray" regions of the control elements used in the LEU core model, which is Table A.4, corresponds to the actual composition at BOC-400, as previously mentioned.

Table A.1. Material composition for LEU fuel

\begin{tabular}{lccc}
\hline \multicolumn{1}{c}{ Material } & $\begin{array}{c}\text { Density } \\
\left(\mathbf{g} / \mathbf{c m}^{\mathbf{3}}\right)\end{array}$ & $\begin{array}{c}\text { Component } \\
\text { (element) }\end{array}$ & $\begin{array}{c}\text { Content } \\
\text { (wt \%) }\end{array}$ \\
\hline U-10Mo & \multirow{2}{*}{17.02} & $\mathrm{U}$ & 90.000 \\
& & $\mathrm{Mo}$ & 10.000 \\
\hline Diffusion barrier & \multirow{2}{*}{6.49} & $\mathrm{Zr}$ & 100.000 \\
layer & & $\mathrm{Al}$ & 97.155 \\
& & $\mathrm{C}$ & 1.000 \\
& & $\mathrm{Si}$ & 0.600 \\
& & $\mathrm{Cu}$ & 0.400 \\
Clad & \multirow{2}{*}{2.70} & $\mathrm{Fe}$ & 0.350 \\
(AL-6061) & & $\mathrm{Cr}$ & 0.195 \\
& & $\mathrm{Mn}$ & 0.075 \\
& & $\mathrm{Ti}$ & 0.075 \\
& & $\mathrm{Ni}$ & 0.021 \\
& & $\mathrm{H}$ & 0.021 \\
\hline & & $\mathrm{Al}$ & 99.300 \\
Filler $^{a}$ & & $\mathrm{Fe}$ & 0.250 \\
(AL-1100) $^{2}$ & & $\mathrm{Si}$ & 0.250 \\
& & $\mathrm{Cu}$ & 0.175 \\
& & $\mathrm{Mn}$ & 0.025 \\
\hline
\end{tabular}

${ }^{a}$ Fuel in IFE includes boron carbide $\mathrm{B}_{4} \mathrm{C}$ in the filler, with a density of $2.52 \mathrm{~g} / \mathrm{cm}^{3}$. It is assumed that $\mathrm{B}_{4} \mathrm{C}$ is uniformly distributed in the filler material. The isotopic composition in at $\%$ of $\mathrm{B}$ in $\mathrm{B}_{4} \mathrm{C}$ is $19.9^{10} \mathrm{~B}$ and $81.1^{11} \mathrm{~B}$. A total of $5.4 \mathrm{~g}$ of ${ }^{10} \mathrm{~B}$ is present in the IFE filler material. 
Table A.2. Isotopic composition of $\mathrm{U}$, Mo, and $\mathrm{Zr}$ in LEU fuel

\begin{tabular}{ccr}
\hline Element & Isotope & $\begin{array}{r}\text { Content } \\
\text { (wt \%) }\end{array}$ \\
\hline $\mathrm{U}$ & ${ }^{234} \mathrm{U}$ & 0.165 \\
& ${ }^{235} \mathrm{U}$ & 19.750 \\
& ${ }^{236} \mathrm{U}$ & 0.909 \\
& ${ }^{238} \mathrm{U}$ & 79.176 \\
\hline $\mathrm{Mo}^{a}$ & ${ }^{92} \mathrm{Mo}$ & 14.84 \\
& ${ }^{94} \mathrm{Mo}$ & 9.24 \\
& ${ }^{95} \mathrm{Mo}$ & 15.92 \\
& ${ }^{96} \mathrm{Mo}$ & 16.68 \\
& ${ }^{97} \mathrm{Mo}$ & 9.55 \\
& ${ }^{98} \mathrm{Mo}$ & 24.13 \\
& ${ }^{100} \mathrm{Mo}$ & 9.63 \\
\hline${ }^{90} \mathrm{Zr}$ & 51.45 \\
& ${ }^{91} \mathrm{Zr}$ & 11.22 \\
& ${ }^{92} \mathrm{Zr}$ & 17.15 \\
& ${ }^{94} \mathrm{Zr}$ & 17.38 \\
& ${ }^{96} \mathrm{Zr}$ & 2.80 \\
\hline
\end{tabular}

${ }^{a}$ Isotopic composition as provided in J. K. Tuli, Nuclear Wallet Card 2005, National Nuclear Data Center, Brookhaven

National Laboratory, www.nndc.bnl.gov.

Table A.3. Composition of curium targets in the HFIR LEU core model

\begin{tabular}{crcc}
\hline Nuclide ID & Atoms/b-cm & Nuclide ID & Atoms/b-cm \\
\hline${ }^{16} \mathrm{O}$ & $6.6358 \mathrm{E}-03$ & ${ }^{243} \mathrm{Am}$ & $3.7252 \mathrm{E}-05$ \\
${ }^{27} \mathrm{Al}$ & $4.1858 \mathrm{E}-02$ & ${ }^{242} \mathrm{Cm}$ & $1.1234 \mathrm{E}-09$ \\
${ }^{238} \mathrm{Pu}$ & $1.4608 \mathrm{E}-08$ & ${ }^{243} \mathrm{Cm}$ & $3.7128 \mathrm{E}-07$ \\
${ }^{239} \mathrm{Pu}$ & $1.9706 \mathrm{E}-08$ & ${ }^{244} \mathrm{Cm}$ & $6.1759 \mathrm{E}-04$ \\
${ }^{240} \mathrm{Pu}$ & $3.7969 \mathrm{E}-05$ & ${ }^{245} \mathrm{Cm}$ & $9.2061 \mathrm{E}-06$ \\
${ }^{241} \mathrm{Pu}$ & $1.1256 \mathrm{E}-09$ & ${ }^{246} \mathrm{Cm}$ & $1.3000 \mathrm{E}-03$ \\
${ }^{242} \mathrm{Pu}$ & $2.9825 \mathrm{E}-07$ & ${ }^{247} \mathrm{Cm}$ & $3.7719 \mathrm{E}-05$ \\
${ }^{241} \mathrm{Am}$ & $1.5978 \mathrm{E}-04$ & ${ }^{248} \mathrm{Cm}$ & $2.5183 \mathrm{E}-04$ \\
${ }^{242} \mathrm{Am}$ & $4.2253 \mathrm{E}-07$ & & \\
\hline
\end{tabular}


Table A 4. Composition ${ }^{a}$ of materials in control elements for the HFIR LEU core model

\begin{tabular}{llcc}
\hline Nuclide & $\begin{array}{c}\text { Inner } \\
\text { control element } \\
\text { (at/b-cm) }\end{array}$ & $\begin{array}{c}\text { Outer } \\
\text { control element } \\
\text { (at/b-cm) }\end{array}$ \\
\hline Gray region & H-1 & $2.820 \mathrm{E}-03$ & $2.774 \mathrm{E}-03$ \\
& O-16 & $1.400 \mathrm{E}-03$ & $1.393 \mathrm{E}-03$ \\
& Al-27 & $3.357 \mathrm{E}-02$ & $3.227 \mathrm{E}-02$ \\
& Ta-181 & $1.424 \mathrm{E}-02$ & $1.797 \mathrm{E}-02$ \\
& Ta-182 & $3.383 \mathrm{E}-05$ & $2.838 \mathrm{E}-05$ \\
& W-182 & $2.843 \mathrm{E}-04$ & $1.197 \mathrm{E}-04$ \\
& W-183 & $4.614 \mathrm{E}-03$ & $1.777 \mathrm{E}-03$ \\
& W-184 & $1.635 \mathrm{E}-03$ & $1.449 \mathrm{E}-04$ \\
& W-186 & $1.540 \mathrm{E}-06$ & $1.742 \mathrm{E}-08$ \\
\hline Black region & O-16 & $1.312 \mathrm{E}-02$ & $1.260 \mathrm{E}-02$ \\
& Al-27 & $3.938 \mathrm{E}-02$ & $3.783 \mathrm{E}-02$ \\
& Sm-152 & $1.713 \mathrm{E}-04$ & $4.879 \mathrm{E}-05$ \\
& Eu-151 & $2.690 \mathrm{E}-03$ & $3.581 \mathrm{E}-03$ \\
& Eu-152 & $6.754 \mathrm{E}-04$ & $2.690 \mathrm{E}-04$ \\
& Eu-153 & $4.472 \mathrm{E}-03$ & $4.290 \mathrm{E}-03$ \\
& Eu-154 & $2.612 \mathrm{E}-04$ & $8.156 \mathrm{E}-05$ \\
& Eu-155 & $2.448 \mathrm{E}-05$ & $2.479 \mathrm{E}-06$ \\
Gd-152 & $3.843 \mathrm{E}-04$ & $1.170 \mathrm{E}-04$ \\
Gd-154 & $4.220 \mathrm{E}-05$ & $5.186 \mathrm{E}-06$ \\
Gd-155 & $3.598 \mathrm{E}-06$ & $2.144 \mathrm{E}-07$ \\
Gd-156 & $7.061 \mathrm{E}-06$ & $1.532 \mathrm{E}-07$ \\
\hline
\end{tabular}

\footnotetext{
${ }^{a}$ At the beginning of the LEU irradiation cycle.
} 



\section{APPENDIX B. METHODOLOGY FOR SIMULATING THE IRRADIATION OF THE CONTROL ELEMENTS IN HFIR}

The control elements (CEs) in HFIR are used in the core for a large number of reactor cycles, for periods of time that can total as much as a thousand days of irradiation. A control element can be removed from the core after a number of irradiation cycles and inserted back in the core after a period of decay time. During irradiation, the composition of the poison materials in the CEs changes due to neutron interactions, therefore leading to a change in the absorption properties (cross sections) of these materials. Quantifying these changes throughout the CEs' history will enable a better estimation of the isotopic composition for use in models of HFIR for various studies.

A methodology has been developed to simulate the irradiation of the CEs during irradiation. Simulation of the irradiation and decay history of a control rod material is performed using the point depletion and decay code ORIGEN-S in the pre-release version 6.1 of the SCALE ${ }^{7}$ code system. Though a point depletion code is used, the spatial effects (CEs change locations during an irradiation cycle) are accounted for through the way the cross sections used with ORIGEN-S are generated. One unique material is used for each of the gray and black regions in the inner control element (ICE) and the outer control element (OCE) for the purpose of generating these cross sections. The ORIGEN-S cross sections are determined based on data obtained from depletion simulations with VESTA of HFIR cycle 400.

\section{B.1 ORIGEN-S CROSS-SECTION GENERATION}

New capabilities are available in the SCALE 6.1pre- release for ORIGEN-S and its associated library management code COUPLE. These new features allow the user to apply multigroup cross sections and neutron flux data from a user-defined reactor physics model (for problem-dependent design and operating conditions) to collapse multigroup cross-section libraries available with ORIGEN-S to effective onegroup data used in ORIGEN-S calculations. In addition, user-provided one-group cross sections may be used to override the cross-section data existing on a binary library for ORIGEN-S.

The cross sections for the gray and black regions of the CEs change during an irradiation cycle, compared to the beginning of the cycle, mainly due to the change of axial locations of CEs with respect to the core midline. The flux seen by these regions varies, decreasing when the elements are moved further from the core midline towards the core edges. In addition to the change in neutron flux to which these regions are subjected, there is a resonance self-shielding effect that needs to be considered when generating effective one-group cross sections. This effect is due to geometry and material details specific to the CEs (very thin regions of absorbing material surrounded by water).

The fluxes in the gray and black regions of ICE and OCE were calculated in a multigroup structure as a function of the CE axial location (with time) during cycle 400. Tallies were defined for each of these four material zones in each of the MCNP input files that were generated, one for each depletion step, during the depletion simulations with VESTA. There are 25 flux data sets for each material zone, one for each of the depletion steps in VEST A, which correspond to 25 different locations of the CEs during cycle 400 . The flux data were extracted in a 44-group structure, with the energy binning consistent with the 44-group structure used in SCALE.

It is assumed here that the effective one-group cross sections for each of the four zones in the CEs are a function of the CE axial location only. One set of effective one-group cross sections is generated therefore to correspond to each of the $25 \mathrm{CE}$ locations in the core during irradiation. The 44-group flux tallied with MCNP is used in COUPLE to obtain the binary library for ORIGEN-S. The COUPLE code builds the one-group effective cross sections by weighting the 44-group SCALE activation library with the 44-group user-provided flux. There are 44-group, 49-group, 238-group, and 300-group activation libraries in SCALE 6.1. Note though that these libraries are not self-shielded (problem-dependent) and correspond to an infinite dilution case. In addition to the neutron cross-section data, a binary library for ORIGEN-S includes decay data, which are not problem-dependent. 
A routine was developed to generate the input files for COUPLE $(4 \times 25$ files). The binary libraries obtained were checked against cross-section data (neutron capture in particular) directly available from VESTA simulations for cycle 400. It was observed that for most of the relevant isotopes in the black regions (europium, samarium, gadolinium), the variation of the one-group cross sections obtained via COUPLE was in reasonable agreement with the corresponding data available from VESTA. However, a large difference was seen for the one-group capture cross section in ${ }^{181} \mathrm{Ta}$ between COUPLE and VESTA values. This indicates that a 44-group flux (and activation file) as used with the COUPLE input would not be sufficient to approximate the resonance structure in the cross section as a function of energy for this nuclide. This was confirmed when replacing in one of the 100 considered COUPLE input files the 44group flux (and 44-group activation cross sections) by a 238-group flux (and 238-group activation cross sections); in this case the difference between the COUPLE and VESTA one-group capture cross sections for ${ }^{181}$ Ta decreased, though not to a reasonable agreement level. Note that in VEST A, a very fine, 43,000group flux is used in the depletion simulations to obtain one-group cross sections for ORIGEN.

To resolve the observed difference in the cross sections for ${ }^{181} \mathrm{Ta}$, the generation of the cross-section data with COUPLE as described above was modified. The change consisted of using one-group capture cross sections for this nuclide as available from VESTA output files to override the corresponding data on the binary ORIGEN-S library obtained as mentioned previously.

The use of these models resulted in the generation of 100 binary library files for use with ORIGEN-S: 25 files for each of the gray and black materials in ICE and OCE, one for each of the 25 locations of the CEs with respect to the core midline.

\section{B.2 ORIGEN-S BURNUP SIMULATIONS FOR CONTROL ELEMENTS}

Burnup simulations with ORIGEN-S can be performed for any irradiation history of a CE using the one-group cross-section libraries generated as described previously. The total flux in each of the four different CE materials is used as input data. This flux is calculated from the MCNP tallies along with the 44-group flux needed to generate the cross sections for each of the $25 \mathrm{CE}$ locations.

A routine was developed to write the input files for ORIGEN-S (one for each CE material) for any provided irradiation history data. The irradiation history data include the number of cycles the material was irradiated, the duration of the cycle, and the decay time between two periods of irradiation. The methodology is illustrated in Fig. B.1.

\section{B.3 APPLICATION TO BURNUP SIMULATIONS FOR HFIR CYCLE 400}

The methodology discussed previously was applied to estimate the composition of the CE materials at the time of BOC-400. A detailed irradiation history was available for the OCE. As the four OCE safety elements have the same irradiation history in this case, one gray and one black material can be considered (as opposed to one gray and one black for each quadrant) in the ORIGEN-S simulations. The OCE was inserted in the core in cycle 390 with fresh composition, irradiated for seven cycles, to cycle 396, removed from the core during cycles 397 to 399, and reinserted for cycle 400. An incomplete irradiation history was available for the ICE. It is known that this element was present in the core continuously, since the cycle it was inserted with fresh composition to cycle 400. History data for the ICE are available from cycle 388 further; the burnup of the element at BOC-388 is also available. The history data prior to cycle 388 was approximated based on the available information. The start cycle was estimated to be cycle 375. Cycle duration and post-cycle outage for cycles 375 to 388 were calculated as average values based on data available for later cycles. 


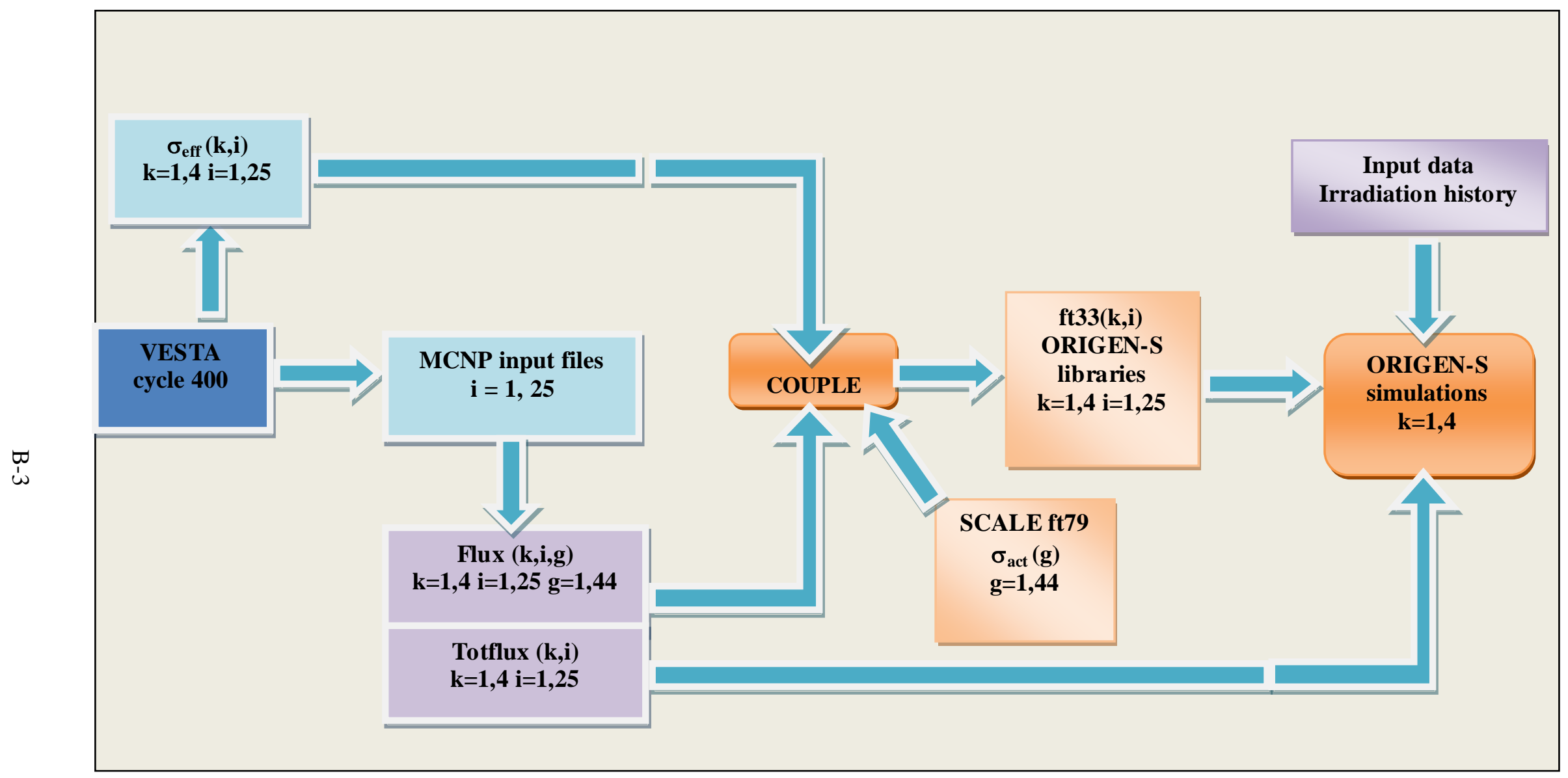

Fig. B.1. Burnup simulation methodology for control elements. 
The determined material composition for CEs was used in the VESTA depletion model for HFIR cycle 400. The cross sections for the Monte Carlo-based depletion were based on ENDF/B-VII data. The most important (with respect to neutron capture) isotopes determined for the ICE and OCE black and gray regions at BOC-400 are listed in Table B.1, including the half-life and the neutron capture cross-section range for these isotopes. As seen, there are stable (or large half-life) nuclides produced by transmutations with significant absorption properties compared to the isotopes present in the fresh composition.

Table B.1. Isotopes in CE gray and black regions at BOC-400

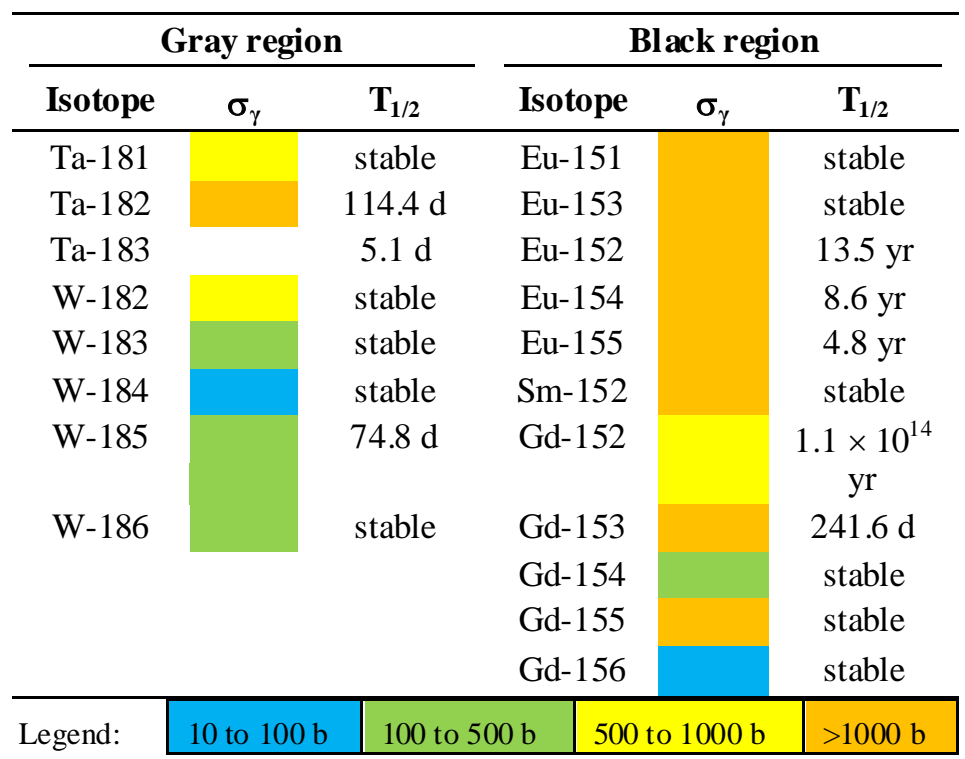

The effect of the change in the CEs' compositions (and therefore cross sections) on the variation of $\mathrm{k}_{\text {eff }}$ during cycle 400 is significant with respect to both $\mathrm{k}_{\mathrm{eff}}$ values and shape, as illustrated in Fig. B.2. Results from two similar models for HFIR cycle 400 are compared. In the old model, ${ }^{21}$ the material compositions of the CEs at BOC 400 were assumed to be fresh compositions, whereas in the new model, the material compositions as determined with the methodology described in this report were used. The old model used ENDF/B-VI cross sections, whereas the new model used the most recent ENDF/B-VII cross sections. As shown, the $\mathrm{k}_{\mathrm{eff}}$ variation as a function of time for the new composition data in the new model is smoother than for the old model with assumed composition data for the CE materials. Part of the source of an apparent burnup-dependence of calculated $k_{\text {eff }}$ has been removed by properly accounting for the control element irradiation history in HFIR cycle 400 depletion simulations. 


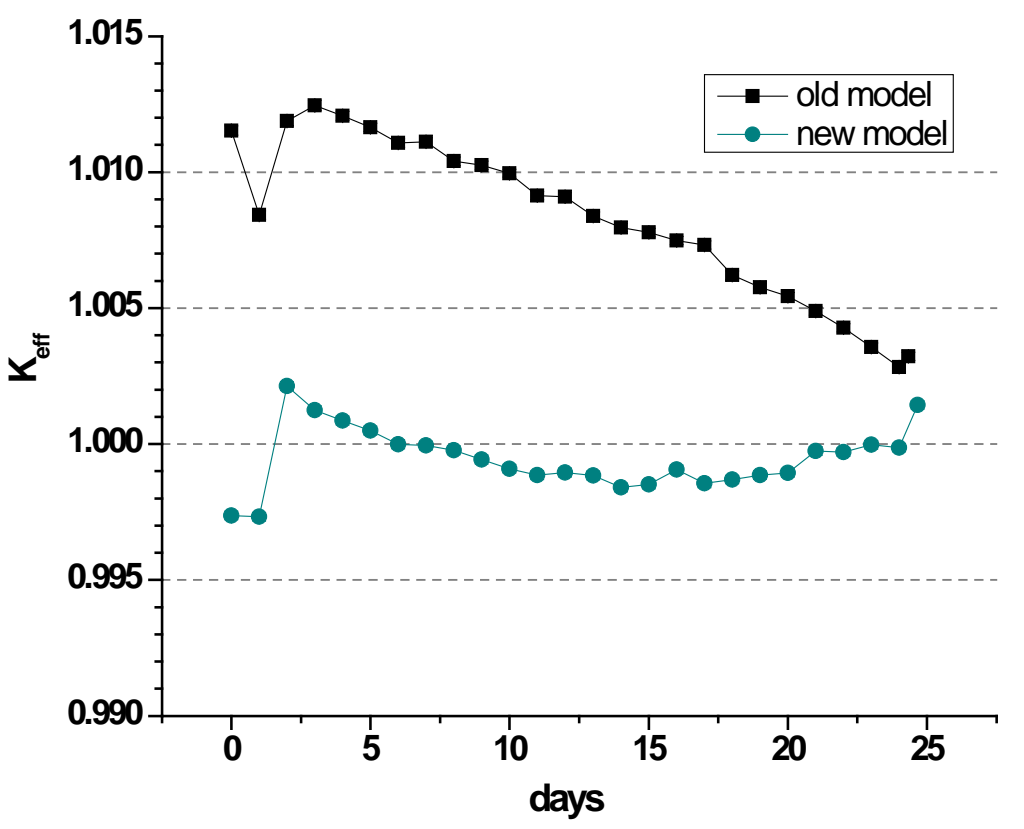

Fig. B.2. Variation of $k_{\mathrm{eff}}$ during HFIR cycle 400.

\section{B.4 VALIDATION OF METHODOLOGY AGAINST EXPERIMENTAL DATA}

Measurement data for the irradiated ICE, obtained from destructive analysis, have been reported by Knight and Richt. ${ }^{30}$ The data correspond to the control element irradiated to 48,615 MWd. ${ }^{22}$ For the gray region of the ICE, it is stated in Ref. 30, "Mass spectrographic analysis of the specimen from the tantalum-bearing section of the cylinder indicated that 0.7 neutrons had been absorbed for every tantalum atom initially present.” Isotopic data are provided for five specimens from the black region of the ICE, selected from locations at $0.5,2,5,10$, and $20 \mathrm{in}$. with respect to the interface between the gray and the black region. The data include the europium isotopic composition in atomic percent as well as the Eu-Gd fraction in weight percent for each of the five specimens. No experimental uncertainty is provided for the reported measured data.

Calculations were performed using the methodology described previously to simulate the burnup of the ICE to a value of 48,615 MWd. It was assumed that the irradiation history consisted of 23 cycles, each of 24.87 days duration, with a 25 day outage between each consecutive cycles. The compositions of the two materials considered in the black and gray regions of the ICE were determined to correspond to the reported burnup.

An estimation based on the calculated atom densities resulted in a value of 0.71 for the number of neutrons absorbed per tantalum atom initially present. This value is in very good agreement with the reported value in Ref. 30 based on experimental data and is consistent with the value estimated using different methods. ${ }^{26}$

A direct comparison of calculated and experimental data as reported for the europium region is not possible, because the measured data are reported as a function of spatial location inside the region; however, the burnup simulation methodology in this work considers one material only for the europium region, and the results for the isotopic composition are determined as average values over the region (no spatial dependence). To facilitate some level of comparison, region-averaged values were estimated from the reported experimental data by integrating the available curves representing the isotopic compositions as a function of distance. A comparison of these data with the data obtained from simulation is shown in Table B.2. The agreement is reasonable, considering the approximation made to estimate region-averaged values based on measured data for the isotopic composition. The comparison of the region-averaged 
calculated Eu-Gd weight fractions to values inferred based on measured data shows a good agreement between experiment and calculation.

Table B.2. Isotopes in CE gray and black regions at $\mathrm{BOC}-400$

\begin{tabular}{|c|c|c|c|}
\hline \multicolumn{4}{|c|}{ Eu isotopic composition (at \%) } \\
\hline Isotope & Calculated & Measured & Difference \\
\hline Eu-151 & 34.18 & 37.83 & -3.65 \\
Eu-153 & 54.58 & 54.91 & -0.33 \\
Eu-152 & 7.98 & 3.75 & 4.23 \\
Eu-154 & 3.00 & 2.60 & 0.40 \\
Eu-155 & 0.26 & 0.91 & -0.65 \\
\hline \multicolumn{4}{|c|}{ Eu-Gd fractions (wt \%) } \\
\hline Element & Calculated & Measured & Difference \\
\hline Eu & 95.3 & 94.4 & 0.9 \\
Gd & 4.7 & 5.6 & -0.9 \\
\hline
\end{tabular}




\section{APPENDIX C. MODELING OF CONTROL ELEMENTS IN THE LEU CORE}

The two control elements (CEs) in the HFIR HEU core, described in detail in Refs. 10 and 31, consist of thin annular concentric cylinders, termed inner control element (ICE) or regulating element and outer control element (OCE) or safety element, respectively. Each of these two elements includes three axial regions with different neutron absorption properties: a "black" strong neutron absorber region containing $\mathrm{Eu}_{2} \mathrm{O}_{3}$ dispersed in an aluminum matrix, a "gray" moderate neutron absorber region with tantalum particles in an aluminum matrix, and a "white" region of perforated aluminum. The control elements dimensions and height of each region are shown in Fig. C.1. ${ }^{10}$

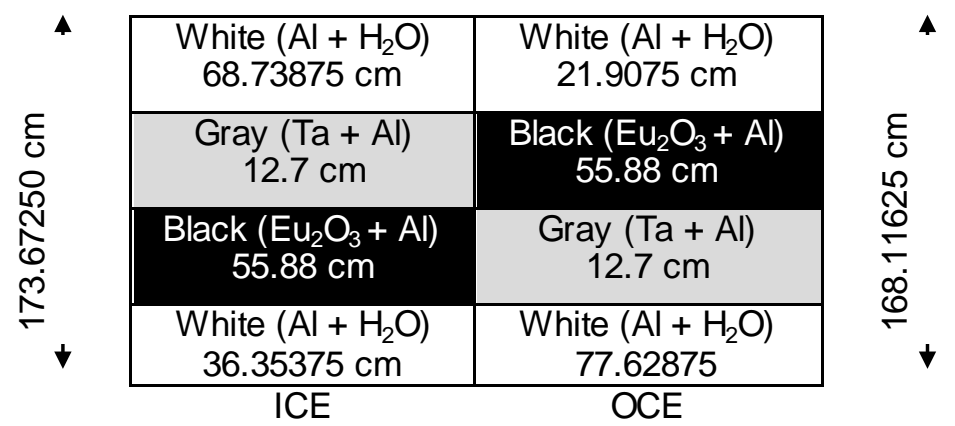

Fig. C 1. Axial dimensions of control elements in HFIR HEU core.

The CEs are moving in different directions with respect to the core centerline during the cycle-the ICE moves down (is inserted) and the OCE moves up (is withdrawn). The movement of the CEs during the cycle is simulated in the depletion model by the use of MCNP surface transformation cards, in order to set the CEs at the corresponding axial positions for the desired time. The CEs positions corresponding to cycle 400 depletion model are presented in Table C.1. The values (in $\mathrm{cm}$ ) used for the transformation (i.e., translation) cards listed in this table are the measured positions as recorded by the reactor operators for cycle 400. These values are expressed with respect to the shutdown position-the state at which the upper edge of the ICE black region is located at the upper edge of the unfueled core region $(30.48 \mathrm{~cm}$ with respect to core centerline) and the lower edge of the OCE black region is located at the lower edge of the unfuelled core region ( $-30.48 \mathrm{~cm}$ with respect to core centerline). Also shown in Table C.1 is the actual position relative to the core centerline of the upper edge of the ICE gray region. The values used in the transformation cards for the ICE and OCE in the depletion model for cycle 400 have the same absolute value but have different signs (the ICE is inserted and the OCE is withdrawn symmetrically with respect to the core axial centerline). The axial location of the surfaces used to define the CEs positioning in the MCNP model are listed in Table C.2; the transformation cards are applied to these surfaces to obtain the actual position during the irradiation relative to the core centerline.

The CEs' geometry data for the LEU core is the same as used in HEU model - the same dimensions are used for the gray, black, and white regions of the CEs as used for the HEU cycle 400. The axial locations of the surfaces used to define the CEs' positioning in the MCNP model for the LEU core are the same as those listed in Table C.2. The data for the transformation cards in the LEU model and the actual position relative to the core centerline of the upper edge of the ICE gray region are listed in Table C.3. 
Table C.1. Control element position in HEU cycle 400 model

\begin{tabular}{ccc}
\hline $\begin{array}{c}\text { Time } \\
\text { (days) }\end{array}$ & $\begin{array}{c}\text { Transformation card } \\
\text { axial translation } \\
\text { (cm) }\end{array}$ & $\begin{array}{c}\text { Actual axial location } \\
\text { of upper edge of } \\
\text { ICE gray region }\end{array}$ \\
\hline (cm)
\end{tabular}

${ }^{a} \mathrm{With}$ respect to core centerline at $\mathrm{z}=0 \mathrm{~cm}$.

Table C.2. Control element surface data in MCNP model for HEU cycle 400

\begin{tabular}{cccccccc}
\hline \multicolumn{3}{c}{ Inner control element } & & \multicolumn{3}{c}{ Outer control element } \\
\cline { 1 - 3 } \cline { 5 - 7 } Surface \# & $\mathbf{z}^{\boldsymbol{a}} \mathbf{( c m )}$ & Region & & Surface \# & $\mathbf{z}^{\boldsymbol{a}} \mathbf{( c m )}$ & Region \\
\hline 300 & 111.91875 & Upper white & & 310 & 47.3075 & Upper white \\
301 & 43.18 & Gray & & 311 & 25.40 & Black \\
302 & 30.48 & Black & & 312 & -30.48 & Gray \\
303 & -25.40 & Lower white & & 313 & -43.18 & Lower white \\
304 & -61.75375 & & & 314 & -120.80875 & \\
\hline
\end{tabular}

${ }^{a}$ With respect to core centerline at $\mathrm{z}=0 \mathrm{~cm}$. 
Table C.3. Control element position in LEU depletion model

\begin{tabular}{ccc}
\hline $\begin{array}{c}\text { Time } \\
\text { (days) }\end{array}$ & $\begin{array}{c}\text { Transformation card } \\
\text { axial translation } \\
\text { (cm) }\end{array}$ & $\begin{array}{c}\text { Actual axial location } \\
\text { of upper edge of } \\
\text { ICE gray region }\end{array}$ \\
\hline $\mathbf{( c m )}$
\end{tabular}

${ }^{a} \mathrm{With}$ respect to core centerline at $\mathrm{z}=0 \mathrm{~cm}$. 



\section{APPENDIX D. IMPORTING VOLUME-CALCULATED POWER DENSITY DATA INTO THE HSSHTC SPATIAL MESH}

As noted in the description provided in Refs. 3 and 23, the HSSHTC was written to receive, as input, power densities calculated at spatial mesh points throughout the reactor core. The HSSHTC determines a volume power density by computing the arithmetic mean of the four bounds that bound a twodimensional square region on the surface of a plate. In the MCNP model for HFIR, the user defines surfaces of the regions and the power densities are calculated over the volumes bounded by these surfaces. When using MCNP-calculated volume-averaged power densities as input to the HSSHTC, the HSSHTC algorithm is unchanged, but each of the MCNP-calculated power density data are duplicated both radially and axially in the HSSHTC input file. Figure D.1 provides an illustration for explaining the concept.

The red letters (A, B, C, D) identify zones defined in the MCNP model. The HSSHTC requires as input four power density values for zone $A$, corresponding to the local power densities in the four corners of the spatial mesh at $r_{2} z_{2}, r_{3} z_{2}, r_{2} z_{3}$, and $r_{3} z_{3}$, and then computes the mean of these four values. One way to make the mean of these four values equal to the power density value in zone A calculated with MCNP is to assign this MCNP-based value to each of the four points in the HSSHTC mesh. But how to repeat this process for zone $B$ ? Zone A MCNP values have already been assigned to $r_{3} z_{2}$ and $r_{3} z_{3}$. In order for the correct zone power density for zone $\mathrm{B}$ to be computed from the mean of the four values that should be assigned to the corners of the B mesh-all equal to the MCNP-based value for zone B-zero volume zones are introduced into the model between the B zone and each of its four neighboring zones.

By replicating each radial (r) mesh line and each axial (z) mesh line and assigning the value of zero to alternating radial and axial region thicknesses, the user can "isolate” the MCNP volumes that are being translated into HSSHTC input (and their associated four-corner mesh points) from each other. Each MCNP-calculated zone power density is assigned to each of the four corners of the "MCNP zone," and the HSSHTC code will correctly calculate the zone power density. Assigning zero volumes to the regions created by "doubling” the radial and axial meshes eliminates any power generation due to an averaging of adjacent MCNP regions.

The addition of duplicate radial (r) and axial (z) zones required that the HSSHTC arrays and "loop indices" be increased from the values in the original code. The number of radial intervals was increased from 15 to 30, and the number of axial intervals was increased from 40 to 50. This "MCNP input scheme" was verified to be accurate by observing the results of the volume integrated power density profile-that integration encoded in the HSSHTC — and by replicating HEU fuel results generated with the original, unmodified code.

It is noteworthy that in the maximum operating power search portion of the HSSHTC code, the search is over mesh points rather than spatial intervals, resulting in the possibility that the maximum power will be determined to be located at a position of zero volume. The HSSHTC could be re-coded to avoid this problem, but the second author's observation of the HSSHTC output showed that re-coding to ignore zero-volume intervals would have no significant impact on the conclusions presented in this report. 


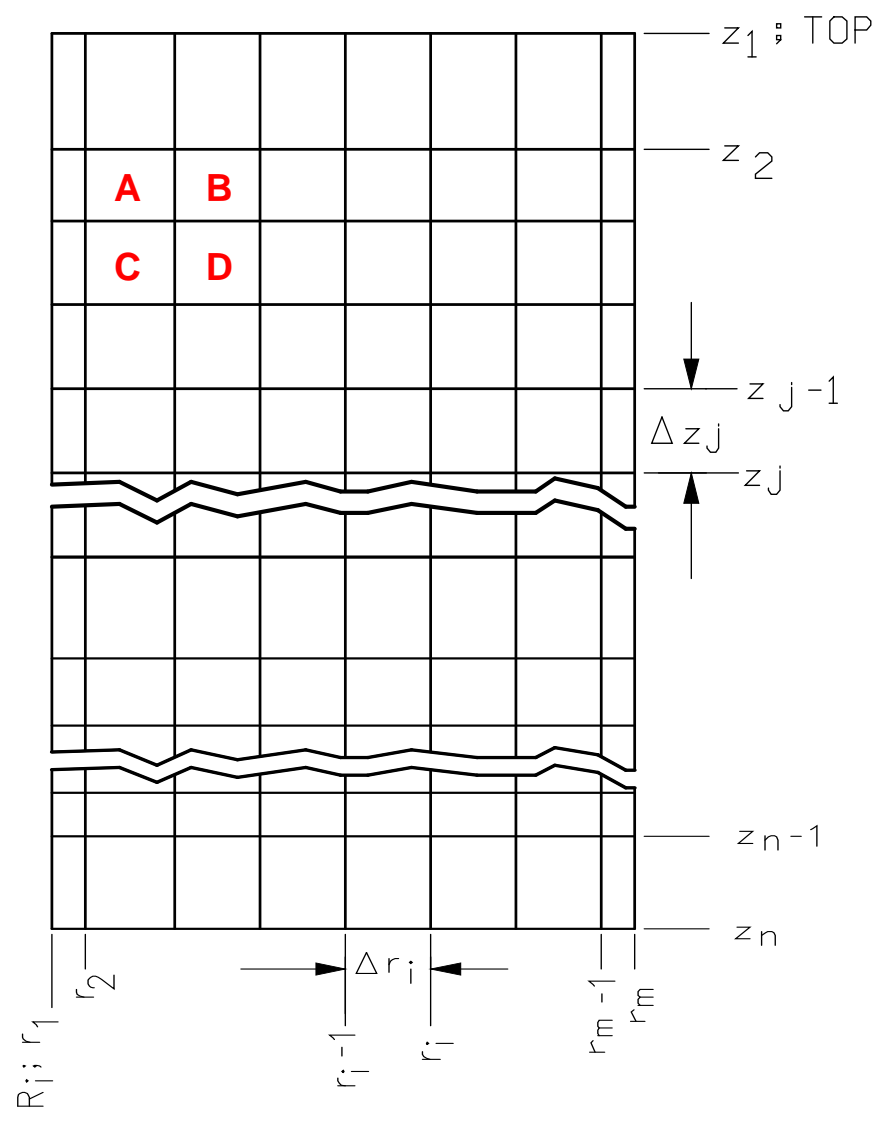

Fig. D.1. Mapping MCNP zones to an HSSHTC mesh. 


\section{APPENDIX E. FISSION DENSITY DISTRIBUTIONS FOR LEU CORE}

The relative fission density data in the LEU fuel elements at days 1, 5, 10, 15, 20, and 23 during the 26 day irradiation cycle are presented in Tables E.1 to E.6. The relative fission densities at BOC and EOC are shown in Tables 5 and 6 of Section 5.1.2. 
Table E.1. Relative fission density for HFIR LEU at 1 day irradiation

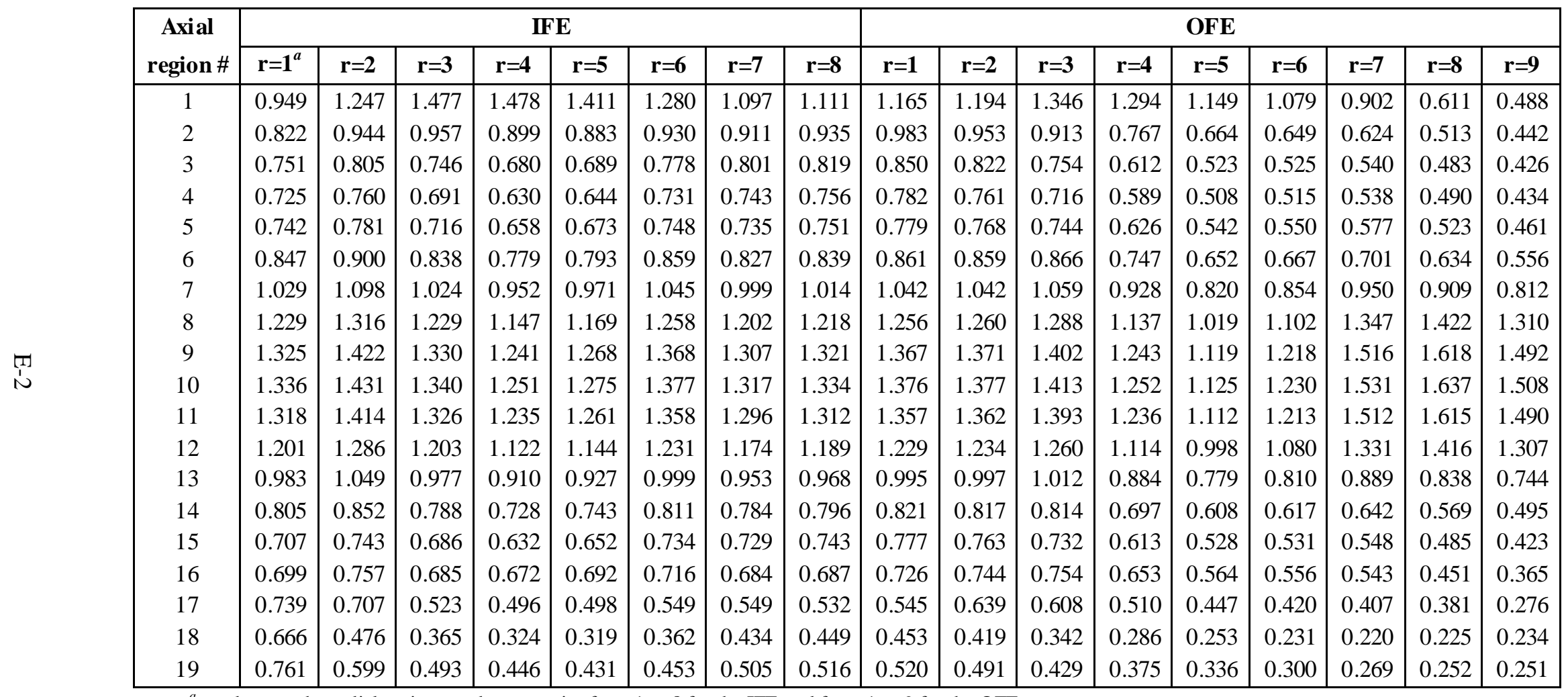

${ }^{a} \mathrm{r}=\mathrm{n}$ denotes the radial region number; $\mathrm{n}$ varies from 1 to 8 for the IFE and from 1 to 9 for the OFE. 
Table E.2. Relative fission density for HFIR LEU at 5 days irradiation

\begin{tabular}{|c|c|c|c|c|c|c|c|c|c|c|c|c|c|c|c|c|c|}
\hline \multirow{2}{*}{$\begin{array}{c}\text { Axial } \\
\text { region \# }\end{array}$} & \multicolumn{8}{|c|}{ IFE } & \multicolumn{9}{|c|}{ OFE } \\
\hline & $\mathrm{r}=1^{a}$ & $r=2$ & $r=3$ & $r=4$ & $r=5$ & $r=6$ & $\mathrm{r}=7$ & $r=8$ & $r=1$ & $r=2$ & $r=3$ & $r=4$ & $r=5$ & $r=6$ & $r=7$ & $r=8$ & $r=9$ \\
\hline \multirow{11}{*}{ } & 0.928 & 1.252 & 1.479 & 1.471 & 1.403 & 1.269 & 1.079 & 1.085 & 1.141 & 1.169 & 1.338 & 1.308 & 1.166 & 1.107 & 0.942 & 0.656 & 0.525 \\
\hline & 0.816 & 0.963 & 0.973 & 0.900 & 0.881 & 0.929 & 0.903 & 0.928 & 0.962 & 0.942 & 0.909 & 0.774 & 0.673 & 0.662 & 0.650 & 0.543 & 0.467 \\
\hline & 0.726 & 0.782 & 0.705 & 0.634 & 0.647 & 0.730 & 0.735 & 0.752 & 0.778 & 0.756 & 0.713 & 0.586 & 0.507 & 0.516 & 0.545 & 0.496 & 0.438 \\
\hline & 0.743 & 0.804 & 0.731 & 0.662 & 0.674 & 0.746 & 0.733 & 0.746 & 0.770 & 0.756 & 0.739 & 0.622 & 0.541 & 0.552 & 0.580 & 0.525 & 0.460 \\
\hline & 0.843 & 0.924 & 0.853 & 0.782 & 0.792 & 0.854 & 0.815 & 0.829 & 0.852 & 0.848 & 0.856 & 0.743 & 0.651 & 0.670 & 0.715 & 0.651 & 0.573 \\
\hline & 1.295 & 1.461 & 1.359 & 1.240 & 1.256 & 1.343 & 1.265 & 1.289 & 1.327 & 1.326 & 1.368 & 1.212 & 1.090 & 1.192 & 1.491 & 1.563 & 1.424 \\
\hline & 1.301 & 1.471 & 1.363 & 1.245 & 1.266 & 1.353 & 1.273 & 1.297 & 1.335 & 1.335 & 1.378 & 1.221 & 1.098 & 1.201 & 1.503 & 1.573 & 1.436 \\
\hline & 1.288 & 1.451 & 1.351 & 1.230 & 1.247 & 1.334 & 1.260 & 1.283 & 1.320 & 1.317 & 1.361 & 1.207 & 1.084 & 1.187 & 1.486 & 1.556 & 1.419 \\
\hline & 1.183 & 1.325 & 1.230 & 1.121 & 1.135 & 1.217 & 1.150 & 1.171 & 1.203 & 1.201 & 1.238 & 1.095 & 0.984 & 1.074 & 1.339 & 1.409 & 1.287 \\
\hline & 0.981 & 1.085 & 1.003 & 0.915 & 0.928 & 0.995 & 0.942 & 0.960 & 0.987 & 0.984 & 1.006 & 0.883 & 0.786 & 0.836 & 0.979 & 0.982 & 0.889 \\
\hline & 0.809 & 0.881 & 0.809 & 0.736 & 0.746 & 0.812 & 0.783 & 0.796 & 0.820 & 0.814 & 0.814 & 0.700 & 0.612 & 0.627 & 0.661 & 0.591 & 0.516 \\
\hline 19 & 0.761 & 0.615 & 0.509 & 0.458 & 0.443 & 0.462 & 0.509 & 0.520 & 0.514 & 0.487 & 0.429 & 0.380 & 0.345 & 0.316 & 0.292 & 0.282 & 0.285 \\
\hline
\end{tabular}

${ }^{a} \mathrm{r}=\mathrm{n}$ denotes the radial region number; $\mathrm{n}$ varies from 1 to 8 for the IFE and from 1 to 9 for the OFE. 
Table E.3. Relative fission density for HFIR LEU at 10 days irradiation

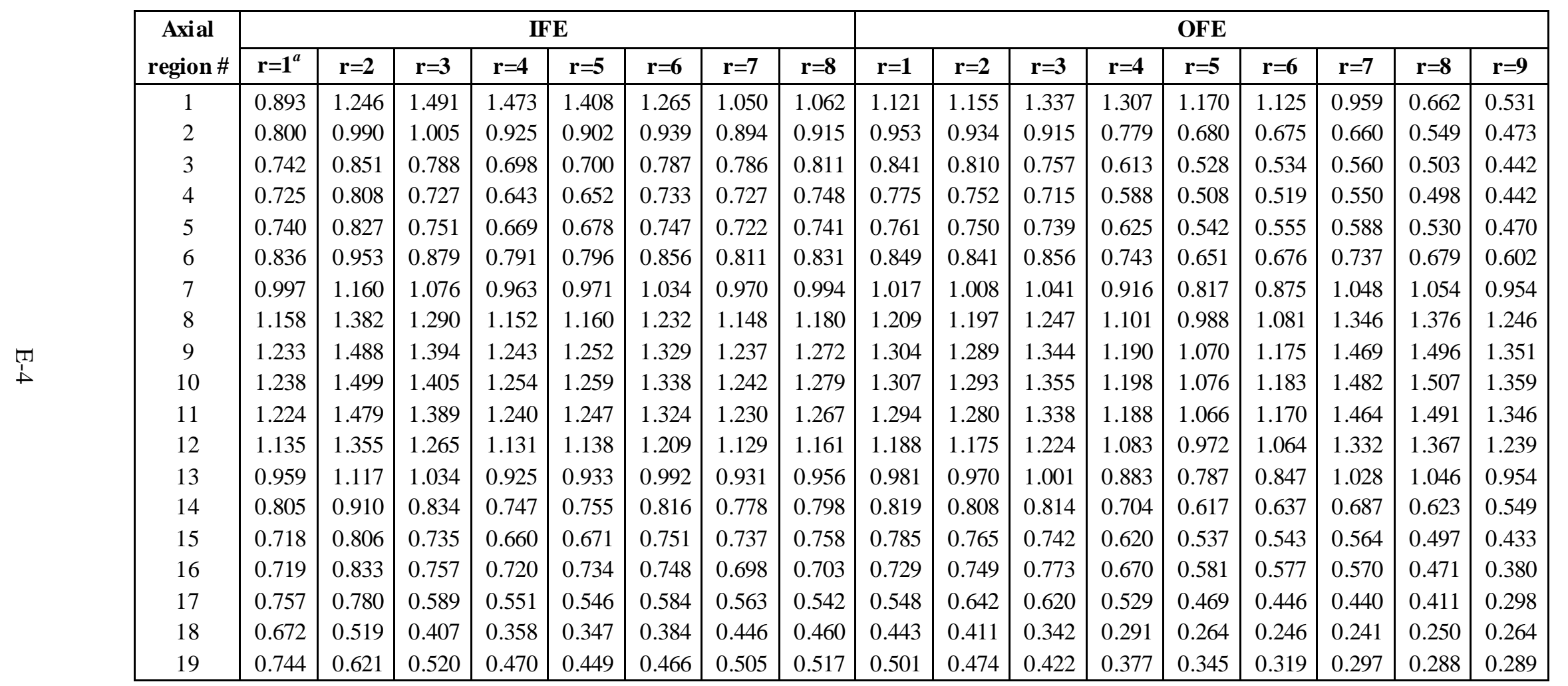

${ }^{a} \mathrm{r}=\mathrm{n}$ denotes the radial region number; $\mathrm{n}$ varies from 1 to 8 for the IFE and from 1 to 9 for the OFE. 
Table E.4. Relative fission density for HFIR LEU at 15 days irradiation

\begin{tabular}{|c|c|c|c|c|c|c|c|c|c|c|c|c|c|c|c|c|c|}
\hline \multirow{2}{*}{$\begin{array}{c}\text { Axial } \\
\text { region \# }\end{array}$} & \multicolumn{8}{|c|}{ IFE } & \multicolumn{9}{|c|}{ OFE } \\
\hline & $\mathrm{r}=1^{a}$ & $r=2$ & $r=3$ & $r=4$ & $r=5$ & $r=6$ & $r=7$ & $r=8$ & $r=1$ & $r=2$ & $r=3$ & $r=4$ & $r=5$ & $r=6$ & $r=7$ & $r=8$ & $r=9$ \\
\hline 1 & 0.845 & 1.228 & 1.495 & 1.482 & & 1.259 & & & 1.104 & & & & & & & 0.684 & 0.547 \\
\hline 2 & 0.772 & 0.997 & 1.032 & 0.942 & 0.917 & 0.951 & 0.888 & 0.915 & 0.953 & 0.932 & 0.924 & 0.794 & 0.690 & 0.690 & 0.682 & 0.567 & 0.489 \\
\hline 3 & 0.727 & 0.871 & 0.814 & 0.714 & 0.713 & 0.799 & 0.786 & 0.811 & 0.837 & 0.808 & 0.763 & 0.621 & 0.536 & 0.546 & 0.576 & 0.521 & 0.462 \\
\hline 4 & 0.711 & 0.830 & 0.749 & 0.657 & 0.661 & 0.743 & 0.727 & 0.750 & 0.771 & 0.750 & 0.722 & 0.595 & 0.513 & 0.528 & 0.569 & 0.518 & 0.462 \\
\hline 5 & 0.726 & 0.847 & 0.774 & 0.680 & 0.684 & 0.752 & 0.722 & 0.744 & 0.765 & 0.748 & 0.742 & 0.630 & 0.548 & 0.567 & 0.611 & 0.559 & 0.499 \\
\hline 6 & 0.810 & 0.967 & 0.898 & 0.798 & & 0.856 & & 0.829 & 0.848 & 0.833 & 0.854 & & & & 0.796 & 0.766 & 0.693 \\
\hline 7 & 0.948 & 1.167 & 1.096 & 0.970 & 0.970 & & & & 1.011 & 0.990 & & & & & & & 1.003 \\
\hline 8 & 1.077 & 1.371 & 1.306 & 1.152 & 1.152 & 1.216 & 1.119 & 1.162 & 1.191 & 1.164 & 1.225 & 1.087 & 0.977 & 1.075 & 1.343 & 1.342 & 1.207 \\
\hline 9 & 1.133 & 1.469 & 1.411 & 1.242 & 1.242 & 1.304 & 1.196 & 1.246 & 1.275 & 1.245 & 1.317 & 1.170 & 1.051 & 1.159 & 1.453 & 1.436 & 1.285 \\
\hline 10 & 1.137 & 1.479 & 1.419 & 1.249 & 1.246 & 1.313 & 1.205 & 1.252 & 1.281 & 1.252 & 1.326 & 1.178 & 1.058 & 1.166 & 1.461 & 1.440 & 1.285 \\
\hline 11 & 1.125 & 1.460 & 1.402 & 1.234 & 1.233 & 1.298 & 1.189 & 1.237 & 1.273 & 1.242 & 1.312 & 1.164 & 1.047 & 1.155 & 1.446 & 1.430 & 1.280 \\
\hline 12 & 1.057 & 1.348 & 1.284 & 1.132 & 1.131 & 1.193 & 1.099 & 1.141 & 1.171 & 1.145 & 1.206 & 1.069 & 0.960 & 1.058 & 1.328 & 1.330 & 1.197 \\
\hline 13 & 0.915 & 1.126 & 1.055 & 0.933 & 0.937 & 0.991 & 0.921 & 0.953 & 0.976 & 0.957 & 0.998 & 0.881 & 0.790 & 0.863 & 1.075 & 1.100 & 1.002 \\
\hline 14 & 0.785 & 0.931 & 0.858 & 0.757 & 0.762 & 0.823 & 0.779 & 0.802 & 0.823 & 0.806 & 0.822 & 0.710 & 0.627 & 0.662 & 0.759 & 0.731 & 0.658 \\
\hline 15 & 0.710 & 0.829 & 0.762 & 0.676 & 0.683 & 0.763 & 0.743 & 0.766 & 0.791 & 0.767 & 0.752 & 0.633 & 0.547 & 0.560 & 0.592 & 0.525 & 0.462 \\
\hline 16 & 0.713 & 0.862 & 0.791 & 0.750 & 0.756 & 0.767 & 0.705 & 0.716 & 0.737 & 0.754 & 0.789 & 0.685 & 0.597 & 0.597 & 0.593 & 0.490 & 0.398 \\
\hline 17 & 0.750 & 0.807 & 0.619 & 0.578 & 0.570 & 0.602 & 0.568 & 0.548 & 0.548 & 0.642 & 0.629 & 0.540 & 0.481 & 0.461 & 0.455 & 0.425 & 0.309 \\
\hline 18 & 0.652 & 0.526 & 0.421 & 0.373 & 0.360 & 0.392 & 0.445 & 0.459 & 0.438 & 0.405 & 0.343 & 0.295 & 0.269 & 0.251 & 0.247 & 0.258 & 0.273 \\
\hline 19 & 0.711 & 0.611 & 0.522 & 0.477 & 0.456 & 0.467 & 0.502 & 0.512 & 0.490 & 0.464 & 0.419 & 0.376 & 0.346 & 0.323 & 0.305 & 0.295 & 0.299 \\
\hline
\end{tabular}

${ }^{a} \mathrm{r}=\mathrm{n}$ denotes the radial region number; $\mathrm{n}$ varies from 1 to 8 for the IFE and from 1 to 9 for the OFE. 
Table E.5. Relative fission density for HFIR LEU at 20 days irradiation

\begin{tabular}{|c|c|c|c|c|c|c|c|c|c|c|c|c|c|c|c|c|c|}
\hline \multirow[t]{2}{*}{ Axial } & \multicolumn{8}{|c|}{ IFE } & \multicolumn{9}{|c|}{ OFE } \\
\hline & $\mathbf{r}=1^{a}$ & $r=2$ & $r=3$ & $r=4$ & $r=5$ & $r=6$ & $r=7$ & $r=8$ & $r=1$ & $r=2$ & $r=3$ & $r=4$ & $r=5$ & $r=6$ & $r=7$ & $r=8$ & $r=9$ \\
\hline 1 & 0.794 & 1.198 & 1.493 & 1.487 & 1.423 & 1.261 & 1.023 & 1.038 & 1.092 & 1.127 & 1.348 & 1.352 & 1.224 & 1.192 & 1.045 & 0.733 & 0.592 \\
\hline 2 & 0.741 & 1.001 & 1.057 & 0.963 & 0.938 & 0.964 & 0.883 & 0.907 & 0.949 & 0.929 & 0.942 & 0.815 & 0.716 & 0.722 & 0.730 & 0.617 & 0.534 \\
\hline 4 & 0.688 & 0.838 & 0.767 & 0.666 & 0.671 & 0.750 & 0.727 & 0.756 & 0.779 & 0.752 & 0.730 & 0.605 & 0.528 & 0.556 & 0.629 & 0.602 & 0.542 \\
\hline 5 & 0.700 & 0.854 & 0.788 & 0.692 & 0.694 & 0.758 & 0.722 & 0.750 & 0.767 & 0.745 & 0.751 & 0.640 & 0.564 & 0.600 & 0.698 & 0.684 & 0.622 \\
\hline 6 & 0.773 & 0.967 & 0.910 & 0.802 & 0.803 & 0.856 & 0.797 & 0.827 & 0.850 & 0.830 & 0.860 & 0.755 & 0.673 & 0.731 & 0.899 & 0.919 & 0.843 \\
\hline 9 & 1.015 & 1.415 & 1.408 & 1.228 & 1.218 & 1.271 & 1.151 & 1.209 & 1.239 & 1.198 & 1.285 & 1.144 & 1.029 & 1.140 & 1.432 & 1.373 & 1.221 \\
\hline 10 & 1.017 & 1.424 & 1.413 & 1.230 & 1.226 & 1.277 & 1.156 & 1.215 & 1.246 & 1.204 & 1.292 & 1.150 & 1.035 & 1.146 & 1.440 & 1.378 & 1.225 \\
\hline 11 & 1.010 & 1.410 & 1.400 & 1.220 & 1.211 & 1.264 & 1.146 & 1.205 & 1.237 & 1.195 & 1.278 & 1.137 & 1.024 & 1.135 & 1.427 & 1.369 & 1.217 \\
\hline 12 & 0.961 & 1.311 & 1.286 & 1.125 & 1.119 & 1.170 & 1.064 & 1.116 & 1.147 & 1.109 & 1.183 & 1.053 & 0.947 & 1.049 & 1.322 & 1.289 & 1.152 \\
\hline 13 & 0.857 & 1.116 & 1.069 & 0.937 & 0.936 & 0.986 & 0.907 & 0.947 & 0.971 & 0.944 & 0.995 & 0.883 & 0.794 & 0.876 & 1.109 & 1.122 & 1.018 \\
\hline 14 & 0.751 & 0.935 & 0.872 & 0.766 & 0.770 & 0.825 & 0.774 & 0.805 & 0.828 & 0.805 & 0.828 & 0.722 & 0.645 & 0.704 & 0.879 & 0.912 & 0.841 \\
\hline 19 & 0.664 & 0.592 & 0.518 & 0.476 & 0.457 & 0.466 & 0.492 & 0.505 & 0.480 & 0.456 & 0.415 & 0.378 & 0.352 & 0.331 & 0.316 & 0.314 & 0.322 \\
\hline
\end{tabular}

${ }^{a} \mathrm{r}=\mathrm{n}$ denotes the radial region number; $\mathrm{n}$ varies from 1 to 8 for the IFE and from 1 to 9 for the OFE. 
Table E.6. Relative fission density for HFIR LEU at 23 days irradiation

\begin{tabular}{|c|c|c|c|c|c|c|c|c|c|c|c|c|c|c|c|c|c|}
\hline Axial & & & & IF & & & & & & & & & OFE & & & & \\
\hline region \# & $\mathrm{r}=1^{a}$ & $r=2$ & $r=3$ & $r=4$ & $r=5$ & $r=6$ & $r=7$ & $r=8$ & $r=1$ & $r=2$ & $r=3$ & $r=4$ & $r=5$ & $r=6$ & $r=7$ & $r=8$ & $r=9$ \\
\hline 1 & 0.767 & 1.182 & 1.495 & 1.495 & 1.436 & 1.271 & 1.019 & 1.032 & 1.093 & 1.132 & 1.373 & 1.386 & 1.273 & 1.258 & 1.143 & 0.839 & 0.692 \\
\hline 2 & 0.719 & 1.001 & 1.072 & 0.973 & 0.949 & 0.977 & 0.890 & 0.917 & 0.955 & 0.940 & 0.961 & 0.836 & 0.745 & 0.765 & 0.821 & 0.733 & 0.648 \\
\hline 3 & 0.684 & 0.885 & 0.850 & 0.739 & 0.738 & 0.822 & 0.792 & 0.816 & 0.847 & 0.820 & 0.793 & 0.653 & 0.571 & 0.609 & 0.723 & 0.722 & 0.658 \\
\hline 4 & 0.670 & 0.841 & 0.781 & 0.673 & 0.681 & 0.760 & 0.735 & 0.761 & 0.786 & 0.758 & 0.743 & 0.621 & 0.547 & 0.594 & 0.734 & 0.766 & 0.709 \\
\hline 5 & 0.685 & 0.858 & 0.798 & 0.694 & 0.699 & 0.765 & 0.728 & 0.753 & 0.772 & 0.750 & 0.758 & 0.653 & 0.581 & 0.635 & 0.801 & 0.843 & 0.783 \\
\hline 6 & 0.747 & 0.965 & 0.918 & 0.805 & 0.806 & 0.858 & 0.795 & 0.828 & 0.852 & 0.828 & 0.863 & 0.762 & 0.684 & 0.752 & 0.957 & 0.994 & 0.914 \\
\hline 7 & 0.843 & 1.136 & 1.108 & 0.967 & 0.964 & 1.011 & 0.921 & 0.966 & 0.992 & 0.961 & 1.022 & 0.909 & 0.819 & 0.907 & 1.148 & 1.144 & 1.035 \\
\hline 8 & 0.917 & 1.301 & 1.302 & 1.132 & 1.124 & 1.169 & 1.057 & 1.114 & 1.148 & 1.102 & 1.185 & 1.056 & 0.950 & 1.055 & 1.331 & 1.277 & 1.136 \\
\hline 9 & 0.944 & 1.371 & 1.393 & 1.212 & 1.200 & 1.245 & 1.121 & 1.185 & 1.216 & 1.164 & 1.259 & 1.125 & 1.013 & 1.124 & 1.413 & 1.330 & 1.178 \\
\hline 10 & 0.946 & 1.378 & 1.401 & 1.218 & 1.205 & 1.249 & 1.124 & 1.187 & 1.223 & 1.172 & 1.266 & 1.129 & 1.018 & 1.129 & 1.421 & 1.337 & 1.183 \\
\hline 11 & 0.941 & 1.366 & 1.389 & 1.203 & 1.193 & 1.238 & 1.112 & 1.177 & 1.210 & 1.161 & 1.255 & 1.120 & 1.010 & 1.121 & 1.410 & 1.328 & 1.174 \\
\hline 12 & 0.903 & 1.279 & 1.281 & 1.115 & 1.107 & 1.152 & 1.040 & 1.098 & 1.129 & 1.086 & 1.166 & 1.039 & 0.936 & 1.040 & 1.314 & 1.261 & 1.122 \\
\hline 13 & 0.817 & 1.102 & 1.072 & 0.935 & 0.932 & 0.979 & 0.897 & 0.938 & 0.965 & 0.934 & 0.991 & 0.879 & 0.793 & 0.879 & 1.120 & 1.123 & 1.017 \\
\hline 14 & 0.729 & 0.934 & 0.884 & 0.772 & 0.773 & 0.829 & 0.774 & 0.805 & 0.835 & 0.806 & 0.833 & 0.729 & 0.655 & 0.726 & 0.935 & 0.982 & 0.906 \\
\hline 15 & 0.679 & 0.851 & 0.798 & 0.699 & 0.707 & 0.786 & 0.752 & 0.781 & 0.809 & 0.780 & 0.780 & 0.662 & 0.588 & 0.643 & 0.814 & 0.861 & 0.800 \\
\hline 16 & 0.686 & 0.890 & 0.842 & 0.794 & 0.800 & 0.802 & 0.715 & 0.728 & 0.753 & 0.772 & 0.826 & 0.731 & 0.651 & 0.689 & 0.793 & 0.765 & 0.654 \\
\hline 17 & 0.714 & 0.828 & 0.660 & 0.617 & 0.609 & 0.629 & 0.579 & 0.558 & 0.551 & 0.650 & 0.655 & 0.577 & 0.528 & 0.528 & 0.571 & 0.591 & 0.450 \\
\hline 18 & 0.606 & 0.519 & 0.433 & 0.387 & 0.376 & 0.402 & 0.445 & 0.459 & 0.436 & 0.404 & 0.350 & 0.309 & 0.289 & 0.280 & 0.292 & 0.327 & 0.357 \\
\hline 19 & 0.638 & 0.578 & 0.515 & 0.475 & 0.458 & 0.465 & 0.494 & 0.507 & 0.481 & 0.455 & 0.417 & 0.386 & 0.365 & 0.350 & 0.347 & 0.355 & 0.370 \\
\hline
\end{tabular}

${ }^{a} \mathrm{r}=\mathrm{n}$ denotes the radial region number; $\mathrm{n}$ varies from 1 to 8 for the IFE and from 1 to 9 for the OFE. 



\section{APPENDIX F. CALCULATION OF THE EFFECTIVE DELAYED NEUTRON FRACTION}

The traditional approach for calculation of the effective delayed neutron fraction $\beta_{\text {eff }}$ that involves an adjoint and spectrum weighting of the delayed neutron production rate has not been implemented in a Monte Carlo approach due to difficulty in adjoint calculation with continuous energy data. However, there have been various approaches developed that can be used with Monte Carlo methods, which do not involve adjoint calculation.

Starting with the definition of $\beta_{\text {eff }}$ as the ratio of the effective delayed neutron production rate and the effective neutron production rate by fission (Eq. 1), there have been different approximations to estimate the quantities involved within a eigenvalue (kcode) mode Monte Carlo calculation. ${ }^{32,33}$ A summary of these methods is presented in Ref. 33 along with a comparison to experimental data of results calculated with these methods. One of the mentioned approaches, called "prompt method"33 or "k-ratio method,"34,35 can be used with a standard Monte Carlo kcode calculation.

$$
\beta_{\text {eff }}=\frac{P_{d, e f f}}{P_{e f f}}=\frac{\int \psi\left(\vec{r}, E^{\prime} \Omega^{\prime}\right) \chi_{d}\left(E^{\prime}\right) v_{d}(E) \Sigma_{f}(\vec{r}, E) \phi(\vec{r}, E, \Omega) d E d \Omega d E^{\prime} d \Omega^{\prime} d \vec{r}}{\int \psi\left(\vec{r}, E^{\prime} \Omega^{\prime}\right) \chi\left(E^{\prime}\right) v(E) \Sigma_{f}(\vec{r}, E) \phi(\vec{r}, E, \Omega) d E d \Omega d E^{\prime} d \Omega^{\prime} d \vec{r}}=\frac{\left\langle\chi_{d} v_{d}\right\rangle}{\langle\chi v\rangle}
$$

The k-ratio method approximates $\beta_{\text {eff }}$ from Eq. (1) as follows:

$$
\beta_{e f f}=\frac{\left\langle\chi_{d} v_{d}\right\rangle}{\langle\chi v\rangle}=1-\frac{\left\langle\chi v_{p}-\left(\chi_{d}-\chi\right) v_{d}\right\rangle}{\langle\chi v\rangle} \approx 1-\frac{\left\langle\chi_{p} v_{p}\right\rangle}{\langle\chi v\rangle} \approx 1-\frac{k_{p}}{k}
$$

where indices $p$ and $d$ stand for prompt and delayed, respectively. The values $k_{p}$ and $k$ can be estimated from two MCNP kcode criticality calculations, one in which only the prompt neutrons are included in the simulation and one in which both prompt and delayed neutrons are included in the simulation. For the first case the "totnu no" card needs be included in the MCNP input file. The default value in MCNP is that both (prompt plus delayed) types of neutrons are considered.

The k-ratio approximation might be considered reasonable. The average calculated-to-experimental (C/E) ratio reported in Ref. 33 for the k-ratio method over a set of eight experiments is approximately $1.014 \pm 0.045$ (ENDF/B-VI.8 cross section used). Note that the corresponding average C/E calculated ${ }^{33}$ with the other two methods are $0.964 \pm 0.050$ and $1.230 \pm 0.367$, respectively. 



\section{APPENDIX G. GAMMA SOURCE SPECTRA FROM DISCHARGED LEU FUEL}

To provide estimates of the decay gamma (and decay heat) following irradiation of LEU fuel, calculations were carried out to determine concentrations and source terms at specified decay times. While it would be possible to generate a spatially dependent gamma source, homogeneously distributing sources noted below throughout the HFIR elements should provide sufficient accuracy to demonstrate the level of security protection and to accurately estimate shielding requirements for storage and transportation.

\section{G.1 INNER FUEL ELEMENT}

Gamma source strengths at various times following the shutdown of the reactor for the LEU-fueled inner element are provided in Tables G.1 and G.2. The gamma source is for the entire inner element, the element having been irradiated at a reactor power of $100 \mathrm{MW}$ for 26 days.

\section{G.2 OUTER FUEL ELEMENT}

Gamma source strengths at various times following the shutdown of the reactor for the LEU-fueled outer element are provided in Tables G.3 and G.4. The gamma source is for the entire outer element, the element having been irradiated at a reactor power of $100 \mathrm{MW}$ for 26 days. 
Table G.1. Decay gamma spectra for LEU, inner element for times up to 1 day (energy boundaries in MeV)

\begin{tabular}{|c|c|c|c|c|c|c|c|c|c|c|c|c|}
\hline Grp & Upper bdy & Lower bdy & $0.0 \mathrm{~s}$ & $10.0 \mathrm{~s}$ & $30.0 \mathrm{~s}$ & 100.0s & $300.0 \mathrm{~s}$ & $1000.0 \mathrm{~s}$ & $3000.0 \mathrm{~s}$ & $10000.0 \mathrm{~s}$ & $30000.0 \mathrm{~s}$ & $86400.0 \mathrm{~s}$ \\
\hline 1 & 1.00E-02 & $5.00 \mathrm{E}-02$ & $3.97 \mathrm{E}+18$ & $2.26 \mathrm{E}+18$ & $1.59 \mathrm{E}+18$ & $1.32 \mathrm{E}+18$ & $1.12 \mathrm{E}+18$ & $8.98 \mathrm{E}+17$ & $6.90 \mathrm{E}+17$ & $5.18 \mathrm{E}+17$ & $4.00 E+17$ & $2.91 E+17$ \\
\hline 3 & $1.00 \mathrm{E}-01$ & 2.00E-01 & $1.94 \mathrm{E}+18$ & $1.09 \mathrm{E}+18$ & $7.98 \mathrm{E}+17$ & $6.64 \mathrm{E}+17$ & $5.73 E+17$ & $4.69 \mathrm{E}+17$ & $3.68 \mathrm{E}+17$ & $2.80 \mathrm{E}+17$ & $2.26 \mathrm{E}+17$ & 1.76E +17 \\
\hline 4 & 2.00E-01 & 3.00E-01 & $.13 E+18$ & $6.92 \mathrm{E}+17$ & $5.29 \mathrm{E}+17$ & $4.32 E+17$ & $3.64 \mathrm{E}+17$ & $2.95 \mathrm{E}+17$ & $2.34 \mathrm{E}+17$ & $1.96 \mathrm{E}+17$ & $1.74 \mathrm{E}+17$ & $.32 \mathrm{E}+17$ \\
\hline 5 & 3.00E-01 & 4.00E-01 & $9.51 E+17$ & $5.90 \mathrm{E}+17$ & $4.56 \mathrm{E}+17$ & $3.64 E+17$ & $2.93 E+17$ & $2.16 \mathrm{E}+17$ & $1.29 \mathrm{E}+17$ & $8.05 E+16$ & $6.42 \mathrm{E}+16$ & $5.24 \mathrm{E}+16$ \\
\hline 6 & 4.00E-01 & $6.00 \mathrm{E}-01$ & $1.71 \mathrm{E}+18$ & $1.03 E+18$ & $7.99 \mathrm{E}+17$ & $6.49 \mathrm{E}+17$ & $5.37 \mathrm{E}+17$ & 4.19E+17 & $3.10 \mathrm{E}+17$ & $2.18 \mathrm{E}+17$ & $1.65 \mathrm{E}+17$ & 1.12E+17 \\
\hline 7 & 6.00E-01 & 8.00E-01 & $1.30 \mathrm{E}+18$ & $9.11 \mathrm{E}+17$ & $7.51 E+17$ & $6.14 \mathrm{E}+17$ & $5.09 E+17$ & $4.16 \mathrm{E}+17$ & $3.42 E+17$ & $2.69 \mathrm{E}+17$ & $2.16 \mathrm{E}+17$ & $1.61 E+17$ \\
\hline 8 & 8.00E-01 & $1.00 E+00$ & $1.11 \mathrm{E}+18$ & $7.25 E+17$ & $6.27 \mathrm{E}+17$ & $5.47 \mathrm{E}+17$ & $4.65 E+17$ & $3.55 E+17$ & $2.44 \mathrm{E}+17$ & $1.16 \mathrm{E}+17$ & +16 & $3.63 E+16$ \\
\hline 9 & $1.00 \mathrm{E}+00$ & $1.33 \mathrm{E}+00$ & $8.88 \mathrm{E}+17$ & $5.82 E+17$ & $4.69 E+17$ & 3.72E+17 & $2.93 E+17$ & $2.08 \mathrm{E}+17$ & $1.31 \mathrm{E}+17$ & $7.90 \mathrm{E}+16$ & 4.37E+16 & $1.61 E+16$ \\
\hline 10 & $1.33 E+00$ & $1.66 \mathrm{E}+00$ & $6.68 \mathrm{E}+17$ & $4.65 E+17$ & $3.87 E+17$ & $3.13 E+17$ & $2.56 \mathrm{E}+17$ & 2.15E+17 & $1.65 E+17$ & $1.02 E+17$ & 6.77E+16 & $5.51 E+16$ \\
\hline 11 & $1.66 \mathrm{E}+00$ & $2.00 \mathrm{E}+00$ & 4.14E+17 & $2.27 E+17$ & $1.63 \mathrm{E}+17$ & 1. $25 \mathrm{E}+17$ & $9.74 \mathrm{E}+16$ & $7.05 E+16$ & $4.57 E+16$ & $2.50 E+16$ & $1.05 E+16$ & $2.91 \mathrm{E}+15$ \\
\hline 12 & $2.00 E+00$ & $2.50 \mathrm{E}+00$ & $4.96 \mathrm{E}+17$ & $2.65 E+17$ & $1.83 \mathrm{E}+17$ & $1.38 \mathrm{E}+17$ & $1.09 \mathrm{E}+17$ & $7.97 \mathrm{E}+16$ & $4.88 \mathrm{E}+16$ & $2.14 E+16$ & $5.59 E+15$ & $1.32 E+15$ \\
\hline 13 & $2.50 E+00$ & $3.00 E+00$ & $4.35 E+17$ & $1.95 \mathrm{E}+17$ & 1.10E+17 & $7.17 E+16$ & $4.90 E+16$ & $3.31 E+16$ & $1.93 E+16$ & $7.24 E+15$ & $2.14 \mathrm{E}+15$ & $1.62 \mathrm{E}+15$ \\
\hline 14 & $3.00 \mathrm{E}+00$ & $4.00 E+00$ & $2.91 \mathrm{E}+17$ & 1. $23 \mathrm{E}+17$ & $6.68 \mathrm{E}+16$ & $4.03 E+16$ & $2.25 \mathrm{E}+16$ & $1.13 E+16$ & $5.19 E+15$ & $1.63 E+15$ & $1.56 \mathrm{E}+14$ & $1.38 \mathrm{E}+13$ \\
\hline 15 & $4.00 E+00$ & $5.00 \mathrm{E}+00$ & $5.62 E+16$ & $2.56 \mathrm{E}+16$ & $1.69 \mathrm{E}+16$ & $9.22 \mathrm{E}+15$ & $3.11 \mathrm{E}+15$ & $3.68 \mathrm{E}+14$ & $9.08 \mathrm{E}+13$ & $3.93 E+13$ & $9.74 \mathrm{E}+12$ & $2.13 E+11$ \\
\hline 16 & $5.00 \mathrm{E}+00$ & $6.50 \mathrm{E}+00$ & $1.20 \mathrm{E}+16$ & $4.87 E+15$ & $2.97 E+15$ & $1.35 \mathrm{E}+15$ & $3.01 E+14$ & $1.10 \mathrm{E}+13$ & $3.17 \mathrm{E}+11$ & $1.96 \mathrm{E}+11$ & $5.04 \mathrm{E}+10$ & 1.10E+09 \\
\hline 17 & $6.50 \mathrm{E}+00$ & $8.00 \mathrm{E}+00$ & $4.30 \mathrm{E}+14$ & $6.52 E+13$ & $3.08 E+13$ & $6.52 E+12$ & $4.55 \mathrm{E}+11$ & $6.82 \mathrm{E}+07$ & $8.01 E+01$ & $8.04 \mathrm{E}+01$ & $8.10 \mathrm{E}+01$ & $8.21 \mathrm{E}+01$ \\
\hline 18 & $8.00 E+00$ & $1.00 E+01$ & $2.79 E+12$ & $7.34 \mathrm{E}+10$ & $5.52 E+08$ & $1.33 E+07$ & $2.66 \mathrm{E}+03$ & $1.69 \mathrm{E}+01$ & $1.70 E+01$ & $1.70 E+01$ & $1.71 E+01$ & $1.74 \mathrm{E}+01$ \\
\hline totals & & & $1.70 \mathrm{E}+19$ & $1.02 \mathrm{E}+19$ & $7.63 E+18$ & $6.22 \mathrm{E}+18$ & $5.16 \mathrm{E}+18$ & $4.05 E+18$ & $2.99 \mathrm{E}+18$ & $2.08 \mathrm{E}+18$ & $1.56 \mathrm{E}+18$ & $1.13 \mathrm{E}+18$ \\
\hline
\end{tabular}


Table G.2. Decay gamma spectra for LEU, inner element for times up to 100 years (energy boundaries in MeV)

\begin{tabular}{|c|c|c|c|c|c|c|c|c|c|c|c|}
\hline Grp & & & & $0.1 y$ & & & & $10.0 y$ & $30.0 y$ & $50.0 y$ & \\
\hline 1 & & & & $.75 E+16$ & $.85 E+15$ & $.14 \mathrm{E}+15$ & $.35 E+14$ & & & & \\
\hline 2 & $5.00 \mathrm{E}-02$ & 1.00E-01 & $64 E+16$ & $.76 \mathrm{E}+15$ & $1.33 \mathrm{E}+15$ & $3.62 E+14$ & $7.35 \mathrm{E}+13$ & $1.41 \mathrm{E}+13$ & $.52 \mathrm{E}+12$ & $5.32 \mathrm{E}+12$ & $.70 \mathrm{E}+12$ \\
\hline 3 & 1.00E-01 & & & $.97 \mathrm{E}+15$ & $.36 \mathrm{E}+15$ & & & & & & \\
\hline 4 & 2.00E-01 & 3.00E-01 & $32 E+17$ & $.99 E+14$ & $3.09 E+14$ & $8.87 E+13$ & $1.76 \mathrm{E}+13$ & $3.01 \mathrm{E}+12$ & $1.80 \mathrm{E}+12$ & & $.33 E+11$ \\
\hline 5 & & & & 15 & $.42 \mathrm{E}+14$ & & & & & & \\
\hline 6 & 4.00E-01 & 6.00E-01 & 17 & $28 \mathrm{E}+16$ & $2.09 \mathrm{E}+15$ & $1.24 \mathrm{E}+14$ & -13 & $93 \mathrm{E}+12$ & & & +11 \\
\hline 7 & & & & 16 & & & & & & & \\
\hline 8 & 8.00E-01 & $.00 E+00$ & $63 E+16$ & $99 \mathrm{E}+15$ & $9.58 E+13$ & $.19 E+13$ & $7.45 E+12$ & $.83 E+11$ & $1.98 \mathrm{E}+$ & 11 & $3.09 E+10$ \\
\hline 9 & & & & $30 E+14$ & & & & & & & \\
\hline 10 & $1.33 \mathrm{E}+00$ & $1.66 \mathrm{E}$ & $51 E+16$ & $.09 E+15$ & $1.66 \mathrm{E}+14$ & $7.48 \mathrm{E}+12$ & $1.59 E+12$ & $75 E+10$ & 2.27 & & $E+09$ \\
\hline 11 & $1.66 \mathrm{E}+00$ & $2.00 E+00$ & $.91 E+15$ & $39 t+13$ & $2.57 \mathrm{E}+12$ & $1.21 \mathrm{E}+12$ & $2.42 \mathrm{E}+11$ & $6.48 \mathrm{E}+09$ & $3.30 E+09$ & & +08 \\
\hline 12 & $2.00 \mathrm{E}+00$ & $2.50 \mathrm{E}+00$ & $32 \mathrm{E}+15$ & $1.06 \mathrm{E}+14$ & $2.10 \mathrm{E}+13$ & $1.04 \mathrm{E}+13$ & $1.78 \mathrm{E}+12$ & 4.24E+09 & 1.69 & & +07 \\
\hline 13 & $2.50 \mathrm{E}+00$ & $3.00 E+00$ & $62 E+15$ & $2.62 \mathrm{E}+14$ & $5.01 \mathrm{E}+12$ & $4.29 E+10$ & $1.02 \mathrm{E}+10$ & $7.86 \mathrm{E}+07$ & 8.37E+05 & 05 & $=+05$ \\
\hline 14 & $3.00 \mathrm{E}+00$ & $4.00 E+00$ & $1.38 \mathrm{E}+13$ & $2.13 E+12$ & $4.51 \mathrm{E}+10$ & $3.13 E+09$ & $8.07 E+08$ & $7.03 E+06$ & $2.13 E+03$ & r03 & $E+03$ \\
\hline 15 & $4.00 \mathrm{E}+00$ & $5.00 \mathrm{E}+00$ & $2.13 E+11$ & $1.05 E+03$ & $9.89 \mathrm{E}+02$ & $8.86 \mathrm{E}+02$ & $8.24 \mathrm{E}+02$ & $7.78 \mathrm{E}+02$ & $6.97 \mathrm{E}+02$ & $6.56 \mathrm{E}+02$ & $3 \mathrm{E}+02$ \\
\hline 16 & $5.00 \mathrm{E}+00$ & $6.50 \mathrm{E}+00$ & 1.10E+09 & $4.16 \mathrm{E}+02$ & $3.94 \mathrm{E}+02$ & $3.52 E+02$ & $3.27 E+02$ & $3.08 \mathrm{E}+02$ & $2.75 \mathrm{E}+02$ & $2.58 \mathrm{E}+02$ & $2.43 \mathrm{E}+02$ \\
\hline 17 & $6.50 \mathrm{E}+00$ & $8.00 E+00$ & $8.21 \mathrm{E}+01$ & $8.10 E+01$ & $7.67 \mathrm{E}+01$ & $6.86 \mathrm{E}+01$ & $6.36 \mathrm{E}+01$ & $5.97 \mathrm{E}+01$ & $5.30 \mathrm{E}+01$ & $4.97 \mathrm{E}+01$ & 4. $67 \mathrm{E}+01$ \\
\hline 18 & $8.00 \mathrm{E}+00$ & $1.00 \mathrm{E}+01$ & $1.74 \mathrm{E}+01$ & $1.71 \mathrm{E}+01$ & $1.62 \mathrm{E}+01$ & $1.45 \mathrm{E}+01$ & $1.34 \mathrm{E}+01$ & $1.26 \mathrm{E}+01$ & $1.11 \mathrm{E}+01$ & $1.04 \mathrm{E}+01$ & $9.79 \mathrm{E}+00$ \\
\hline totals & & & $1.13 \mathrm{E}+18$ & $8.26 \mathrm{E}+16$ & $2.54 \mathrm{E}+16$ & $3.49 E+15$ & $5.67 E+14$ & $1.54 \mathrm{E}+14$ & $9.15 \mathrm{E}+13$ & $5.71 \mathrm{E}+13$ & $1.78 \mathrm{E}+13$ \\
\hline
\end{tabular}


Table G.3. Decay gamma spectra for LEU, outer element for times up to 1 day (energy boundaries in MeV)

\begin{tabular}{|c|c|c|c|c|c|c|c|c|c|c|c|c|}
\hline Grp & Upper bdy & Lower bdy & $0.0 \mathrm{~s}$ & 10.0s & $30.0 \mathrm{~s}$ & 100.0s & 300.0s & 1000.0s & 3000.0s & 10000.0s & 30000.0s & 86400.0s \\
\hline 1 & 1.00E-02 & 5.00E-02 & $7.54 \mathrm{E}+18$ & $4.29 E+18$ & $3.01 \mathrm{E}+18$ & $2.51 E+18$ & $2.14 \mathrm{E}+18$ & 1.71E+18 & $1.31 \mathrm{E}+18$ & $9.84 \mathrm{E}+17$ & $7.60 E+17$ & $5.53 E+17$ \\
\hline 2 & 5.00E-02 & 1.00E-01 & $3.17 \mathrm{E}+18$ & $1.84 \mathrm{E}+18$ & $1.31 \mathrm{E}+18$ & $1.08 \mathrm{E}+18$ & $9.00 \mathrm{E}+17$ & $6.96 \mathrm{E}+17$ & $4.81 \mathrm{E}+17$ & $3.22 E+17$ & $2.46 \mathrm{E}+17$ & $1.82 E+17$ \\
\hline 3 & 1.00E-01 & 2.00E-01 & $3.68 \mathrm{E}+18$ & $2.08 \mathrm{E}+18$ & $1.52 \mathrm{E}+18$ & 1.27E+18 & 1.10E+18 & $8.99 E+17$ & $7.09 \mathrm{E}+17$ & $5.43 E+17$ & $4.39 E+17$ & $3.41 E+17$ \\
\hline 4 & 2.00E-01 & 3.00E-01 & $2.15 E+18$ & 1.32E+18 & $1.02 E+18$ & $8.32 E+17$ & $7.02 E+17$ & $5.72 E+17$ & 4.57E+17 & $3.84 \mathrm{E}+17$ & $3.40 \mathrm{E}+17$ & $2.55 E+17$ \\
\hline 5 & 3.00E-01 & 4.00E-01 & $1.80 E+18$ & $1.11 \mathrm{E}+18$ & 8.60E+17 & $6.86 E+17$ & $5.53 E+17$ & $4.06 \mathrm{E}+17$ & $2.44 \mathrm{E}+17$ & $1.51 \mathrm{E}+17$ & $1.21 \mathrm{E}+17$ & $9.83 E+16$ \\
\hline 6 & 4.00E-01 & 6.00E-01 & $3.23 E+18$ & $1.93 E+18$ & $1.51 \mathrm{E}+18$ & $1.22 \mathrm{E}+18$ & $1.01 \mathrm{E}+18$ & $7.87 E+17$ & $5.82 E+17$ & $4.08 \mathrm{E}+17$ & $3.09 E+17$ & $2.09 E+17$ \\
\hline 7 & 6.00E-01 & 8.00E-01 & $2.45 E+18$ & $1.72 \mathrm{E}+18$ & $1.41 \mathrm{E}+18$ & 1.15E+18 & $9.56 \mathrm{E}+17$ & $7.80 \mathrm{E}+17$ & $6.39 E+17$ & $5.02 E+17$ & $4.04 \mathrm{E}+17$ & $2.99 E+17$ \\
\hline 8 & 8.00E-01 & $1.00 E+00$ & $2.10 \mathrm{E}+18$ & 1.37E+18 & $1.18 \mathrm{E}+18$ & $1.03 E+18$ & $8.78 \mathrm{E}+17$ & $6.68 \mathrm{E}+17$ & $4.59 E+17$ & $2.18 \mathrm{E}+17$ & $9.92 E+16$ & $6.70 E+16$ \\
\hline 9 & $1.00 E+00$ & $1.33 E+00$ & $1.68 \mathrm{E}+18$ & 1.10E+18 & 8.87E+17 & $7.04 \mathrm{E}+17$ & $5.54 \mathrm{E}+17$ & $3.93 E+17$ & 2.47E+17 & $1.49 \mathrm{E}+17$ & $8.23 E+16$ & $3.02 E+16$ \\
\hline 10 & $1.33 E+00$ & $1.66 \mathrm{E}+00$ & $1.26 \mathrm{E}+18$ & $8.79 E+17$ & $7.30 \mathrm{E}+17$ & $5.89 \mathrm{E}+17$ & $4.80 E+17$ & $4.04 \mathrm{E}+17$ & $3.09 E+17$ & $1.90 \mathrm{E}+17$ & $1.25 \mathrm{E}+17$ & $1.01 E+17$ \\
\hline 11 & $1.66 \mathrm{E}+00$ & $2.00 E+00$ & $7.86 \mathrm{E}+17$ & 4.30E+17 & $3.09 E+17$ & $2.36 \mathrm{E}+17$ & $1.84 \mathrm{E}+17$ & 1.33E+17 & 8.63E+16 & 4.71E+16 & 1.97E+16 & $5.46 E+15$ \\
\hline 12 & $2.00 E+00$ & $2.50 \mathrm{E}+00$ & $9.43 E+17$ & $5.03 E+17$ & $3.47 E+17$ & $2.62 \mathrm{E}+17$ & $2.06 \mathrm{E}+17$ & $1.51 \mathrm{E}+17$ & $9.26 \mathrm{E}+16$ & 4.07E+16 & $1.06 \mathrm{E}+16$ & $2.43 E+15$ \\
\hline 13 & $2.50 \mathrm{E}+00$ & $3.00 E+00$ & $8.25 E+17$ & $3.69 E+17$ & $2.09 \mathrm{E}+17$ & $1.36 \mathrm{E}+17$ & $9.27 \mathrm{E}+16$ & $6.26 \mathrm{E}+16$ & $3.64 \mathrm{E}+16$ & $1.36 \mathrm{E}+16$ & $3.95 E+15$ & $2.97 E+15$ \\
\hline 14 & $3.00 \mathrm{E}+00$ & $4.00 \mathrm{E}+00$ & $5.53 E+17$ & $2.34 \mathrm{E}+17$ & 1.27E+17 & $7.64 \mathrm{E}+16$ & 4. $27 \mathrm{E}+16$ & $2.13 E+16$ & $9.83 E+15$ & $3.09 E+15$ & $2.95 E+14$ & $2.54 \mathrm{E}+13$ \\
\hline 15 & $4.00 \mathrm{E}+00$ & $5.00 E+00$ & 1.07E+17 & $4.88 \mathrm{E}+16$ & $3.22 \mathrm{E}+16$ & $1.76 \mathrm{E}+16$ & $5.94 \mathrm{E}+15$ & $7.01 E+14$ & $1.73 E+14$ & $7.48 \mathrm{E}+13$ & $1.86 \mathrm{E}+13$ & $4.06 E+11$ \\
\hline 16 & $5.00 E+00$ & $6.50 \mathrm{E}+00$ & $2.31 E+16$ & $9.31 E+15$ & $5.66 \mathrm{E}+15$ & $2.58 \mathrm{E}+15$ & $5.74 \mathrm{E}+14$ & $2.11 \mathrm{E}+13$ & $6.04 \mathrm{E}+11$ & $3.73 E+11$ & $9.61 \mathrm{E}+10$ & $2.10 \mathrm{E}+09$ \\
\hline 17 & $6.50 \mathrm{E}+00$ & $8.00 E+00$ & 8.29E+14 & $1.25 \mathrm{E}+14$ & $5.89 \mathrm{E}+13$ & $1.25 \mathrm{E}+13$ & $8.70 E+11$ & $1.30 \mathrm{E}+08$ & $9.07 E+01$ & $9.09 E+01$ & $9.14 \mathrm{E}+01$ & $9.23 E+01$ \\
\hline 18 & $8.00 E+00$ & $1.00 E+01$ & $5.39 E+12$ & $1.41 \mathrm{E}+11$ & $1.06 \mathrm{E}+09$ & $2.54 \mathrm{E}+07$ & $5.08 \mathrm{E}+03$ & $1.91 \mathrm{E}+01$ & $1.91 \mathrm{E}+01$ & $1.92 \mathrm{E}+01$ & $1.93 \mathrm{E}+01$ & $1.95 \mathrm{E}+01$ \\
\hline totals & & & $3.23 E+19$ & $1.92 \mathrm{E}+19$ & $1.45 E+19$ & $1.18 \mathrm{E}+19$ & $9.80 \mathrm{E}+18$ & $7.68 \mathrm{E}+18$ & $5.66 \mathrm{E}+18$ & $3.96 \mathrm{E}+18$ & $2.96 \mathrm{E}+18$ & $2.15 \mathrm{E}+18$ \\
\hline
\end{tabular}


Table G.4. Decay gamma spectra for LEU, outer element for times up to 100 years (energy boundaries in MeV)

\begin{tabular}{|c|c|c|c|c|c|c|c|c|c|c|c|}
\hline Grp & Upper & Lowe & $3 E-03 y$ & $0.1 y$ & $0.3 y$ & $1.0 y$ & $3.0 y$ & $10.0 y$ & $30.0 y$ & $50.0 y$ & \\
\hline 1 & & & & $.23 E+16$ & $.91 \mathrm{E}+15$ & $.08 \mathrm{E}+15$ & $31 \mathrm{E}+14$ & & & & \\
\hline 2 & 5.00E-02 & $1.00 \mathrm{E}-01$ & $82 \mathrm{E}+17$ & $79 E+15$ & $2.44 \mathrm{E}+15$ & $6.64 E+14$ & $1.35 \mathrm{E}+14$ & $2.60 \mathrm{E}+13$ & $1.56 \mathrm{E}+13$ & $9.68 \mathrm{E}+12$ & \\
\hline 3 & & & & & & & & & & & \\
\hline 4 & 2.00E-01 & 3.00E-01 & $55 \mathrm{E}+17$ & $1.84 \mathrm{E}+15$ & 5.67E+14 & $1.62 \mathrm{E}+14$ & $3.22 \mathrm{E}+13$ & $5.51 \mathrm{E}+12$ & $3.31 E+12$ & $2.04 \mathrm{E}+12$ & $12 \mathrm{E}+11$ \\
\hline 5 & & & & & & & & & & & \\
\hline 6 & 4.00E-01 & $.00 \mathrm{E}-01$ & D9E- & +16 & & & +13 & $4.99 \mathrm{E}+12$ & 12 & & +11 \\
\hline 7 & & & & & & & & & & & \\
\hline 8 & 8.00E-01 & $1.00 \mathrm{E}+00$ & $70 E+16$ & $51 E+15$ & $.71 E+14$ & $60 E+13$ & 1.15E+13 & $1.35 \mathrm{E}+12$ & $3.50 \mathrm{E}+$ & -11 & $5.72 \mathrm{E}+10$ \\
\hline 9 & & & & & & & & & & & \\
\hline 10 & $33 E+00$ & $1.66 \mathrm{E}+00$ & $1.01 \mathrm{E}+17$ & $1.49 \mathrm{E}+16$ & $3.04 \mathrm{E}+14$ & $.34 \mathrm{E}+13$ & $2.76 \mathrm{E}+12$ & $1.32 \mathrm{E}+11$ & -10 & 10 & +09 \\
\hline 11 & $.66 \mathrm{E}+00$ & $2.00 E+00$ & $5.46 \mathrm{E}+15$ & $2.41 E+13$ & 4. $60 \mathrm{E}+12$ & $2.20 \mathrm{E}+12$ & +11 & 1.19E+10 & $6.09 \mathrm{E}$ & & \\
\hline 12 & $2.00 E+00$ & $2.50 \mathrm{E}+00$ & $.43 E+15$ & 1.93E+14 & $3.85 E+13$ & $1.90 \mathrm{E}+13$ & $3.26 \mathrm{E}+12$ & $7.76 \mathrm{E}$ & 3.10 & & +07 \\
\hline 13 & $50 E+00$ & $3.00 \mathrm{E}+00$ & $97 \mathrm{E}+15$ & $82 E+14$ & $22 \mathrm{E}+12$ & 7.70E+10 & $1.83 \mathrm{E}+10$ & $1.40 \mathrm{E}+08$ & $1.39 \mathrm{E}+06$ & +06 & +05 \\
\hline 14 & $3.00 E+00$ & $4.00 \mathrm{E}+00$ & $2.54 \mathrm{E}+13$ & $3.92 \mathrm{E}+12$ & $8.27 E+10$ & $5.59 \mathrm{E}+09$ & $1.44 \mathrm{E}+09$ & $1.25 \mathrm{E}+07$ & $3.02 E+03$ & +03 & $3.11 \mathrm{E}+03$ \\
\hline 15 & $4.00 E+00$ & $5.00 \mathrm{E}+00$ & $4.05 E+11$ & $1.20 \mathrm{E}+03$ & $1.15 \mathrm{E}+03$ & $1.07 E+03$ & $1.03 E+03$ & $1.01 E+03$ & $9.83 E+02$ & $9.64 \mathrm{E}+02$ & $9.38 \mathrm{E}+02$ \\
\hline 16 & $5.00 \mathrm{E}+00$ & $6.50 \mathrm{E}+00$ & $2.10 E+09$ & 4.74E+02 & 4.57E+02 & $4.25 \mathrm{E}+02$ & $4.08 \mathrm{E}+02$ & $4.00 \mathrm{E}+02$ & $3.86 \mathrm{E}+02$ & $3.78 \mathrm{E}+02$ & $3.68 \mathrm{E}+02$ \\
\hline 17 & $6.50 \mathrm{E}+00$ & $8.00 \mathrm{E}+00$ & $9.23 \mathrm{E}+01$ & $9.19 \mathrm{E}+01$ & $8.85 E+01$ & $8.23 E+01$ & $7.88 \mathrm{E}+01$ & $7.72 \mathrm{E}+01$ & $7.43 E+01$ & $7.27 \mathrm{E}+01$ & $7.08 \mathrm{E}+01$ \\
\hline 18 & $8.00 E+00$ & $1.00 \mathrm{E}+01$ & $1.95 \mathrm{E}+01$ & $1.94 \mathrm{E}+01$ & $1.86 \mathrm{E}+01$ & $1.73 \mathrm{E}+01$ & $1.66 \mathrm{E}+01$ & $1.62 \mathrm{E}+01$ & $1.56 \mathrm{E}+01$ & $1.52 \mathrm{E}+01$ & $1.48 \mathrm{E}+01$ \\
\hline totals & & & $2.15 \mathrm{E}+18$ & $1.52 E+17$ & 4.67E+16 & $6.37 E+15$ & $1.03 E+15$ & $2.80 \mathrm{E}+14$ & $1.68 \mathrm{E}+14$ & $1.05 \mathrm{E}+14$ & $3.25 E+13$ \\
\hline
\end{tabular}



ORNL/TM-2010/318

\section{INTERNAL DISTRIBUTION}

1. K. J. Beierschmitt (beierschmitt@ornl.gov)

2. G. I. Bell (bellgi@ornl.gov)

3. J. L. Binder (binderjl@ornl.gov)

4. S. M. Bowman (bowmansm2ornl.gov)

5. S. E. Burnette (burnettese@ornl.gov)

6. D. H. Cook (dhc@ornl.gov)

7. B. S. Cowell (cowellbs@ornl.gov)

8. R. A. Crone (cronera@ornl.gov)

9. R. J. Ellis (ellisrj@ornl.gov)

10. J. D. Freels (freelsjd@ornl.gov)

11. J. C. Gehin (gehinjc@ornl.gov)

12. S. R. Greene (srg@ornl.gov)

13. A. S. Icenhour (icenhouras@ornl.gov)

14. G. Ilas (ilasg@ornl.gov)
15. B. C. Jolly (jollybc@ornl.gov)

16. J. H. Miller (millerjh2@ornl.gov)

17. L.J. Ott (ottlj@ornl.gov)

18. C. V.Parks (parkscv@ornl.gov)

19. D. G. Renfro (renfrodg@ornl.gov)

20. L. J. Satkowiak (satkowiaklj@ornl.gov)

21. J. D. Sease (seasejd@ornl.gov)

22. K. A. Smith (smithka@ornl.gov)

23. R. L. Snipes (snipesrl@ornl.gov)

24. W. J. Toth (tothwj@ornl.gov)

25. J. C. Wagner (wagnerjc@ornl.gov)

26. S. J. Zinkle (zinklesj@ornl.gov)

27. ORNL Laboratory Records (hamrindr@ornl.gov)

\section{EXTERNAL DISTRIBUTION}

28. A. Adams, U.S. Nuclear Regulatory Commission, One White Flint North, 11555 Rockville Pike, Rockville, Maryland 20852-2738 (axa@nrc.gov)

29. R. A. Butler, Director, Research Reactor Center, 1513 Research Park Drive, Columbia, MO 65211 (ButlerRa@missouri.edu)

30. G. S. Chang, Idaho National Laboratory, P.O. Box 1625, Idaho Falls, ID 83415-3885 (gray.chang@inl.gov)

31. J. Chamberlin, NA-212, U.S. Department of Energy, 1000 Independence Avenue SW, Washington, DC 20585 (jeffry.chamberlin@nnsa.doe.gov)

32. D. Chong, NA-212, U.S. Department of Energy, 1000 Independence Avenue SW, Washington, DC 20585 (Daniel.Chong@nnse.doe.gov)

33. M. D. DeHart, Idaho National Laboratory, P.O. Box 1625, Idaho Falls, Idaho 83415-8370 (Mark.DeHart@inl.gov)

34. B. DeWald, (bruce.dewald@nuclearassociates.com).

35. D. Diamond, Brookhaven National Laboratory, P.O. Box 5000, Upton, NY 11973-5000 (diamond@bnl.gov)

36. J. Dwight, Idaho National Laboratory, P.O. Box 1625, Idaho Falls, ID 83415-3750 (John.Dwight@inl.gov)

37. P. Finck, Associate Laboratory Director - Nuclear Science \& Technology, INL, P.O. Box 1625, MS 3860, Idaho Falls, ID 83415-3860 (Phillip.Finck@inl.gov)

38. L. Foyto, Research Reactor Center, 1513 Research Park Drive, Columbia, MO 65211 (foytol@missouri.edu)

39. L. Jollay, Y-12 National Security Complex,( jollayl@y12.doe.gov)

40. H. Kung, Office of Basic Energy Sciences, SC-22.23, U.S. Department of Energy, 1000 Independence Avenue SW, Washington, DC 20585 (harriet.kung@science.doe.gov)

41. D. Kutikkad, Assistant Reactor Manager-Physics, University of Missouri Research Reactor Facility, Columbia, MO65211(kutikkadk@missouri.edu)

42. C. Landers, NA-212, U.S. Department of Energy, 1000 Independence Avenue SW, Washington, DC 20585 (Christopher.landers@nnsa.doe.gov)

43. P. Lee, Office of Basic Energy Sciences, U.S. Department of Energy, 1000 Independence Avenue SW, Washington, DC 20585 (peter.lee@science.doe.gov) 
44. J. Matos, Argonne National Laboratory, 9700 S. Cass Avenue, Argonne, IL 60439 (jim.matos@anl.gov)

45. D. McDaniel, Idaho National Laboratory, P.O. Box 6188, Idaho Falls, ID 83415 (David.McDaniel@inl.gov)

46. C. McKibben, University of Missouri Research Reactor Facility, Columbia, MO 65211 (mckibben@missouri.edu)

47. J. O. Moore, U.S. Department of Energy, (moorejo@ornl.gov)

48. T. Newton, MIT Nuclear Reactor Laboratory, 138 Albany St., Cambridge, MA 02139 (tnewton@mit.edu)

49. S. O’Kelly, NIST Center for Neutron Research, 100 Bureau Drive, Stop 8560, Gaithersburg, MD 20899-8560 (sean.okelly@nist.gov)

50. R.T. Primm III, Primm Consulting, Laurel Hill Road, Knoxville, TN 37923 (trentprimm@primmconsultingllc.com)

51. D. Reed, U.S. Department of Energy, (reeddr@ornl.gov)

52. W. Richards, NIST Center for Neutron Research, 100 Bureau Drive, Stop 8561, Gaithersburg, MD 208998561 (wade.richards@nist.gov)

53. W. C. Richardson, BWXT Technology, Inc., 2016 Mount Athos Rd., Lynchburg, VA 24504 (WCRichardson@bwxt.com)

54. J. Roglans, Argonne National Laboratory, 9700 S. Cass Avenue, Argonne, IL 60439 (roglans@anl.gov)

55. D. Rosine, U.S. Department of Energy, (rosinedb@ornl.gov)

56. P. Roth, Idaho National Laboratory, P.O. Box 6188, Idaho Falls, ID 83415 (Paul.Roth@inl.gov)

57. C. Sohn, Office of Basic Energy Sciences, U.S. Department of Energy (carol.sohn@pnso.science.doe.gov)

58. G. Solbrekken, University of Missouri, Columbia, MO 65211 (solbrekkeng@missouri.edu)

59. P. Staples, NA-212, U.S. Department of Energy, 1000 Independence Avenue SW, Washington, DC 20585 (Parrish.Staples@nnsa.doe.gov)

60. J. G.Stevens, Argonne National Laboratory, 9700 S. Cass Avenue, Argonne, IL 60439 (johnstevens@anl.gov)

61. D. M. Wachs, MFC 791 B-147, Idaho National Laboratory, P.O. Box 6188, Idaho Falls, ID 83415 (Daniel.Wachs@inl.gov)

62. R. E. Williams, NIST Center for Neutron Research, 100 Bureau Drive, Stop 8560, Gaithersburg, MD 208998560 (robert.williams@nist.gov)

63. E. C Woolstenhulme, P.O. Box 1625, Idaho Falls, ID 83415-3750 (Eric.Woolstenhulme@inl.gov) 